University of Zurich

Department of Economics

Working Paper Series

ISSN 1664-7041 (print)

ISSN 1664-705X (online)

Working Paper No. 353

\title{
Sorting and wage premiums in immoral work
}

Florian H. Schneider, Fanny Brun and Roberto A. Weber

June 2020 


\title{
Sorting and wage premiums in immoral work
}

\author{
Florian H. Schneider, Fanny Brun and Roberto A. Weber*
}

June 29, 2020

We use surveys, laboratory experiments and administrative labor-market data to study how heterogeneity in the perceived immorality of work and in workers' aversion to acting immorally interact to impact labor market outcomes. Specifically, we investigate whether those individuals least concerned with acting morally select into jobs generally perceived as immoral and whether the aversion among many individuals to performing such acts contributes to immorality wage premiums, a form of compensating differential. We show that immoral work is associated with higher wages, both using correlational evidence from administrative labor-market data and causal evidence from a laboratory experiment. We also measure individuals' aversion to performing immoral acts and show that those who find immoral behavior least aversive are more likely to be employed in immoral work in the lab and have a relative preference for work perceived as immoral outside the laboratory. We note that sorting by "immoral" types into jobs that can cause harm may be detrimental for society. Our study highlights the value of employing complementary research methods.

Keywords: Wage premium, immoral behavior, sorting, experiments

JEL Codes: C92, J31, D03

\footnotetext{
* Department of Economics, University of Zurich, Blümlisalpstrasse 10, 8006 Zurich, Switzerland. Schneider: florian.schneider2@econ.uzh.ch, Brun: fanny.brun@econ.uzh.ch, Weber: roberto.weber@econ.uzh.ch.We thank participants at several conferences and seminars for helpful comments and suggestions. We also gratefully acknowledge the financial support of the Swiss National Science Foundation (Grant No. 100018_165943).
} 


\section{Introduction}

Immoral workplace behavior has the potential to cause significant social harm. For example, financial industry scandals involving the intentional sale of toxic assets to unsuspecting clients (US Department of Justice, 2016) and the aiding of tax evasion (Hill, 2012) create significant burdens for public funds and erode trust in the financial sector. Tobacco companies have long been accused of engaging in misleading marketing regarding smoking's harmful effects (Heath, 2016) and intentionally targeting underage smokers (Bates and Rowell, 1998). Aggressive marketing of opioids by pharmaceutical firms contributed to a serious public health crisis (Okie, 2010; Case and Deaton, 2015). In cases like these, as well as in less extreme examples, corporate activities that many regard as "immoral" or "unethical"- but are nevertheless profitable-may have serious negative impacts on social welfare.

Rather than representing isolated incidents, there exists a widespread impression that some jobs-e.g., marketing tobacco products, manufacturing weapons-likely involve inherently immoral acts. Conventional wisdom further posits that such jobs disproportionately attract those individuals who experience the least displeasure from acting immorally and that workers performing these kinds of jobs receive high wages, a form of compensating differential for unethical conduct. ${ }^{1}$ Thus, "immoral" work shares features with other aspects of employment that people may find heterogeneously aversive, such as risk of physical harm (Rosen, 1986), and implies potentially higher labor costs for firms in industries tainted with the perception of immorality. ${ }^{2}$

However, despite the intuitive appeal of such relationships, little empirical evidence links heterogeneity in the willingness to perform work generally perceived as immoral to resulting differential labor market outcomes; we review this and related work in the next section. Moreover, there are many reasons to believe that concerns for moral conduct may be mitigated in competitive markets (Levitt and List, 2008; Lazear, Malmendier and Weber, 2013), where wages are set by the preferences of the marginal worker and where repeatedly

\footnotetext{
${ }^{1}$ This view dates back to Adam Smith (1776; Book I; Ch. X), who wrote that, "The exorbitant rewards of players, opera-singers, opera-dancers, etc., are founded upon [..] the discredit of employing them in this manner. [..] Should the public opinion or prejudice ever alter with regard to such occupations, their pecuniary recompense would quickly diminish. More people would apply to them, and the competition would quickly reduce the price of their labour." At the time, such professions were seen as morally tainted; Smith equated them with "a sort of public prostitution."

${ }^{2}$ This perception is reflected in press accounts and corporate statements. For example, following the Cambridge Analytica scandal, Facebook struggled to attract top talent (CNBC, 2019). Tobacco companies deem difficulties in recruitment arising from their image as sufficiently important to warrant disclosure to regulators and shareholders (British American Tobacco, 2015, p. 37; Philip Morris International Inc., 2015, p. 14).
} 
forgoing profitable job opportunities may erode workers' aversion to performing immoral acts. On the other hand, moral concerns might be particularly relevant in labor markets, as job choices are typically visible to others and may significantly impact workers' social image.

In this paper, we provide novel evidence testing the above relationships between the perceived immorality of work, workers' heterogeneous concerns for acting morally and outcomes in labor markets. We employ a combination of surveys, laboratory experiments and administrative labor market data, in which we obtain measures of individuals' concerns for morality and relate these to variation in the morality of work. The administrative data provides the clearest evidence of the economic relevance of these relationships, but in these data "immoral" industries might differ in many unobservable aspects from other industries, making it difficult to establish a causal relationship from the immorality of work to labor market outcomes. The control provided by laboratory experiments allows us to observe the kinds of outcomes that arise as the nature of work changes only in the extent to which it is immoral. We additionally use evidence from surveys to obtain insights into relationships between individuals' concerns for morality and their willingness to work in different realworld firms and industries. Thus, our paper highlights the value of employing complementary research methods to address complex economic phenomena.

Our work is focused on two specific hypotheses that arise from a simple theoretical analysis of how individuals' heterogeneous aversion to performing immoral work may interact with jobs that vary in the immorality of the work they require. The two hypotheses reflect the perceptions that we note above: first, that more immoral work yields higher wages — as long as workers care enough about moral conduct — and, second, that immoral work attracts those workers least concerned with acting morally.

Our results provide support for these two hypotheses, both in and out of the laboratory. Table 1 provides an overview of our main findings.

First, we show that immoral work commands a wage premium over comparable work not perceived as immoral. We show this in Section 4, using administrative labor market data, where we find that industries generally perceived as immoral yield higher wages, controlling for observable worker and industry characteristics. Moreover, in our laboratory labor markets - which vary by treatment only whether being employed requires doing something immoral—we observe a causal relationship indicating that wages are persistently higher for immoral work (Section 5). This wage premium is large and does not decrease with market experience, reflecting a stable aversion to immoral work. 
Second, we provide evidence of sorting by immoral types into immoral work, both in the laboratory and in the field. We obtain two measures of individuals' aversion to acting immorally, from a behavioral task and from a survey conducted several days apart, and find that the measures are correlated. These two measures of immorality predict individual labor market outcomes: in our laboratory labor markets (Section 5), immoral types are employed more frequently, but only when work involves doing something immoral. In our survey data (Section 6), immoral types report a significantly greater willingness to work in firms and industries that are generally perceived by others as immoral. ${ }^{3}$

\section{Table 1. Overview of our evidence on wage premiums and sorting}

\section{Laboratory labor market Labor markets outside the laboratory}

\begin{tabular}{|l|l|l|}
\cline { 2 - 3 } $\begin{array}{l}\text { Immorality } \\
\text { premium }\end{array}$ & $\begin{array}{l}\text { Causal evidence for a wage } \\
\text { premium for immoral work } \\
\text { (Section 5; Figure 5) }\end{array}$ & $\begin{array}{l}\text { Correlation between perceived industry } \\
\text { immorality and wages in the Swiss labor } \\
\text { market (Section 4; Figure 1, Table 2) }\end{array}$ \\
\cline { 2 - 3 } Sorting & $\begin{array}{l}\text { Immoral types are more } \\
\text { likely to be hired, but only for } \\
\text { immoral work } \\
\text { (Section 5; Figure 6, Table 5) }\end{array}$ & $\begin{array}{l}\text { Immoral types state a greater willingness } \\
\text { to work in firms and industries perceived } \\
\text { by others as immoral } \\
\text { (Section 6; Figure 9, Table 7) }\end{array}$ \\
\hline
\end{tabular}

Our findings have important policy implications, which we discuss further in the Conclusion. For example, our evidence of sorting in laboratory and non-laboratory labor markets suggests that industries with great potential for social harm-e.g., weapons manufacturing - may attract those individuals least concerned with those impacts. Moreover, this sorting process may also mean that perceptions that a firm or industry involves immoral behavior may be self-reinforcing if they lead to a workforce mainly comprising those individuals least concerned with acting morally. Thus, even in industries that may not be inherently immoral, like financial services, the perception that they involve immorality may be sufficient to tilt the labor force toward individuals more likely to commit immoral acts.

The rest of our paper proceeds as follows. In the next section, we discuss how this paper relates and contributes to previous literature. Section 3 describes a simple theoretical framework that we use to develop hypotheses. In Section 4, we use Swiss labor market data to investigate the relationship between the perceived immorality of work and wages. Section

\footnotetext{
${ }^{3}$ While these job choices are hypothetical, Wiswall and Zafar (2018) provide evidence that stated labor market preferences predict subsequent employment.
} 
5 presents the design and results of our laboratory experiment, while Section 6 describes our survey study. Section 7 concludes by discussing implications of our findings for policy.

\section{Related Literature}

The closest prior evidence supporting the relationships we investigate comes from studies documenting positive correlations between the perceived immorality of work and the wages obtained by workers in those "immoral" firms or industries (Frank, 1996; Moffatt and Peters, 2004; Arunachalam and Shah, 2008; Edlund, Engelberg and Parsons, 2009). This is similar to the correlational evidence we provide in Section 4, but prior evidence focuses on more limited samples. For example, Frank (1996) used data from a Cornell University employment survey that included graduates' occupations, employers and reported salaries. ${ }^{4}$ He then asked students in a business ethics class to rate the "social responsibility" of the most common occupations and employers of Cornell graduates. A regression controlling for other observable characteristics — such as a student's major, grades and gender-reveals a premium for occupations and employers that are rated as less socially responsible.

Frank's evidence is consistent with the notion that concerns for avoiding immoral work produce differential wages across occupations and industries. However, there remain important gaps in documenting that the relationships observed by Frank are really the result of sorting, heterogeneous moral preferences and compensating differentials. Most obviously, correlational evidence between wages and the perceived immorality of work might result from other unobserved worker and job characteristics. For instance, Moffatt and Peters (2004) document a wage premium for prostitution, which they attribute to a compensating differential (see, also, Arunachalam and Shah, 2008; Edlund, Engelberg and Parsons, 2009); but it is unclear whether the compensation is for the perceived immorality or for other aversive aspects of the job (Edlund and Korn, 2002; Gertler, Shah and Bertozzi, 2005). ${ }^{5}$ Moreover, such studies fail to measure a critical element - the identification of workers' heterogeneous concerns for morality — as a key driver of the relationship. ${ }^{6}$

\footnotetext{
${ }^{4}$ Note that these wages may not correspond to (average) industry wages because his sample is very selective. Unlike Frank (1996), we use a sample that is representative of the national workforce in Switzerland.

${ }^{5}$ Related work in finance (e.g., Fabozzi, Ma and Oliphant, 2008; Hong and Kacperczyk, 2009; Colonnello, Curatola and Gioffré, 2019) demonstrates that investing in firms that engage in immoral activities ("sin stocks") yields higher returns. However, other industry and firm characteristics, such as litigation risk, may also differ between these types of investments (Blitz and Fabozzi, 2017).

${ }^{6}$ While there is some correlational evidence that people in some industries exhibit lower concerns for morality (Carter and Irons, 1991; Sjöberg and Engelberg, 2009), these studies do not document that these moral concerns drive differential selection into different kinds of work rather than the relationship being perhaps the other way around (Frank, Gilovich and Regan, 1993; Cohn, Fehr and Maréchal, 2014; Ashraf and Bandiera, 2017).
} 
Our work also relates to the broader literature on compensating differentials. A substantial number of studies investigate whether nonprofit employees earn less than forprofit employees (e.g., Leete, 2001; Mocan and Tekin, 2003; Ruhm and Borkoski, 2003; Benedict, McClough and McClough, 2006; Jones, 2015). These studies yield mixed correlational evidence, likely due to methodological challenges in estimating compensating wage differentials using observational data (see the discussion in Mas and Pallais, 2017). Recent papers on compensating differentials instead rely on experimental methods and/or stated preferences (Eriksson and Kristensen, 2014; Pörtner, Hassairi and Toomim, 2015; Carpenter, Matthews and Robbett, 2017; Mas and Pallais, 2017; Maestas et al., 2018; Wiswall and Zafar, 2018). We differ from this work in that we explore the immorality of work and the aversion to acting immorally as the driving sources of heterogeneity and we present causal evidence on compensating wage differentials in the domain of morality.

There is also related evidence on sorting by pro-social "mission-oriented" types into the public sector (Carpenter and Myers, 2010; Gregg, et al., 2011; Buurman, et al., 2012; Dur and Zoutenbier, 2014; Fisman et al, 2015; Hanna and Wang, 2017; Ashraf, et al., 2019; Friebel, Kosfeld and Thielmann, 2019). However, none of this work tests how differential sorting by heterogeneous types impacts labor market outcomes such as wages. Moreover, our focus on sorting into immoral work can have distinct policy implications. For example, sorting by immoral types into jobs where they can cause social harm may often exacerbate the negative social impacts of such work. That is, from society's perspective we may want those people most inclined to act morally working in industries with the greatest potential for producing social harm, but our results suggest the opposite will occur. Conversely, sorting by pro-socially oriented types into the public sector is likely to increase the positive social impacts of their work. ${ }^{7}$

Finally, we also contribute to the literature on moral behavior in markets (e.g., Falk and Szech, 2013; Bartling, Weber and Yao, 2015; Kirchler, Huber, Stefan and Sutter, 2016). Levitt and List $(2007,2008)$ question whether social preferences matter in markets, due to factors including high stakes, market competition and experience. Our estimates from the administrative labor market data indicate a substantial wage premium for immoral work, suggesting that many workers are willing to forgo financial gains to not work in immoral

\footnotetext{
${ }^{7}$ Our study also relates to research on effort and sorting by mission-oriented types (Besley and Ghatak, 2005; Prendergast, 2007; Delfgaauw and Dur, 2008; Ariely, Bracha and Meier, 2009; Dal Bó, Finan and Rossi, 2013; Fehrler and Kosfeld, 2014; Tonin and Vlassopoulos, 2015; Carpenter and Gong, 2016; Cassar and Meier, 2018; Cassar, 2019; Deseranno, 2019; Dur and van Lent, 2019), though this line of research typically focuses on worker motivation and effort within firms and not on worker morality and labor demand in competitive labor markets.
} 
industries. Our survey data indicates that concerns for moral conduct predict sorting into industries. Finally, in the laboratory labor market, we find that neither the wage premium nor sorting decrease with market experience. These findings suggest that moral preferences matter for labor markets, and that they can impact both market wages and individual market outcomes.

\section{Theoretical framework}

Our study is guided by hypotheses obtained from a simple model of labor markets with varying degrees of perceived job immorality and workers' heterogeneous concern for avoiding immoral behavior. ${ }^{8}$ We present the detailed model and analysis in Appendix D; in this section, we focus only on the model's key predictions.

We examine a labor market for a job, $j \in J$, which might involve doing immoral work. The immorality of $j$ is measured by a function $I: J \rightarrow[0, \infty)$, where $I\left(j^{\prime}\right)>I(j)$ means that job $j^{\prime}$ is more immoral than job $j$. Firms decide whether to hire a worker to do $j$ at the market wage, $w$, and workers decide whether to accept work $j$ for the market wage. Workers differ in degree to which they are concerned with acting morally, $\theta_{i} \geq 0$. A worker of type $\theta_{i}$ accepts job $j$ if the utility from doing so is higher than that of an outside option, or

$$
u_{i}^{a c c e p t}(j, w)=w-c-\theta_{i} * I(j) \geq \underline{u},
$$

where $c \geq 0$ is the worker's cost of effort and $\underline{u} \geq 0$ is the workers' reservation utility.

Our first two results derive the primary hypotheses that we test across our analysis. The first result (Proposition 1) shows that there is an immorality premium for immoral jobs: an increase in the immorality of a job, $I(j)$, decreases labor supply and therefore increases the equilibrium wage. However, this wage premium will be insignificant if workers do not sufficiently care about morality. Our second main result (Proposition 2) states that those individuals least concerned with avoiding immoral work-i.e., those with low $\theta_{i}$ - sort into accepting immoral jobs, while those more concerned with morality refuse to do the job for the equilibrium wage. That is, wage premiums arise precisely because those who find immoral work most distasteful opt out of such jobs, which also has implications for the resulting composition of the workforce in industries and firms performing immoral work. This important relationship has, to our knowledge, not been previously empirically tested.

\footnotetext{
${ }^{8}$ Our framework is a simplification of the theoretical literature on compensating wage differentials (see, e.g., Rosen, 1986). We do not seek to expand this literature, but rather to apply it to a context in which the relevant job dimension is immorality.
} 
Our next two results are less central, but nevertheless provide useful testable insights into outcomes in labor markets for immoral work. First, we show that that the most immoral types profit from an increase in the immorality of work (Proposition 3). Second, more widespread concern for moral behavior-i.e., more people caring about avoiding immoral work - can have positive externalities for the most immoral types (Proposition 4). That is, if the distribution of types shifts toward greater concern for morality (higher $\theta_{i}$ ), then the supply at any given wage decreases, increasing the equilibrium wage and the utility of those least concerned with morality.

\section{Evidence of an immorality premium in the Swiss labor market}

Our analysis first explores whether individuals working in industries generally perceived as immoral obtain wage premiums. We use data from the Swiss Labor Force Survey (SLSF), a representative sample of Swiss workers compiled by the Swiss Federal Statistical Office, to study the relationship between the perceived immorality of work and the portion of wages that cannot be explained by observable worker and industry characteristics.

We initially identified industries that we jointly perceived as involving work activities likely to be widely seen as immoral; we did so before looking at any data from these industries, including wages. ${ }^{9}$ This yielded six "immoral" industries: gambling and betting activities, monetary intermediations, credit granting, manufacture of tobacco products, wholesale of tobacco products and manufacture of weapons and ammunition. We then chose comparison industries from within the same industrial branch with similar distributions of education levels, as well as nine additional industries representing large shares of employment in Switzerland. ${ }^{10}$ We did not look at wages when selecting any of these industries.

\footnotetext{
${ }^{9}$ Specifically, we started with the complete list of industries listed in the SLFS. Each of the authors went through the list and indicated any industries that he or she believed was widely perceived to have a significant immoral component. We selected those industries for which all three authors agreed. We proceed this way, rather than using the entire set of Swiss industries, to keep the number of questions we ask in subsequent surveys manageable. A natural concern is that choosing the sample of industries ourselves possibly (unconsciously) biases the sample toward those likely to confirm our hypothesis. In Appendix B we provide evidence for an immorality premium that does not rely on our sample of industries. First, we show that "immoral industries" (based on survey respondent's ratings) are also estimated to pay a wage premium when we add all other industries as control industries. Second, we replicate the entire analysis with another set of industries selected by research assistants who were not familiar with the research question. We thank Uri Gneezy for suggesting this approach.

${ }^{10}$ We chose five comparison industries: non-life insurance (for monetary intermediations; credit granting), organization and operation of sport facilities (for gambling and betting activities), processing of tea and coffee (for manufacture of tobacco products), manufacture of electronic components (for manufacture of weapons and ammunitions), wholesale of perfume and cosmetics (for wholesale of tobacco products).
} 
We next obtained independent ratings of the perceived (im)morality of the selected industries. We asked a sample of 177 students on the campus of the University of Zurich and the Federal Institute of Technology $(\mathrm{ETH})$ to rate each industry on a 5-point Likert scale ranging from "very moral" to "very immoral," re-scaled the responses to lie on the -1 to 1 interval and averaged the responses. (These survey data were collected as part of our survey studies, which we describe in more detail in Section 5.) We interpret this variable as a measure of the perceived immorality of working in industry $j$, or $I(j)$, a key component of our theoretical analysis. The mean ratings for each industry are shown on the horizontal axis of Figure 1. They confirm that our initial judgments with respect to the perceived immorality of certain industries are shared by the survey respondents.

Figure 1: Correlation between wages and perceived industry immorality

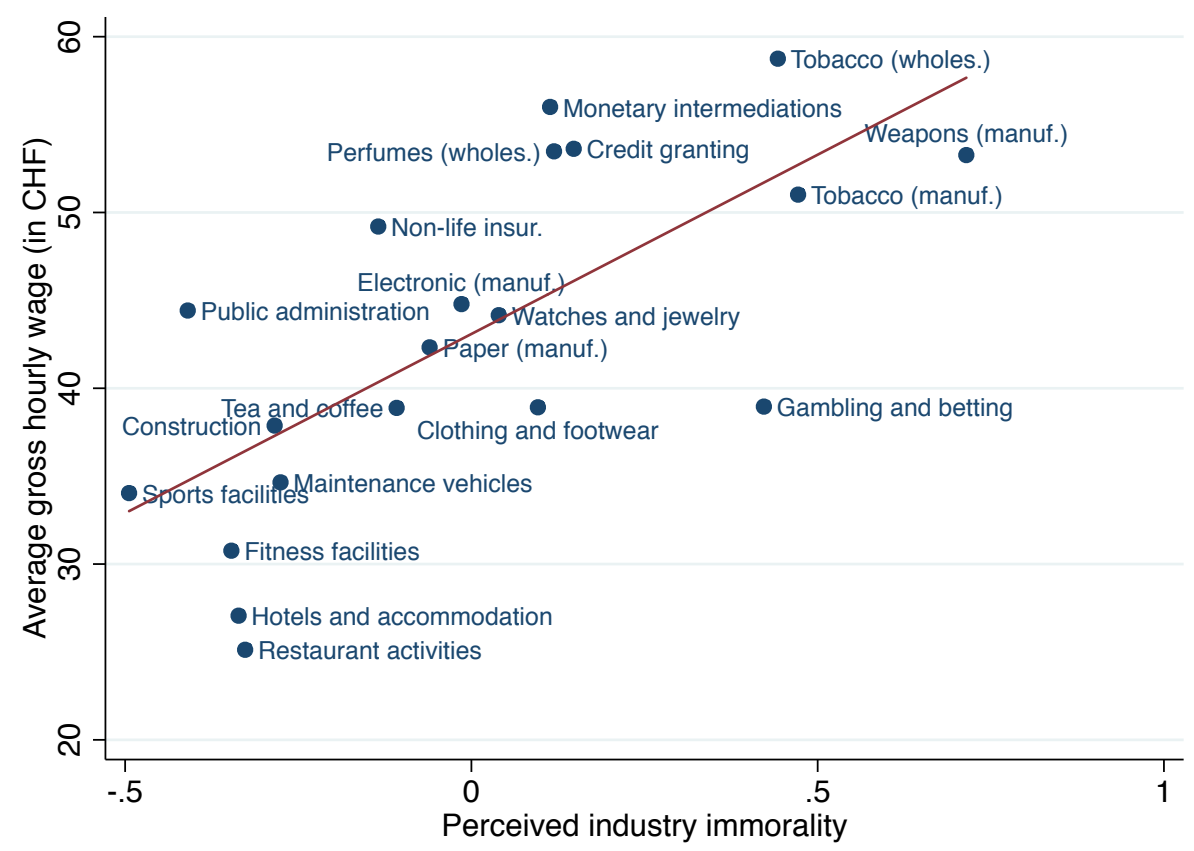

Source: Weighted data from the SLFS, years 2010-2016 (wage) and our own survey (perceived industry immorality). Notes: Perceived immorality is in [-1, 1] where -1 means very moral, 0 means neutral and 1 means very immoral. Real gross hourly wage in $2010 \mathrm{CHF} . \mathrm{N}=32,638$.

The vertical axis of Figure 1 plots the mean real gross hourly wage (in 2010 Swiss Francs) in each industry. These data are the reported hourly wages of employees surveyed in the SLFS. We use data from the 2010 to 2016 waves. The strong positive relationship supports the hypothesis that work in less moral industries yields a wage premium. This result is not due to our choice of the industry sample-Figure B1 in the Appendix shows similar correlations in another set of industries independently selected by research assistants unaware of the research question (see footnote 9). 
Table 2: Relationship between wages and perceived industry immorality

\begin{tabular}{|c|c|c|c|}
\hline \multicolumn{4}{|c|}{ Dependent variable: ln of real gross hourly wage (in $2010 \mathrm{CHF}$ ) } \\
\hline & $(1)$ & (2) & (3) \\
\hline Perceived industry immorality & $\begin{array}{c}0.929 * * * \\
(2.95)\end{array}$ & $\begin{array}{c}0.736^{* * *} \\
(4.15)\end{array}$ & $\begin{array}{c}0.638 * * * \\
(3.85)\end{array}$ \\
\hline Age & & $\begin{array}{c}0.005^{* * *} \\
(3.32)\end{array}$ & $\begin{array}{c}0.005 * * * \\
(3.64)\end{array}$ \\
\hline Male & & $\begin{array}{c}0.204 * * * \\
(6.60)\end{array}$ & $\begin{array}{c}0.203 * * * \\
\quad(6.80)\end{array}$ \\
\hline Married & & $\begin{array}{c}0.033^{*} \\
(1.88)\end{array}$ & $\begin{array}{c}0.037 * * \\
(2.13)\end{array}$ \\
\hline Education high & & $\begin{array}{c}0.469 * * * \\
(8.38)\end{array}$ & $\begin{array}{c}0.442 * * * \\
\quad(8.64)\end{array}$ \\
\hline Education middle & & $\begin{array}{c}0.177 * * * \\
(4.53)\end{array}$ & $\begin{array}{c}0.170 * * * \\
(4.77)\end{array}$ \\
\hline Swiss & & $\begin{array}{l}0.028 \\
(1.15)\end{array}$ & $\begin{array}{c}0.036^{*} \\
(1.97)\end{array}$ \\
\hline Experience & & $\begin{array}{c}0.005 * * \\
(2.81)\end{array}$ & $\begin{array}{c}0.005^{* * *} * \\
(3.17)\end{array}$ \\
\hline Full-time equivalent & & $\begin{array}{l}-0.037 \\
(-0.51)\end{array}$ & $\begin{array}{l}-0.038 \\
(-0.54)\end{array}$ \\
\hline Managerial duties & & $\begin{array}{l}0.059 \\
(0.71)\end{array}$ & $\begin{array}{l}0.065 \\
(0.82)\end{array}$ \\
\hline Industry sales & & $\begin{array}{l}0.027 \\
(0.94)\end{array}$ & $\begin{array}{l}0.034 \\
(1.25)\end{array}$ \\
\hline Industry size (employees) & & $\begin{array}{c}0.001 * * * \\
(3.77)\end{array}$ & $\begin{array}{c}0.001 * * * \\
(3.69)\end{array}$ \\
\hline Constant & $\begin{array}{c}3.759 * * * \\
(70.71)\end{array}$ & $\begin{array}{c}2.930 * * * \\
(26.43)\end{array}$ & \\
\hline $\mathrm{N}$ & 32,638 & 32,638 & 32,638 \\
\hline Adjusted $\mathrm{R}^{2}$ & 0.140 & 0.379 & 0.397 \\
\hline Year FE & No & No & Yes \\
\hline Region FE & No & No & Yes \\
\hline
\end{tabular}

Source: Weighed data from the SLFS, years 2010-2016 (wage and demographics), STATENT, years 2011-2016 (industry size, industry sales), Value Added Tax Statistics, years 2010-2016 (industry sales) and our own survey (perceived industry immorality).

Notes: Perceived immorality is in $[-1,1]$ where -1 means very moral, 0 means neutral and 1 means very immoral. Control variables: Male in $\{0,1\}$, Married in $\{0,1\}$, Education high: higher vocational education and training or university/college, Education middle: apprenticeship, full-time vocational school, matura or pedagogical training, Education low (reference category): compulsory schooling or pre-vocational education, Swiss in $\{0,1\}$, Experience $=$ number of years in the firm, Full-time equivalent $=$ (working hours /42), set to 1 for working hours $>=42$, managerial duties in $\{0,1\}$, Industry size $=$ number employees in this industry $/ 1000$ (2010 data is not available, we substitute it with 2011 data), Industry sales = Industry sales/number employees in this industry. Model (3) controls for company region fixed effects (26 Swiss cantons) and year fixed effects (2010-2016). Standard errors clustered at the industry level, $t$-statistics in parentheses; ${ }^{*} p<0.1 ; * * p<0.05$; $* * * p<0.01$. 
Of course, the relationship in Figure 1 ignores the potential role of individual worker characteristics, which may vary across industries, and other characteristics of the industries that may account for the wage gaps. To partially address this concern, Table 2 reports regressions of the hourly wage reported by individuals in different industries on the perceived immorality of each industry, along with several additional control variables. Model 1 displays the results of a simple regression of the natural logarithm of real gross hourly wages on the perceived industry's immorality, supporting the positive relationship in Figure 1. Model 2 adds observable worker and industry characteristics, while Model 3 additionally includes indicator variables for each year and indicator variables for the region where the employer is located. ${ }^{11}$ The immorality premium remains large and statistically significant: according to Model 3, individuals working in an industry as immoral as manufacture of tobacco products (i.e., Perceived immorality $=0.47)$ have $($ geometric) mean hourly earnings approximately 35 percent higher than people working in a neutral industry (i.e., Perceived immorality $=0$ ). ${ }^{12}$ Appendix Table B1 shows a statistically significant wage premium using alternative approaches for classifying immoral industries, including firms selected independently by research assistants.

The above analysis is consistent with workers' concern with the perceived immorality of work requiring compensation. However, the correlational aspect of the relationship leaves open the possibility that additional unobserved industry characteristics may explain the relationship in Figure 1. Moreover, the analysis does not tell us whether the workers employed in these industries differ in their concerns for morality. In the following two sections, we explore the model's predictions more carefully-controlling for unobservable aspects of work and making a clearer connection to subjects' heterogeneous concerns for morality.

\section{Sorting and wage premiums in a laboratory labor market}

Our experimental study investigates the preferences and behavior of subjects in the role of workers participating in a labor market. These subjects complete an online questionnaire, and then participate in a laboratory experiment approximately one week later.

\footnotetext{
${ }^{11}$ Since the number of clusters is relatively small, we also computed significance levels using the wild bootstrap (Cameron, Gelbach and Miller, 2008) with 400 replications; p-values for industry immorality are 0.070 for Model 1, 0.000 for Model 2, and 0.005 for Model 3. Note also that numbers of observations differ substantially between industries. If we weight observations by industry size (instead of using survey weights), estimates for perceived immorality are smaller (Model 1: 0.489, Model 2: 0.349, Model 3: 0.344), but still significant ( $\mathrm{t}=3.88$, 3.10 , and 4.03, respectively). Appendix Table A1 provides summary statistics of all variables.

${ }^{12}$ We obtain this number by doing the following calculation: $e^{0.638^{*} 0.47}-1 \approx 0.350$.
} 
The questionnaire measures subjects' concern for morality using survey instruments, as well as their preferences regarding future employment possibilities. We discuss the online questionnaire in detail in Section 6, where we also report the analysis of the resulting data. In this section, we focus on the design and results of the laboratory experiment.

In the laboratory sessions, subjects perform two choice tasks. First, we elicit a measure of concern for morality (corresponding to $\theta$ ) using an incentivized behavioral task, adapted from Gneezy, Rockenbach and Serra-Garcia (2013), that creates a tradeoff between personal monetary gain and moral conduct. We use this measure to investigate whether participants with low concern for morality sort into immoral work. Second, subjects participate in a laboratory labor market for 15 periods, in which they submit reservation wages for performing a task. Labor demand is simulated according to a fixed demand schedule; that is, wage offers are made by computerized employers.

The key feature of our laboratory experiment is that we exogenously vary only the immorality of work-holding constant all other job characteristics, including the specific actions subjects take when employed - to investigate the causal impact on labor market outcomes. We attempt to design an "immoral" act that is unambiguously harmful and for which there is likely widespread agreement regarding its immorality. We opt for an act akin to giving bad financial advice to a non-profit organization, like UNICEF, thereby harming the non-profit's financial standing and thus harming the organization's employees and its ability to help aid recipients. Providing harmful information and misleading customers is a realistic feature of many existing jobs perceived as immoral.

We operationalize this kind of scenario in our experiment by informing subjects that each session is endowed with an initial donation to a UNICEF fund that provides malaria treatments for children (the aid recipients). ${ }^{13}$ However, the actual final donation for a session is influenced by the behavior of participants in the session. Specifically, subjects in our experiment are hired to provide written advice to a "client" (a subject who participates in a subsequent survey and serves a role analogous to the non-profit's employee). We vary, by treatment, whether workers are assigned to a market with neutral jobs that involve honest advice that has little impact on the client and the UNICEF fund or to a market with immoral

\footnotetext{
${ }^{13}$ To strengthen the moral context, these initial donations are linked to a donation generated by a third party's blood donation. Prior to the laboratory session, we approached individuals who had just donated blood as part of a donation campaign. We asked them whether they would agree that the University of Zurich potentially make a donation to UNICEF as a complement to their blood donation. Most donors we approached agreed. We did not otherwise obtain any information or choices from these donors.
} 
jobs that involve dishonest advice that hurts the client and UNICEF. A worker's choice of whether to accept work is visible to other workers in the labor market. ${ }^{14}$

After the laboratory sessions, we recruited a separate sample of individuals at public locations. These participants serve two functions. First, they serve in the role of "clients" who receive written recommendations from laboratory subjects and act on this advice. From these choices, the clients accumulate money and determine the size of the UNICEF donation. Second, these participants complete a survey in which they evaluate the extent to which various industries and firms are "moral" or "immoral." These are the ratings that we already used in Figure 1 and Table 2.

\subsection{Design}

Laboratory sessions consisted of 24 participants. ${ }^{15}$ Before entering the lab, we took a portrait photograph of each subject to make labor market outcomes public. Participants were asked to make a neutral face while the picture was taken. As subjects could influence the amount of a donation to a UNICEF fund providing malaria treatment to children, participants read an information sheet at the beginning of the experiment about the consequences of malaria and the need for treatments - we adopted wording from public UNICEF materials and referred to each donation unit as helping to "save a child" from malaria by providing a treatment.

In the following, we describe each of the choices subjects completed in the laboratory session, in detail. We also provide details on the recruitment and role of the clients.

\subsubsection{Behavioral measure of concern for morality $\left(\theta^{E x p}\right)$}

Participants first played an incentivized game that measures their willingness to lie for personal gain while causing harm to others in a non-market environment. The task builds on a game by Gneezy et al. (2013), and modifies it such that it mimics the consequences of a lie in the immoral work treatment condition in our experimental labor market.

In the game, Participant A privately observes a computerized die roll and sends a message reporting the observed number to Participant B. Participant A may claim that the observed number $r$ is either " 1 ", “2," “3," “4," "5," or " 6 ," regardless of the actual number.

\footnotetext{
${ }^{14}$ Our behavioral measures of aversion to immoral acts confounds both internally-driven concerns for acting immorally and concerns for being perceived as willing to act immorally. Since real-world labor markets typically also confound both motives, we do not draw a distinction in our study, but instead combine both motives to strengthen the (perceived) immoral nature of work.

${ }^{15}$ During the experiment, subjects accumulated earnings in "points," which we converted to money at the rate of 20 points $=1$ CHF $\approx 1$ US Dollar. We present the design and results in terms of ultimate payments in Swiss francs $(\mathrm{CHF})$ to provide a clearer indication of the economic significance.
} 
Participant A receives $5+r \mathrm{CHF}$, which means that she has an incentive to lie if $r$ is less than 6. Participant B then decides whether "to follow" or "not to follow" the message sent by Participant A. If Participant B does not follow the message, he receives $1.5 \mathrm{CHF}$ and the donations to UNICEF are unaffected. If he follows the message and Participant A truthfully reported the observed number, Participant B earns 5 CHF and the initial donation to UNICEF is increased by an amount corresponding to one additional anti-malarial treatment. ${ }^{16}$ However, if Participant B follows the message and Participant A lied, Participant B does not earn any money and the donation decreases by one treatment.

Every participant initially plays the role of Participant A. We use the strategy method to elicit Participant A's message for every possible die roll as this allows us to classify all subjects by their strategies. At the end of the experimental session, 5 of the 24 participants in the session have their role changed from Participant A to Participant B. These Participants B are then matched with five of the remaining Participants $A$ and decide whether or not to follow the corresponding message. All participants whose role is not switched-who remain as Participant $\mathrm{A}$-are paid based on their choice as Participant A, independently of whether or not they are matched with a Participant B. ${ }^{17}$

Participants were informed that, at the end of the session and after all choices had been made, their decisions as Participant A would be publicly displayed to other participants in the session, along with their portrait photograph. This was all explained clearly and publicly at the beginning of the experiment.

\subsubsection{Labor market experiment}

In the labor market, subjects play the role of workers competing to be hired by automated firms. Before interacting in the market, subjects receive general instructions about the labor market and hear a recording of the instructions. Then, participants answer comprehension questions about the market, including how prices and quantities are determined. Only after the above instructions about market procedures, subjects receive information about the nature of the job, which varies by treatment. This ensures that subjects in both conditions interpret the market instructions similarly. Their understanding of these new instructions about the job is again tested through comprehension questions.

\footnotetext{
${ }^{16}$ The actual cost of providing 30 malaria treatments for children, according to UNICEF, was CHF 29. In order to create small units with a strong tangible moral component, our instructions always referred to the amount of money corresponding to treating "one child" and did not specify the exact monetary amounts.

${ }^{17}$ This implies that Participant As (whose role was not switched) received their own payment with certainty. Their decision, however, only had consequences for Participants B (and UNICEF) with a probability of 26.3 percent. This corresponds, roughly, to the stochastic impacts in our experimental labor market.
} 
The job. In both treatment conditions, workers have the opportunity to be hired as an "advisor" whose job is to give advice to another uninvolved participant outside the laboratory, the "client." Specifically, the advisor has to write a recommendation to a client to select one among ten choice options (labeled by the letters "A" through "J"). The treatment varies which option the advisor must recommend to the client. The client receives this recommendation, and then selects one of the ten options. The client only knows that the option he selects determines his financial reward for completing a survey and influences a donation to UNICEF, but does not know the consequences of any specific option. However, the client knows that the advisor had complete payoff information at the time of writing the recommendation. The client is free to choose the recommended option or any other option. ${ }^{18}$

The payoffs associated with each of the ten options are indicated in Table 3. Nine options increase the client's reward by $1 \mathrm{CHF}(\approx 1$ US Dollar) and increase the donation to UNICEF by an amount corresponding to the treatment of one child. However, one of the 10 options - in this case, $D$ - gives 0 CHF to the client, and reduces the UNICEF donation.

Table 3: Options available to the "client"

\begin{tabular}{|l|c|c|c|c|c|c|c|c|c|c|}
\hline & A & B & C & D & E & F & G & H & I & J \\
\hline $\begin{array}{l}\text { Additional number of children } \\
\text { receiving the anti-malarial treatment }\end{array}$ & 1 & 1 & 1 & -1 & 1 & 1 & 1 & 1 & 1 & 1 \\
\hline Financial reward for client (CHF) & 1 & 1 & 1 & 0 & 1 & 1 & 1 & 1 & 1 & 1 \\
\hline
\end{tabular}

Our two conditions vary only in the recommendation that the advisor is hired to make. In neutral work, the advisor's job is to recommend a specific option that is beneficial to the client and to UNICEF (e.g., option $G$ in Table 3). Note that a client is very likely to make such a choice independently of any advice, thereby making the impact of such advice largely neutral. In immoral work, the job is to recommend the single option with negative consequences (option D). In both cases, the advisor makes a recommendation by completing a form stating that the recommended option "will save the highest number of children" and "will give you the highest financial reward." 19 By recommending option D, however, the advisor increases the chance that the client selects the single option that will not increase his earnings and that will reduce the donation to UNICEF. We vary the letter of the

\footnotetext{
${ }^{18}$ Clients followed the recommendation in $84 \%$ of all cases.

${ }^{19}$ Specifically, the advisor has to complete the following recommendation with the option's name (e.g., G) and his initials: "I, [advisor's initials], have reviewed your possible choices and I recommend that you select the option [G]. Following my advice will save the highest number of children and will give you the highest financial reward. Your advisor: [advisor's initials]."
} 
recommended bad (neutral) option across immoral (neutral) laboratory sessions. Note that conditions only differ in the moral nature of the job; everything else, including effort costs, is kept constant.

The market. Participants are randomly allocated to markets consisting of 6 workers who compete to be hired by 6 automated firms. Each worker can provide up to two units of labor-one at a low cost (CHF 2.50) and one at a high cost (CHF 5.50). All workers face the same induced costs, which the instructions clearly explain.

At the beginning of every market period, each worker decides whether or not to participate in the labor market. In the former case, she (privately) provides two wage requests, one for each of the possible units of labor she can provide. Workers may only submit wage requests that are at least as high as the corresponding cost of providing that job.

Firms are simulated by the computer. Each firm can hire up to one unit of labor per period. Firms are identical except for the wage that they offer to the workers. Figure 2 displays the automated demand for labor as well as the induced costs of labor supply. In equilibrium, all workers provide one unit of labor and the market wage is between CHF 2.5 and 2.9. ${ }^{20}$ The workers have no information about the shape of the automated demand.

Figure 2: The automated demand and the induced costs of labor supply

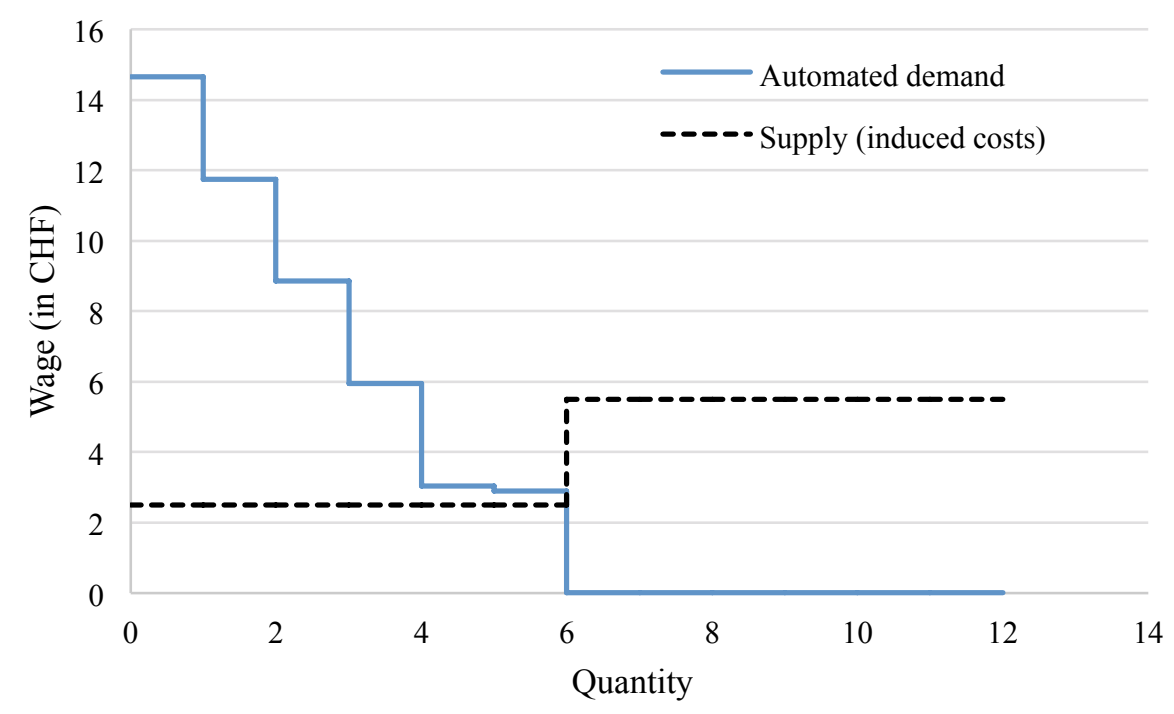

We use a uniform-price sealed-offer auction as the market mechanism, as this provides desirable features. First, Smith et al. (1982) show that this type of market typically converges to the equilibrium prediction. Second, and more importantly, this mechanism allows us to automate labor demand (see also Sausgruber and Tyran, 2011) and therefore

\footnotetext{
${ }^{20}$ We selected this specific labor demand function to facilitate equilibrium convergence. As long as the wage is higher than CHF 3.05, at least two workers will be unemployed, putting downward pressure on wages.
} 
keep demand constant between conditions. Once all six workers have submitted their wage requests, the computer ranks them from lowest to highest and compares the workers' wage requests to the firms' wage offers, ranked from highest to lowest. The market wage is then the lower of two potential candidates: (i) the last wage offer that is higher than the wage request with the same rank, and (ii) the first wage request that is higher than the wage offer with the same rank. This mechanism clears the market in that, for the market wage, labor supply equals labor demand and all workers with wage requests below the market wage are hired. A worker's earnings in a round equal the market wage times the units of labor provided by that worker $(0,1$ or 2$)$, minus the corresponding cost; workers who do not participate in the market do not make any money.

Figure 3: Example of feedback provided after every period

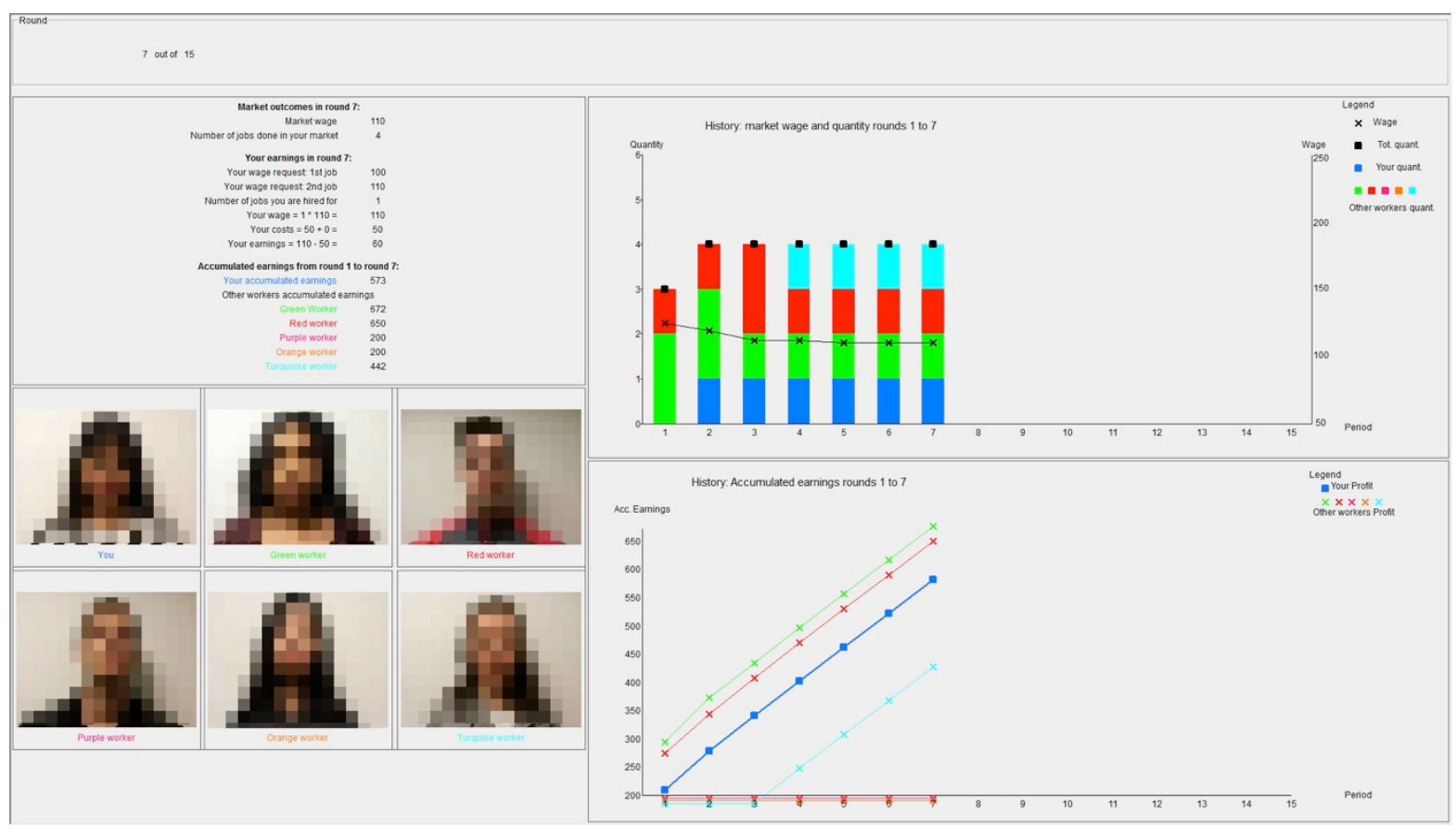

The market repeats for a total of 15 periods. The composition as well as the type (immoral or neutral) of each market is fixed across periods. At the end of each period, the computer reports the market wage, displays the picture of every worker in the market and summarizes information regarding each workers' outcomes across all periods (see Figure 3). Specifically, subjects observe employment outcomes, wages and cumulative earnings for all workers in their market across periods, and can connect these to the other workers' identities through the photographs. After observing outcomes, those participants who are hired in a period complete the paper forms with the recommendations - they write their own initials and 
the appropriate letter (e.g., "G" or "D" in the earlier example). ${ }^{21}$ If a firm does not succeed in hiring a worker in a period, the firm's client will not receive any recommendation. This implies that in the immoral condition, if a participant is not willing to do the job for the market wage, the number of clients who receive bad recommendations (weakly) decreases.

\subsubsection{Procedural details}

All sessions took place at the Decision Sciences Laboratory (DeSciL) at the Federal Institute of Technology in Zurich (ETH) in February, April and May 2017. Participants were recruited using hroot (Bock, Baetge and Nicklisch, 2014) from the joint subject pool of the University of Zurich and the ETH. Every session consisted of 24 participants, who were only accepted at the session if they had previously completed the online survey described in Section $6 .^{22}$ To start a session, subjects had to enter an identifier that allows us to link, anonymously, their answers in the online survey with their behavior in the lab. We conducted ten sessions, resulting in a total of 240 participants, allocated to 28 markets for immoral work and 12 markets for neutral work. The laboratory experiment was implemented with zTree (Fischbacher, 2007).

All instructions were delivered both on paper and with pre-recorded audio files. Instructions and materials are available in Appendix $\mathrm{F}^{23}$

\subsubsection{Survey study with "clients”}

We subsequently recruited a different sample of students on the campus of the University of Zurich and the Swiss Federal Institute of Technology (ETH) $(\mathrm{N}=177)$. We invited student passersby to participate in a brief choice experiment in which they could earn money and generate a donation for UNICEF aimed at providing treatments for children

\footnotetext{
${ }^{21}$ Subjects are informed that each firm has a probability of 25 percent of having a client in every period, independently of whether or not the firm hires a worker. If the firm does not have a client, then the worker's recommendation will be unused, although the worker still completes the recommendation and receives the market wage. However, subjects do not know at the time of submitting wage requests or completing the forms at the end of a period whether or not there will be a client for that period. This represents, for instance, a case in which a worker is hired to prepare promotional materials for a harmful product, which may or may not ultimately be seen by potential customers. At the end of the experiment, subjects learn which of their written recommendations will be distributed. We did this to lower the number of clients we needed to recruit in the follow-up survey. This procedure implies that writing a recommendation only has consequences with a probability of 25 percent and, therefore, works against our hypothesized treatment effect.

${ }^{22}$ We made an exception if less than 24 subjects who completed the survey showed up to the experiment. In total, three subjects were allowed to participate despite not completing the online survey.

${ }^{23}$ At the conclusion of the laboratory session, we collected several additional individual-level measures. First, we measured participants' affect levels-i.e., pleasure, arousal, and dominance - using the Self-Assessment Manikin (Bradley and Lang, 1994). Next, we asked participants whether they thought the clients would or would not follow recommendations; this belief was not incentivized. The participants were then prompted to answer several questions about the reasons underlying their market behavior. Finally, we measured subjects' concerns for social image using the public self-consciousness scale by Leary et al. (2015).
} 
infected by malaria. They were told that they would earn CHF 2 plus possibly some additional money for a 5-minute study. These subjects performed two functions.

First, they served the role of "clients" for the recommendations from the laboratory labor market. Each participant made up to six decisions by choosing one of the ten letters between $\mathrm{A}$ and $\mathrm{J}$. They knew that these decisions influenced their own earnings and also possibly the amount of donations to UNICEF, but they did not know the actual payoffs. Each decision had the payoff structure in Table 3, but we varied which letter corresponded to the bad option. Clients received a mixture of recommendations with good advice, bad advice and no advice (corresponding to cases in which a firm was not able to hire a worker). Clients were only informed of the total payoffs at the end of their decisions.

Second, while their payment was determined and prepared, participants completed a survey in which they rated various firms and industries on a scale from 1 (very immoral) to 5 (very moral). For firms, clients also had the option to choose "I don't know this organization." The complete list of firms and industries is available in Appendix Tables A1 and $\mathrm{A} 2$.

\subsection{Results}

In our analysis, we focus on the existence of an immorality premium and sorting by heterogeneous moral types. We first discuss how we construct our incentivized measure of concern for morality, $\theta^{E x p}$. Next, we study behavior in the labor market, and whether it can be predicted by $\theta^{\operatorname{Exp}}$. We then study outcomes in the labor market and their connection to the behavioral measure of moral concern $\left(\theta^{\operatorname{Exp}}\right)$.

\subsubsection{Construction of $\theta^{\text {Exp }}$}

We construct $\theta^{\operatorname{Exp}}$ based on choices in the behavioral task that subjects completed at the beginning of the laboratory session (Appendix Table A3 shows the distribution of choices). Let $m_{i r}$ be the number that individual $i$ reports if the actual die roll is $r$. We classify an individual as a $\theta_{L}$ type if $m_{i r} \geq r$ for all $r \in\{1,2, \ldots, 6\}$ and $m_{i r}>r$ for at least one $r$; that is, participant $i$ is classified as having a low concern for morality if he or she lies at least once for personal gain and never in a self-harmful manner. We classify the remaining participants as $\theta_{H}$ types. $^{24}$ Based on this classification, we have 66 (27.5 percent) $\theta_{L}$ types

\footnotetext{
${ }^{24}$ A total of 13 subjects (5.4 percent, see Appendix Table A3) harmed themselves at least once with a lie ( $m_{i r}<r$, e.g., reporting $m_{i r}=1$ when $r=2$ ). Since these subjects do not appear to be motivated by egoism, we classify them as $\theta_{H}$. The remaining 161 subjects classified as $\theta_{H}$ always report the true number. Classifying subjects that lied in a self-harmful manner as $\theta_{H}$ types is conservative in that they act less morally than the
} 
and 174 (72.5 percent) $\theta_{H}$ types. $^{25}$ For convenience, given our interpretation of $\theta$ we will often refer to $\theta_{L}$ types as immoral and $\theta_{H}$ types as moral. We next explore the differential behavior of the different types in the labor market and the consequences of this behavior.

\subsubsection{Labor supply of moral and immoral types}

Assuming that $\theta^{\operatorname{Exp}}$ measures a stable concern for morality that translates into labormarket choices, we should observe differential labor-market behavior between $\theta_{H}$ and $\theta_{L}$ types, but only when employment requires immoral work. The data confirm this. In Table 4, we report the results of a double-hurdle regression of the decision of whether to submit a wage request and, conditionally, the actual wage request. The key independent variable is a subject's type from the behavioral task at the beginning of the experiment. In the immoral work condition, $\theta_{H}$ types opted to submit wage requests less frequently, by almost 30 percentage points, than $\theta_{L}$ types (61.6 percent vs. 90.6 percent, $\left.\mathrm{p}<0.001\right)$. By declining to submit a wage request, a subject indicates an unwillingness to do the work even at a wage of $50 \mathrm{CHF}$ per period, the highest possible wage request in our experiment. Furthermore, consistent with the model, $\theta_{L}$ types submit conditional reservation wage requests that are approximately $0.49 \mathrm{CHF}$ lower than those of $\theta_{H}$ types $(\mathrm{p}=0.073)$. These effects do not become weaker over time-if anything, the greater willingness of $\theta_{L}$ types to participate in the immoral labor market becomes slightly stronger over time. ${ }^{26}$ Moreover, 21.5 percent of the $\theta_{H}$ workers never participated in the market (i.e., refused to submit wage requests in any of the 15 periods), but this is true of only 4.3 percent of $\theta_{L}$ workers $(t=-3.78 ; \mathrm{p}=0.001)$. Hence, our behavioral measure of a subject's moral type predicts their willingness to seek employment in an immoral job.

In the neutral work condition, however, non-participation is virtually non-existentthere were only 3 cases in total, representing 0.28 percent of all observations. That is, there is nearly universal participation when the job does not involve immoral behavior. Moreover, the average wage requests of $\theta_{H}$ (CHF 2.91) and $\theta_{L}$ (CHF 2.89) types do not differ in magnitude or in statistical significance ( $\mathrm{p}$-value from truncated linear regression $=0.827$ ).

honest subjects (see Table A5 in the Appendix). Results do not change if we drop these subjects or if we classify them instead as $\theta_{L}$.

${ }^{25}$ In principle, we could classify subjects into more than two categories-e.g., conditional on the number of lies or based on the expected payoff from lying $\left(\frac{1}{6} \sum_{r=1}^{6} m_{i r}-r\right)$. Due to the low number of subjects with different lying-patterns (see Appendix Table A3), we opt for a binary classification. However, we find similar results if we use alternative classifications (see Appendix Table A5).

${ }^{26}$ Specifically, if we add a linear time trend to the hurdle model and its interaction with $\theta_{L}^{E x p}$ (see Appendix Table A4), we find that $\theta_{L}$ types become slightly more likely to participate over time and provide lower reservation wages, relative to $\theta_{H}$ types. However, both coefficients are small and statistically insignificant. 
Table 4: Relationship participation decision/reservation wage and $\theta^{\text {Exp }}$

\begin{tabular}{lcc|c}
\hline Dependent variable: & Participation & $\begin{array}{c}\text { Reservation } \\
\text { wage }\end{array}$ & $\begin{array}{c}\text { Reservation } \\
\text { wage }\end{array}$ \\
\hline Low-theta $\left(\boldsymbol{\theta}_{\boldsymbol{L}}^{\boldsymbol{E x p}}\right)$ & $(1)$ & $(2)$ & $(3)$ \\
& $1.024^{* * *}$ & $-0.494^{*}$ & -0.018 \\
Constant & $(4.64)$ & $(-1.79)$ & $(-0.22)$ \\
& $0.295^{* *}$ & $4.056^{* * *}$ & $2.909^{* * *}$ \\
Sigma & $(2.41)$ & $(20.20)$ & $(43.79)$ \\
Condition & & $2.64^{* * *}$ & $0.609^{* * *}$ \\
$\mathbf{N}$ & Immoral work & Immoral work & Neutral work \\
LL (pseudo) & 2520 & 1755 & 1077 \\
\hline
\end{tabular}

Notes: Estimates from Craggs double-hurdle Model: (1) is a probit model; (2) and (3) are truncated linear regressions (truncated from above at $50 \mathrm{CHF}$ ). Models (1) and (2) use only data from the immoral work condition; model (3) uses only data from the neutral work condition. For neutral work, we focus on reservations wages as we have only 3 incidences in which a subject did not participate. Independent variables: Low-theta in $\{0,1\}$. Standard errors clustered at market level; $z$-statistics in parentheses; $*-p<0.1 ; * *-p<0.05 ; * * *-p$ $<0.01$.

\section{Figure 4: Empirical labor supply for neutral and immoral work in the laboratory}

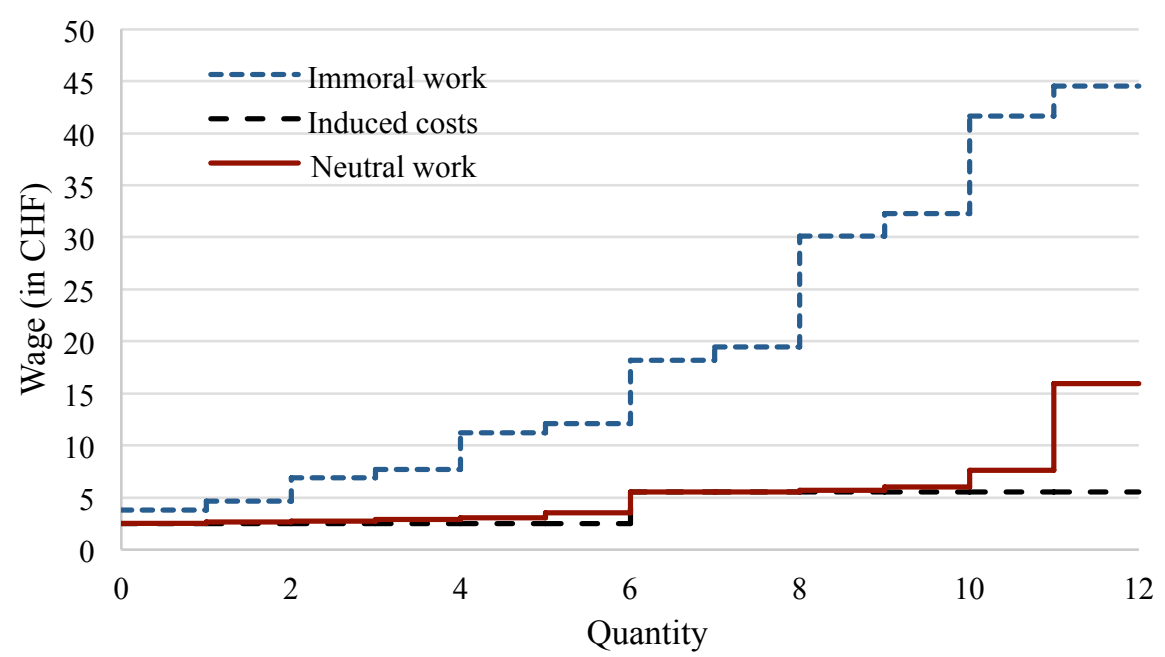

Notes: Wage requests are ranked within each market period of each group. The figure shows the average wage request for each rank for both the immoral work and the neutral work conditions. Note that wage requests are censored at the maximal wage request that subjects could make, $50 \mathrm{CHF}$. For this figure, we set the wage requests of subjects who are not willing to participate to CHF 50. Therefore, the supply curve for the immoral work condition should be interpreted as a lower bound.

Thus, we observe that $\theta_{H}$ types withdraw their participation and make higher wage requests when work requires immoral behavior. However, when the work activity is neutral, both types almost always participate and make similar wage requests. As a direct consequence of these observations, labor supply differs substantially between the two kinds of markets, as shown in Figure $4 .^{27}$ For neutral work, labor supply is fairly close to the

\footnotetext{
${ }^{27}$ Figure A1 in the Appendix shows the labor supply if we only consider the last 5 periods. Figure A2 in the Appendix displays the labor supply in (simulated) labor markets with only low-theta or only high-theta types.
} 
induced costs. However, for any given wage, there is a substantially lower supply of labor with immoral work.

In the following sections, we explore the implications of the above heterogeneous behavior for labor market outcomes.

\subsubsection{Wage premium for immoral work}

We find a substantial immorality premium, as shown in Figure 5. This follows directly from the differential labor supply in Figure 4. While market wages in the neutral work condition converge toward the equilibrium prediction of CHF 2.90, the average market wage is persistently higher for immoral work and this difference is statistically significant in a t-test from a regression with standard errors clustered at the market-level (coefficient $=2.581, \mathrm{t}=6.00, \mathrm{p}<0.001$ ). Hence, our laboratory labor market shows causal evidence of a substantial and persistent wage premium for immoral work. ${ }^{28}$

\section{Figure 5: Immorality wage premium in laboratory labor markets}

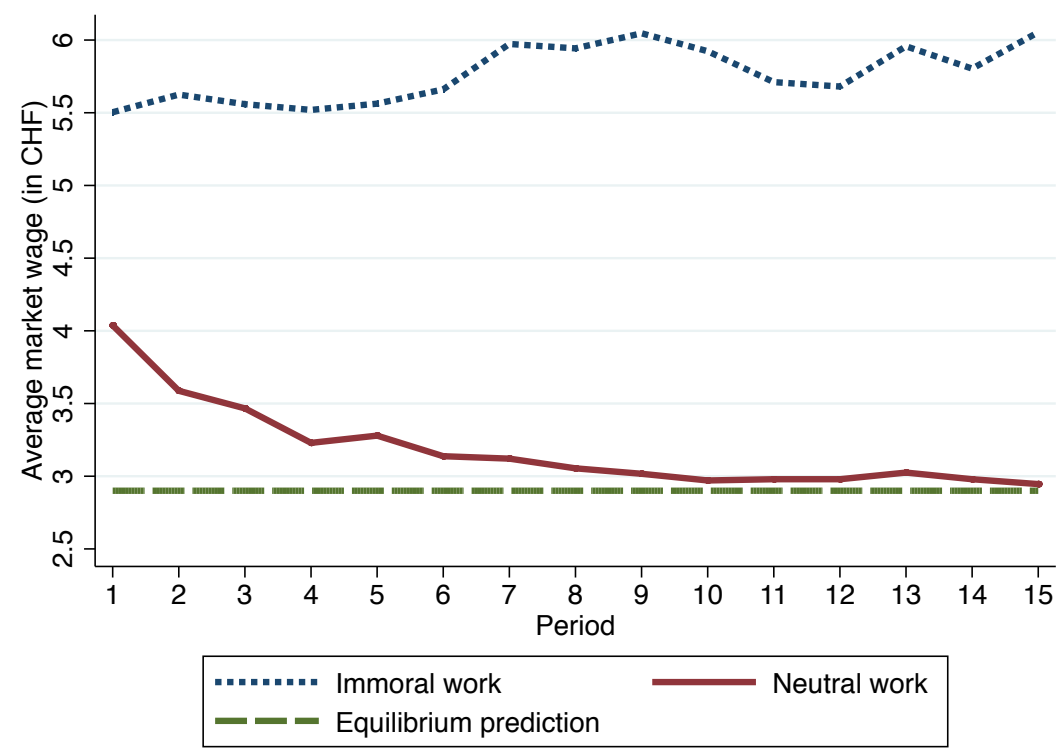

We also find persistent differences in employment levels in the two markets (Figure A3 in the Appendix). While markets for neutral work converge to the equilibrium prediction of 6 , the average market quantity remains below 4 in the immoral work condition. This difference is significant in a t-test comparing the means (coefficient $=-1.201, t=-6.30$, $\mathrm{p}<0.001)$. Moreover, the trends in Figure 5 provide further evidence that the manifestation of

\footnotetext{
${ }^{28}$ A natural concern might be that the immorality premium results from the specific labor demand structure that we employ. However, as evident from the differences in labor supply in Figure 4, workers are sufficiently concerned with acting morally that wage premiums would obtain under a variety of demand specifications.
} 
$\theta_{H}$ types' morality in labor market behavior does not erode over time. This persistence is remarkable given the high amount of social information provided at the end of each market period: in the immoral work condition, participants who forgo working see other participants less concerned with morality repeatedly earning high wages due to their own reluctance to act immorally.

\subsubsection{Sorting in immoral labor markets}

We next turn to our second main prediction, that $\theta_{L}$ types will be disproportionately hired in the market for immoral work. Figure 6 shows that, indeed, $\theta_{H}$ types are consistently employed less frequently in the immoral work condition. Table 5 shows that, on average, $\theta_{L}$ types are $26.6(=26.8-0.2)$ percentage points more likely to be employed than $\theta_{H}$ types (column 1). This difference is statistically significant $(\mathrm{p}<0.001)$ and robust to adding market fixed effects (column 2). The results are similar if we use, as a dependent variable, the number of work units provided $(0,1$ or 2$)$ rather than a binary measure of employment (columns 3 and 4). In the neutral work condition, we do not find a significant difference in employment rates between the two types (columns 1 to 4; see also Appendix Figure A4). This corroborates that the difference in hiring rates in the immoral work condition is driven by differences in concerns for morality and not some other difference between $\theta_{H}$ and $\theta_{L}$ types.

Figure 6: Employment rate by the two types in the immoral work condition

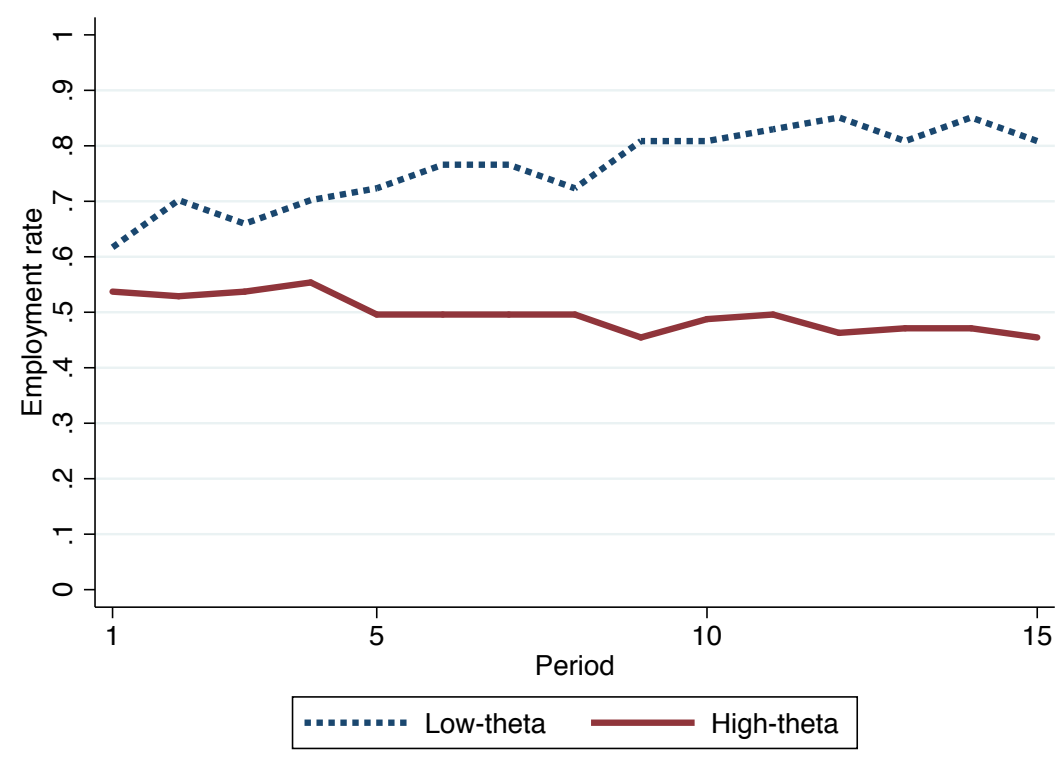


Table 5: Relationship between $\theta^{E x p}$ and outcomes in the experimental labor markets

\begin{tabular}{|c|c|c|c|c|c|c|}
\hline \multirow[t]{2}{*}{ Dependent variable: } & \multicolumn{2}{|c|}{ Employment rate } & \multicolumn{2}{|c|}{ Number of work units } & \multicolumn{2}{|c|}{ Market income } \\
\hline & $(1)$ & $(2)$ & (3) & $(4)$ & $(5)$ & $(6)$ \\
\hline Low-theta $\left(\theta_{L}^{E x p}\right)$ & $\begin{array}{l}-0.002 \\
(-0.05)\end{array}$ & $\begin{array}{l}-0.034 \\
(-0.90)\end{array}$ & $\begin{array}{l}-0.002 \\
(-0.05)\end{array}$ & $\begin{array}{l}-0.034 \\
(-0.90)\end{array}$ & $\begin{array}{c}-1.33 * * \\
(-2.40)\end{array}$ & $\begin{array}{c}-0.56 \\
(-1.39)\end{array}$ \\
\hline Immoral work (IW) & $\begin{array}{c}-0.331 * * * \\
(-7.70)\end{array}$ & & $\begin{array}{c}-0.272 * * * \\
(-7.11)\end{array}$ & & $\begin{array}{c}12.15 * * * \\
(9.96)\end{array}$ & \\
\hline$\theta_{L}^{E x p} * \mathbf{I W}$ & $\begin{array}{c}0.268 * * * \\
(4.54)\end{array}$ & $\begin{array}{c}0.249 * * * \\
(3.58)\end{array}$ & $\begin{array}{c}0.256^{* * *} \\
(4.10)\end{array}$ & $\begin{array}{c}0.264 * * * \\
(3.57)\end{array}$ & $\begin{array}{c}8.42 * * * \\
(2.71)\end{array}$ & $\begin{array}{c}11.37^{* * * *} \\
(3.64)\end{array}$ \\
\hline $\mathbf{N}$ & 240 & 240 & 240 & 240 & 240 & 240 \\
\hline $\mathbf{R}^{2}$ & 0.179 & 0.319 & 0.103 & 0.174 & 0.138 & 0.243 \\
\hline p-value: $\theta_{L}^{E x p}+\theta_{L}^{E x p} * I W=0$ & 0.0000 & 0.0007 & 0.0000 & 0.0009 & 0.026 & 0.001 \\
\hline Market FE & No & Yes & No & Yes & No & Yes \\
\hline
\end{tabular}

Notes: Coefficient estimates of linear regression models. Independent variables: Low-theta in $\{0,1\}$, Immoral work in $\{0,1\}$. Standard errors clustered at market level; -statistics in parentheses; $*-p<0.1 ; * *-p<0.05$; $* * *-p<0.01$.

\subsubsection{Market income in immoral labor markets}

Two additional predictions address heterogeneous treatment effects on worker's utility. As a simple proxy for utility, we use the sum of all earnings accumulated by a worker over the 15 market periods. ${ }^{29}$

\section{Figure 7: Market income by moral type}
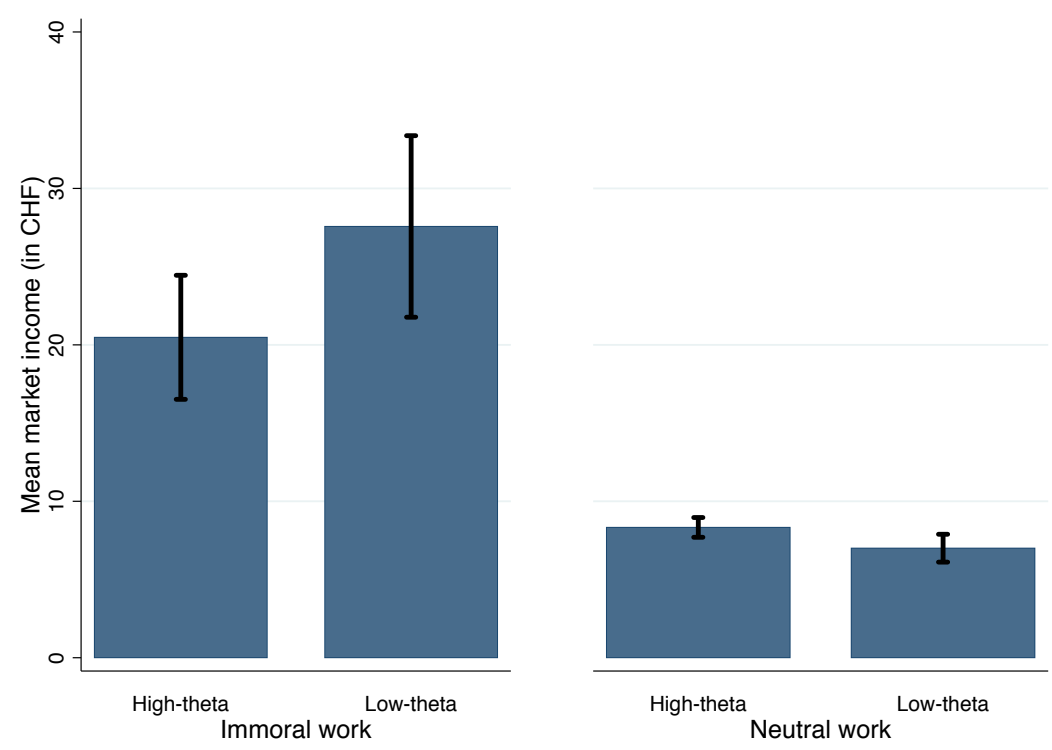

Notes: Average market income by treatment condition and moral type. Error bars show 95\% confidence intervals.

\footnotetext{
${ }^{29}$ As we show in Appendix C, the same results obtain if we use a slightly more complicated measure that incorporates estimates of workers' disutility from work, which we obtain from their wage requests.
} 
First, our theoretical analysis predicts that the immoral types benefit from an increase in the job's immorality (Proposition 3). Figure 7 and results from linear regressions (see Table 5, Columns 5 and 6) show that the $\theta_{L}$ types earn more market income than the $\theta_{H}$ types in the immoral work condition. The difference of CHF 7.09 (8.42 - 1.33 in column 5) is statistically significant $(\mathrm{p}=0.026)$. Note that the potential market income is constrained by the market wage. If we control for the market wage by adding market fixed effects (column 6), the $\theta_{L}$ types are estimated to earn CHF 10.81 more than the $\theta_{H}$ types $(\mathrm{p}=0.001)$. Thus, as predicted, immoral types earn considerably more in a market for immoral work. There is no such difference in markets for neutral work; if anything, $\theta_{L}$ types earn slightly less than the $\theta_{H}$ types.

\section{Figure 8: Externalities of moral behavior for immoral types}
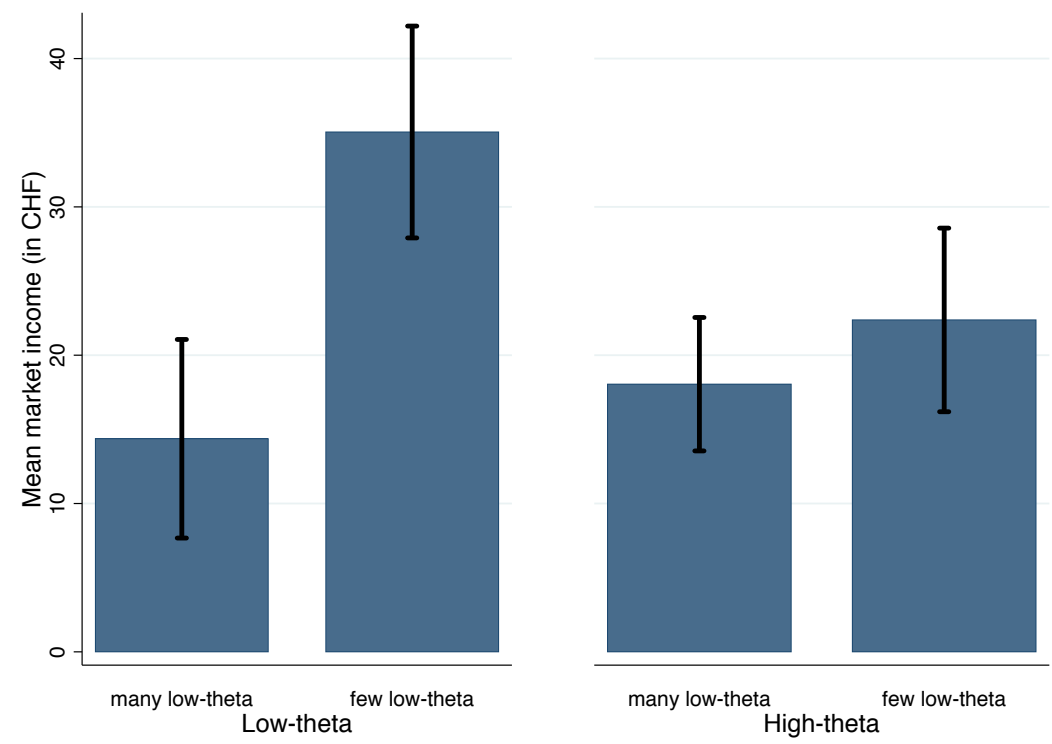

Notes: Average market income by moral type and market composition; data only from immoral work condition. A subject is in a market with many low-theta workers if the number of (other) low-theta workers is 2 or more and in a market with few low-theta workers if the number of (other) low-theta workers is lower than 2. Error bars show the $95 \%$ confidence intervals.

Finally, our analysis predicts that, in the immoral work condition, immoral types have higher utility in the presence of more moral types (Proposition 4). To test this prediction, for each subject we count the number of other $\theta_{L}$ workers in the market and split the sample based on the median of this measure. We thus classify a subject as being in a market with few $\theta_{L}$ types if the number of (other) $\theta_{L}$ workers is lower than 2 , and as being in a market with many $\theta_{L}$ types if the number is 2 or more. Using only the immoral work condition, this results in 70 subjects in the first category, and 98 in the second category. Figure 8 shows these 
subjects' mean earnings, based on their own type and the composition of others' types in their market. The income of $\theta_{H}$ types is CHF 4.33 higher in a market with few $\theta_{L}$ types than in one with many $\theta_{L}$ types $\left(\mathrm{t}=2.05, \mathrm{p}=0.051\right.$, see Table A6 in the Appendix). However, for $\theta_{L}$ types, being in a market with few other $\theta_{L}$ types increases income by an additional CHF 16.35 $(t=3.53, p=0.002)$, resulting in a total difference of CHF $20.68(t=4.29, p<0.001) .{ }^{30}$

Our laboratory findings thus confirm all four predictions from our theoretical analysis. We find evidence that people with high concern for morality consistently refuse to do immoral jobs (or require a high wage), thereby decreasing labor supply and increasing wages and producing a persistent immorality premium. As a consequence, subjects with a low concern for morality are better off in markets for immoral work, particularly when in the presence of more moral subjects. ${ }^{31}$

\section{Stated real-world employment preferences and sorting}

Several days (4-7) before the laboratory session, subjects completed an online survey. ${ }^{32}$ This survey includes questions designed to measure subjects' expectations of their own future labor market outcomes, including the willingness to work for different firms and industries and expected future wages, and questions eliciting subjects' concern for morality. The survey gives us a second measure of moral concern $(\theta)$ and, more importantly, allows us to investigate whether subjects' moral types predict not only behavior in laboratory labor markets, but also expectations for labor market outcomes outside the laboratory.

We first construct an individual measure of concern for morality based on the answers to the psychological survey questions $\left(\theta^{\text {Sur }}\right)$. We then show that this second measure of concern for morality correlates both with the comparable behavioral measure from the laboratory experiment $\left(\theta^{E x p}\right)$ and with outcomes in the laboratory labor market. This validation of $\theta^{\text {Sur }}$ is useful for future research, as it is based solely on survey questions that are easier to collect than the incentivized laboratory measure. Moreover, the comparison of $\theta^{\text {Exp }}$ and $\theta^{\text {Sur }}$ provides some evidence on the stability of moral concerns across time and

\footnotetext{
${ }^{30}$ If we use the number of (other) $\theta_{L}$ types in the market instead of doing a median split, we find similar results. For $\theta_{H}$ types, the income is estimated to increase by CHF 2.45 per additional $\theta_{H}$ type in the market $(\mathrm{t}=2.10$, $\mathrm{p}=0.045)$. For $\theta_{L}$ types, the income increases by CHF 8.21 for every additional $\theta_{H}$ type $(\mathrm{t}=2.62, \mathrm{p}=0.014)$.

31 One additional consequence of heterogeneous concerns for morality is that the income distribution differs substantially between the two treatment conditions. While in the neutral work condition, income is almost equally distributed (Gini coefficient $=0.15$ ), we find substantial income inequality in the immoral work condition (Gini coefficient=0.38). Appendix Figure A5 shows the Lorenz curves for both conditions.

${ }^{32}$ Subjects could only sign up for both the online survey and the lab study. Three (out of 240) subjects did not complete the online-survey. We exclude these subjects from this part of the analysis.
} 
contexts, which is necessary for heterogeneous moral concerns to persistently influence labor market behavior.

We then show that both $\theta^{\text {Sur }}$ and $\theta^{\text {Exp }}$ predict stated labor market preferences in labor markets outside the laboratory, consistent with the prediction regarding sorting (Proposition 2).

\subsection{The online questionnaire}

We first asked subjects several questions about their future labor-market expectations. Subjects were shown a list of 26 well-known companies in Switzerland and another list consisting of the 20 industries in Figure 1. Both lists are available in Tables A1 and A2 in the Appendix. Participants rated their willingness to work for each firm and industry (1: not at all willing; 5: very much willing). For firms, participants also had the option to select, "I don't know this organization." In addition, we asked subjects to provide unstructured responses stating beliefs about their future career trajectories - specifically, what work they expected to do after their studies and how much they expected to earn at the age of 40 . Note that these were the first questions participants answered, meaning that when they encountered them they had not been exposed to any references to morality or moral behavior.

Subjects next encountered several multi-item scales intended to measure an individual's broad concern for morality and moral acts. These were:

1) HEXACO-PI. We administered 10 items from the short version of the HEXACO Personal Inventory (Ashton and Lee, 2009) related to the factor "Honesty-Humility"consisting of the four traits, sincerity ( 3 items), fairness ( 3 items), greed avoidance (2 items) and modesty (2 items). Every item describes a thought that a moral or immoral person might have and participants indicate the extent to which each thought reflects their own opinions.

2) Protected Values. The Protected Values scale (Gibson et al., 2013) measures an individual's position regarding values that can be seen as inviolable, and not substitutable against money, and that are usually central to the person's identity. In our case, and following Gibson et al. (2013), we adapted the Protected Values to a situation where a financial adviser can give bad investment advice to a client for personal benefit. First, 5 items assess the morality of this behavior (Protected value 1); second, 4 items examine how truthfulness matters in such a situation (Protected value 2).

3) Integrity and Work Ethics Test. We used two items from an online test designed to allow firms to measure the integrity of job applicants (Work ethics 1, Work ethics 2). In 
each item, participants read fictitious dialogues between two characters with different opinions about a situation (e.g., calling in sick at work to enjoy a sunny day outside). Participants then rate with which character they have greater agreement.

4) Charity attitude index. We used a 9-item scale developed by Brashear et al. (2000) in which participants rate statements regarding how important they perceive it is to help others in society and how positive and useful they perceive work done by charities.

In each case, subjects expressed agreement or disagreement with statements on either a 5point or 7-point Likert scale. Thorough descriptions of these survey scales are provided in the Appendix F and in Table A7 in the Appendix. ${ }^{33}$ The online questionnaire was implemented with the Qualtrics software.

\subsection{Constructing $\boldsymbol{\theta}^{\text {Sur }}$}

We next discuss how we construct a survey-based measure of concern for morality, $\theta^{\text {Sur }}$. Table 6 lists the 9 subscales from the morality measures; Appendix Table A7 provides summary statistics. We aggregated these nine psychological measures by performing a principal-component factor analysis. We selected the factor with the highest eigenvalue (eigenvalue $=2.44$ ) to represent $\theta^{\text {Sur }} \cdot{ }^{34}$ Column 1 in Table 6 presents the corresponding factor loadings. We normalized $\theta^{\text {Sur }}$ such that it lies between 0 and 1 ; the resulting variable has a mean of 0.5 and a median of 0.5 . Low values represent a low concern for morality. Appendix Figure A6 shows the distribution of $\theta^{\text {Sur }}$. Given our interpretation of $\theta$, we will often refer to subjects with a low $\theta^{\text {Sur }}$ as immoral types and subjects with high $\theta^{\text {Sur }}$ as moral types.

\subsection{Does $\theta^{\text {Sur }}$ predict behavior in the laboratory?}

To validate $\theta^{\text {Sur }}$, we investigate how it correlates with behavior in the laboratory. Table 6, column 2, shows the coefficients from independent simple regressions of a subject's type measured by the behavioral laboratory task, $\theta^{\operatorname{Exp}}$, on each item comprising $\theta^{\text {Sur }}$. The dependent variable is binary, indicating that a subject is a $\theta_{H}$ type according to $\theta^{\operatorname{Exp}}$. The results show a significant positive correlation between $\theta^{\operatorname{Exp}}$ and all personality measures,

\footnotetext{
${ }^{33}$ We also asked subjects whether several non-profit organizations (including UNICEF) are worth supporting and collected additional personal characteristics using a short version of the Big Five (Gosling et al., 2003), which identifies individuals' extraversion, agreeableness, neuroticism, openness, and conscientiousness, but is largely orthogonal to morality. We also elicited several demographic characteristics, such as age, gender and field of study.

${ }^{34}$ In the Appendix (Tables A8, A9 and A10), we show that our results are robust to different aggregation mechanisms. Specifically, we look at two alternatives: i) each of the nine survey measures is given equal weight and ii) the weight of the measures is determined by a regression of $\theta^{\operatorname{Exp}}$ on the survey measures.
} 
except for Work ethics 1 and Work ethics 2. Consistent with the positive relationship of the individual items, a regression of $\theta^{\operatorname{Exp}}$ on $\theta^{\text {Sur }}$ shows a positive and significant relationship (coefficient $=0.723, \mathrm{t}=4.32, \mathrm{p}<0.001$ ), that is, a person who is characterized by a low concern for morality according to our survey-based measures is more likely to lie self-servingly in the behavioral measure in the experiment. These generally positive relationships suggest that $\theta^{E x p}$ and our survey-based measures capture similar individual characteristics.

Table 6: Items comprising $\theta^{\text {Sur }}$ and their relationship to $\theta^{\text {Exp }}$

Factor loadings (weights for $\theta^{\text {Sur }}$ )

(1)

\begin{tabular}{|l|c|c|}
\hline \multicolumn{1}{|c}{} & $\mathbf{( 1 )}$ & $\mathbf{( 2 )}$ \\
\hline Protected value 1 & 0.664 & $\begin{array}{c}0.540^{* * *} \\
(3.66)\end{array}$ \\
\hline Protected value 2 & 0.708 & $\begin{array}{c}0.352^{* *} \\
(2.22)\end{array}$ \\
\hline Work ethics 1 & 0.213 & $\begin{array}{c}-0.039 \\
(-0.39)\end{array}$ \\
\hline Work ethics 2 & 0.252 & $\begin{array}{c}0.042 \\
(0.52)\end{array}$ \\
\hline HEXACO sincerity & 0.482 & $\begin{array}{c}0.362^{* *} \\
(2.53)\end{array}$ \\
\hline HEXACO fairness & 0.611 & $\begin{array}{c}0.353^{* * *} \\
(2.61)\end{array}$ \\
\hline HEXACO greed avoidance & 0.477 & $\begin{array}{c}0.225^{*} \\
(1.73)\end{array}$ \\
\hline HEXACO modesty & 0.508 & $\begin{array}{c}0.236^{*} \\
(1.79)\end{array}$ \\
\hline Charity attitude index & 0.545 & $\begin{array}{c}0.711^{* * *} \\
(3.11)\end{array}$ \\
\hline
\end{tabular}

Notes: Each subscale is constructed by taking averages over all items of the scale, and then normalized such that it lies between 0 and 1. (1): Factor loadings from principal-component factor analysis of survey measures on $\theta^{\text {Sur }}$. (2): Coefficient estimates of linear probability models. $N=237$ for each regression (3 subjects did not complete the online-survey and are excluded). Dependent variable: being a high-theta type according to $\theta^{\text {Exp }}$. Independent variables: survey measures in $[0,1]$, higher numbers indicate more morality. Robust standard errors; t-statistics in parentheses; * $p<0.1 ; *^{*}-p<0.05 ; *^{* *}-p<0.01$.

We next consider the extent to which $\theta^{\text {Sur }}$ also predicts participants' behavior in the laboratory labor market, particularly in the immoral work condition. ${ }^{35}$ Results from a linear regression of the employment rate on $\theta^{\text {Sur }}$ indicate that those participants with the lowest concerns for morality (that is, participants with $\theta^{\text {Sur }}=0$ ) are 43.9 percentage points more likely to be hired in markets for immoral labor than participants with the highest possible concern for morality (that is, with $\theta^{\text {Sur }}=1$ ). This difference is marginally statistically significant ( $\mathrm{p}=0.057$, see Appendix Table A8, column 1). A less noisy measure of subjects'

\footnotetext{
${ }^{35}$ Figure A7 in the Appendix displays the labor supply in a (simulated) labor market with only low $\theta^{\text {Sur }}$ or only high $\theta^{\text {Sur }}$ types.
} 
market behavior is their actual choices. Results from a hurdle model indicate that those subjects with the lowest concerns for morality are 52.1 percentage points more likely to participate in markets for immoral work by submitting a wage request than individuals having the highest possible concerns for morality ( $\mathrm{p}=0.015$, see Appendix Table A9). In the neutral work condition, as expected, we do not find substantial differences in employment rates or in labor market behavior between the two types. We thus conclude that $\theta^{\text {sur }}$ is predictive of behavior in the laboratory and could be a valuable measure future research on moral preferences.

\subsection{Do $\theta^{\text {Sur }}$ and $\theta^{\text {Exp }}$ predict stated real-world labor market preferences?}

Our study collects two measures of subjects' concern for morality $\left(\theta^{\text {Sur }}\right.$ and $\left.\theta^{\operatorname{Exp}}\right)$. The online survey also elicits the same subjects' willingness to work for several firms and industries, without any reference to morality. We also separately obtained independent ratings of the perceived immorality of these firms and industries, from the "clients" (see Section 5.1.4). In this section, we use all of this information to analyze how our measures of concern for morality connect to expectations about labor market outcomes outside the laboratory.

We create a measure of perceived firm immorality in the same way we created perceived industry immorality: by first scaling the ratings such that they lie between -1 (very moral) and +1 (very immoral), and then averaging them. ${ }^{36}$ We use these variables as noisy measures of the immorality of work, $I(j)$, in industry (or, firm) $j$, a key component of our theoretical analysis. The horizontal axes in Figures 9a and 9c plot the resulting normalized ratings for industries in our sample, the horizontal axes in Figures $9 \mathrm{~b}$ and $9 \mathrm{~d}$ plot the normalized ratings for firms (see also Appendix Tables A1 and A2).

Our focus in this section is to investigate whether these perceptions of industry and firm immorality interact with our subjects' measured concern for morality (either $\theta^{\text {Sur }}$ or $\left.\theta^{E x p}\right)$ to produce differential labor market preferences. For this purpose, we normalized subjects' stated willingness to work for firms and industries, such that they take values between 0 (not at all willing) and 1 (very much willing). ${ }^{37}$

\footnotetext{
${ }^{36}$ Remember that for firms, clients also had the option to choose "I don't know this organization" instead of rating the firm. To calculate the perceived firm immorality, we exclude these observations. Alternatively, we could code these as neutral ratings. These two measures are highly correlated (corr $=0.9854)$. Our results do not change substantially if we use the alternative measure (see Table A11).

${ }_{37}$ Incidentally, the list of industries accidentally omitted five industries for five participants that participated in the first lab session, meaning we are missing these data. Other than these cases, all subjects completed the full questionnaire. We exclude all these missing observations from the analysis. Regarding willingness to work for
} 


\section{Figure 9: Correlation between the difference in willingness to work between moral and immoral types and perceived immorality of industries/firms}

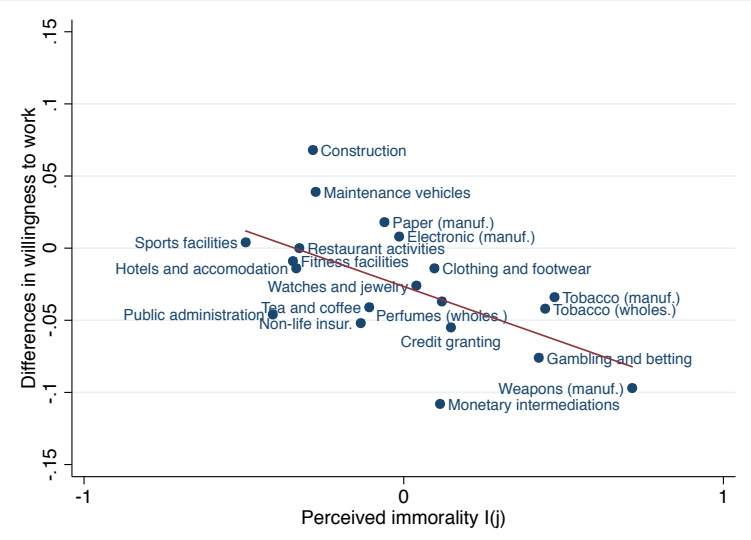

(a) Industries, $\theta^{\operatorname{Exp}}$

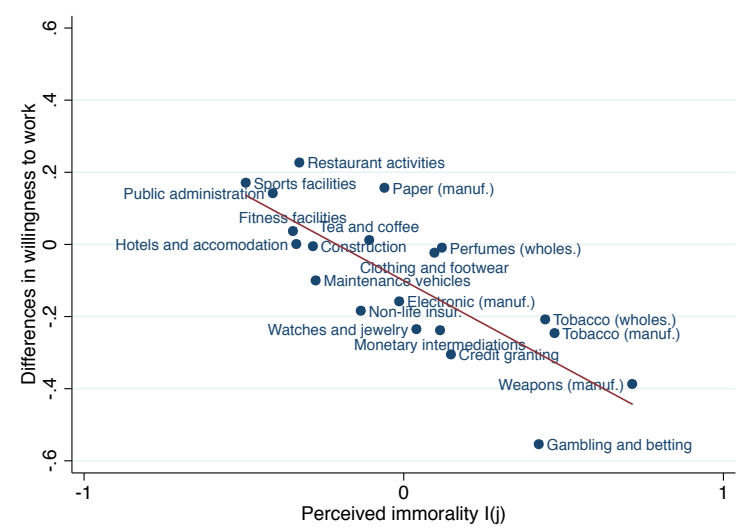

(c) Industries, $\theta^{\text {Sur }}$

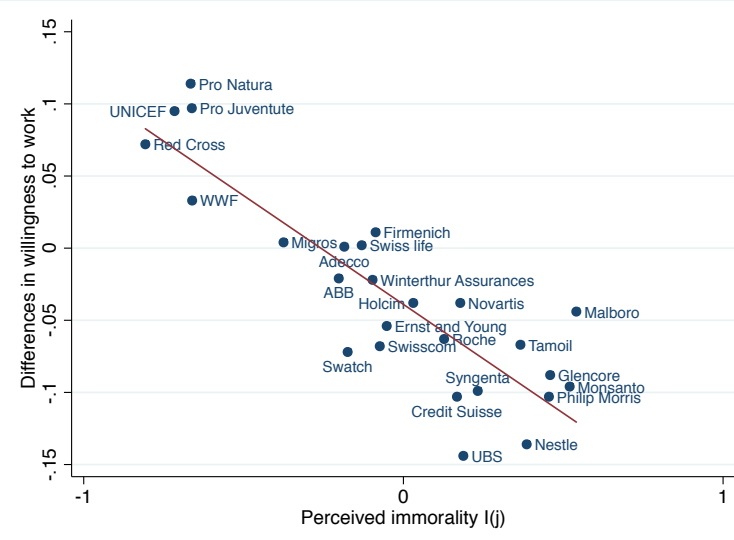

(b) Firms, $\theta^{\text {Exp }}$

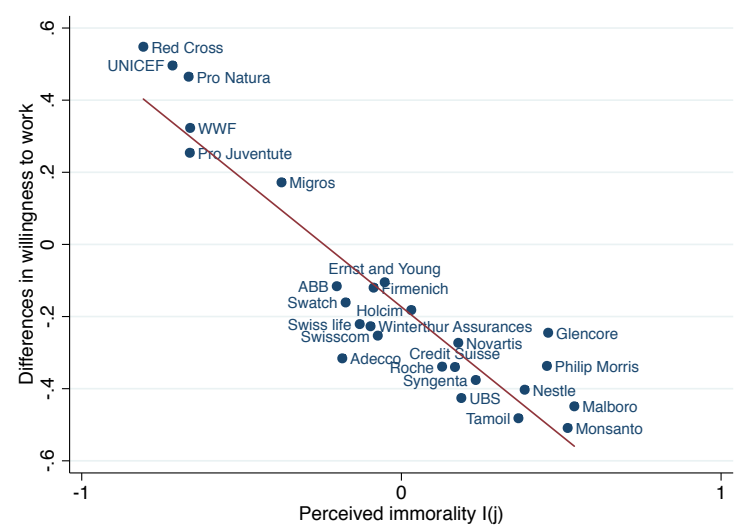

(d) Firms, $\theta^{\text {Sur }}$

Source: Survey study (Perceived immorality), online survey (Willingness to work, $\theta^{\text {Sur }}$ ), laboratory experiment $\left(\theta^{\text {Exp }}\right)$

Notes: Differences in willingness to work: Coefficient estimates of linear regression models of the participants' willingness to work for different industries ( $a$ and $c$ ) or firms ( $b$ and $d$ ) on $\theta_{H}^{\text {Exp }}$ ( $a$ and $b$ ) or $\theta^{\text {Sur }}(c$ and $d$ ). Dependent variable: Willingness to work is in $\{0,0.25,0.5,0.75,1\}$ where 0 means not at all willing to work, 0.5 means indifferent and 1 means really much willing to work. Observations where subjects did not know the firm ("I don't know this organization") or did not fill out the questionnaire are excluded. Independent variables: $a$ and $b$ use $\theta^{\text {Exp }}$ to classify participants, where $\theta_{H}^{E x p}=0$ for low-theta types and $\theta_{H}^{\text {Exp }}=1$ for hightheta types, while $c$ and $d$ use $\theta^{\text {Sur }}$ in $[0,1]$. Perceived immorality is in $[-1,1]$ where -1 means very moral, 0 means neutral and 1 means very immoral.

The vertical axes of Figures 9a and 9c plot the difference in willingness to work for the industries between subjects who were classified as moral or immoral, according to $\theta^{\text {Exp }}$ (Figure 9a) or $\theta^{\text {Sur }}$ (Figure 9c). The strong negative relationship across all of these figures indicates that subjects classified as immoral using either our survey-based or behavioral task are, on average, more willing to work for industries that others perceive as immoral.

firms, participants also had the option to choose "I don't know this organization." This option was chosen in 17.8 percent of all answers. We also exclude these observations. We obtain similar results if we classify such observations as "indifferent" or if we restrict our analysis to subjects that know all firms (see Table A12). 
Table 7, columns (1) to (4) provide statistical evidence of the relationships in Figures 9a and 9c. The dependent variable in the regressions is a subject's willingness to work for an industry, while the explanatory variables include the perceived industry immorality $(I(j)$, obtained from a separate group of respondents), the subject's concern for acting morally $(\theta)$ and the interaction of these two terms. While there is little evidence of a systematic difference in willingness to work for neutral industries between moral and immoral types, subjects' moral types have much stronger predictive power for their willingness to work in industries perceived as immoral. This pattern is significant at least at the 5\%-level, holds for both measures of individual moral concerns, $\theta^{\text {Sur }}$ and $\theta^{\text {Exp }}$, and is robust to controlling for subjects' gender, age, Swiss nationality, area of study, mean industry wages, industry size (number of employees), and industry sales.

Table 7: Regressions of willingness to work for diverse industries and firms on perceived immorality and moral types

\begin{tabular}{|c|c|c|c|c|c|c|c|c|}
\hline \multirow[t]{2}{*}{ Dependent variable: } & \multicolumn{4}{|c|}{ Willingness to work for industry $\boldsymbol{j}$} & \multicolumn{4}{|c|}{ Willingness to work for firm $\boldsymbol{j}$} \\
\hline & $(1)$ & $(2)$ & $(3)$ & (4) & $(5)$ & $(6)$ & $(7)$ & $(8)$ \\
\hline $\begin{array}{l}\text { Perceived } \\
\text { immorality }(\mathrm{I}(\mathrm{j}))\end{array}$ & $\begin{array}{c}-0.232 * * * \\
(-3.99)\end{array}$ & $\begin{array}{c}-0.226 * * * \\
(-4.72)\end{array}$ & $\begin{array}{l}-0.050 \\
(-0.77)\end{array}$ & $\begin{array}{l}-0.043 \\
(-0.74)\end{array}$ & $\begin{array}{c}-0.140 * * \\
(-2.08)\end{array}$ & $\begin{array}{c}-0.139 * * \\
(-2.07)\end{array}$ & $\begin{array}{l}0.114 \\
(1.56)\end{array}$ & $\begin{array}{l}0.110 \\
(1.50)\end{array}$ \\
\hline $\begin{array}{l}\text { Type from } \\
\text { experiment }\left(\theta_{H}^{E x p}\right)\end{array}$ & $\begin{array}{l}-0.027 \\
(-1.34)\end{array}$ & $\begin{array}{l}-0.029 \\
(-1.49)\end{array}$ & & & $\begin{array}{l}-0.043 \\
(-1.58)\end{array}$ & $\begin{array}{c}-0.051 * * \\
(-1.96)\end{array}$ & & \\
\hline$\theta_{H}^{E x p} * \mathbf{I}(\mathbf{j})$ & $\begin{array}{c}-0.078 * * * \\
(-2.56)\end{array}$ & $\begin{array}{c}-0.078 * * \\
(-2.51)\end{array}$ & & & $\begin{array}{c}-0.154 * * * \\
(-4.30)\end{array}$ & $\begin{array}{c}-0.154 * * * \\
(-4.38)\end{array}$ & & \\
\hline $\begin{array}{l}\text { Type from survey } \\
\left(\theta^{\text {Sur }}\right)\end{array}$ & & & $\begin{array}{c}-0.101^{*} \\
(-1.71)\end{array}$ & $\begin{array}{l}-0.107^{*} \\
(-1.72)\end{array}$ & & & $\begin{array}{c}-0.173 * * \\
(-2.28)\end{array}$ & $\begin{array}{c}-0.211 * * * \\
(-2.85)\end{array}$ \\
\hline$\theta^{\text {Sur } *} \mathbf{I}(\mathbf{j})$ & & & $\begin{array}{c}-0.479 * * * \\
(-5.22) \\
\end{array}$ & $\begin{array}{c}-0.479 * * * \\
(-5.24)\end{array}$ & & & $\begin{array}{c}-0.731 * * * \\
(-8.80)\end{array}$ & $\begin{array}{c}-0.722 * * * \\
(-8.53)\end{array}$ \\
\hline $\mathbf{N}$ & 4715 & 4715 & 4715 & 4715 & 5064 & 5064 & 5064 & 5064 \\
\hline Control variables & No & Yes & No & Yes & No & Yes & No & Yes \\
\hline
\end{tabular}

Notes: Coefficient estimates of linear regression models. Dependent variable: Willingness to work is in $\{0$, $0.25,0.5,0.75,1\}$ where 0 means not at all willing to work, 0.5 means indifferent and 1 means really much willing to work. Observations where subjects did not know the firm ("I don't know this organization") or did not fill out the questionnaire are excluded. Independent variables: (1), (2), (5) and (6) use $\theta_{H}^{\text {Exp }}$ to classify participants, where $\theta_{H}^{E x p}=0$ for low-theta types and $\theta_{H}^{E x p}=1$ for high-theta types, while (3), (4), (7) and (8) use $\theta^{\text {Sur }}$ (in [0,1]) instead. Perceived immorality is in $[-1,1]$ where -1 means very moral, 0 means neutral and 1 means very immoral. Control variables: age, gender, Swiss nationality, subject of study, average wage industry 2016 (SLFS; only for industries), industry size 2016 (STATENT; only for industries), industry sales 2015 (Value Added Tax Statistics; only for industries). Standard errors clustered at individual and industry/firm level (Cameron, Gelbach and Miller, 2011); z-statistics in parentheses; * $p<0.1 ; * * p<0.05 ; * * * p<0.01$.

We repeat the same analysis using data on subjects' willingness to work for our selection of well-known firms in Switzerland. The vertical axis of Figures $9 \mathrm{~b}$ and $9 \mathrm{~d}$ plot the difference in willingness to work for firms between subjects who were classified as moral and immoral according to $\theta^{\operatorname{Exp}}$ (Figure 9b) or $\theta^{\text {Sur }}$ (Figure 9d). Again, subjects classified as immoral are, on average, more willing to work for firms perceived as immoral. This 
relationship is confirmed by Table 7, columns (5) to (8): subjects less concerned with moral behavior are more willing to work for firms that other people rate as more immoral $(p<0.01)$, which is again true for both measures of concern for morality $\left(\theta^{\text {Sur }}\right.$ and $\left.\theta^{\operatorname{Exp}}\right)$. Hence, we find that firms that are perceived as immoral attract applicants with a lower concern for morality. ${ }^{38}$

The above analysis provides evidence supporting our second main prediction in labor markets outside the laboratory. Those who are least concerned with morality are significantly more willing to work in firms that are generally perceived as less moral. A limitation of this analysis is that it is based on hypothetical future choices. However, Wiswall and Zafar (2018) provide evidence that such stated preferences are predictive of ultimate employment. To further validate subjects' stated real-world labor market preferences, we can test whether the stated employment preferences correlate with individual employment rates in the immoral work condition of our laboratory experiment. Indeed, we find that people who are hired more often for the immoral job have a statistically significantly higher stated willingness to work in immoral industries outside the laboratory (see Table A13 in the Appendix).

Finally, in the online survey, we also asked subjects to rate how much they expect to earn when they reach the age of 40 . A regression of expected future wages on $\theta^{\text {Sur }}$ suggests a positive relationship such that the least moral types $\left(\theta^{\text {Sur }}=0\right)$ report expected income that is 30,272 CHF higher, on average, than the expected income of the most moral types $\left(\theta^{\text {Sur }}=\right.$ $1)$, but this relationship is not statistically significant $(p=0.125)$. While the point estimate of this relationship is consistent with the model's prediction of a wage premium for the types least concerned with morality, the earnings expectations measures over such a long time horizon - on average, 18 years - are perhaps less reliable than the more contemporaneous statements of willingness to work for different firms.

\section{Discussion and Conclusion}

We investigate whether heterogeneity in individual preferences for avoiding immoral work and the perceived immorality of work influence the jobs that individuals select and individuals' earnings. Our study employs a laboratory experiment, surveys and administrative data to identify heterogeneity in concerns for morality and to create (or, measure) variation in the immorality of jobs. We use these different kinds of data to test two main hypotheses-

\footnotetext{
${ }^{38}$ As we show in the Appendix, the differential willingness to work for immoral firms and industries by moral and immoral types does not depend on how we construct $\theta^{\text {Sur }}$ (Table A10), nor on how we deal with missing observations (Table A11, Table A12).
} 
first, that jobs generally perceived as immoral will yield a wage premium and, second, that individuals less concerned with moral behavior will be more likely to sort into such jobs.

In a laboratory setting, we use a simple behavioral task to classify individuals as "moral" or "immoral" types. We then show that this characteristic predicts the outcomes that individuals obtain as we experimentally vary only the immorality of work. We find support for both our hypotheses. Labor markets for immoral work yield significantly higher wages. Moreover, immoral workers are significantly more likely to be hired for immoral work than are moral workers; but this relationship disappears in a labor market for neutral work. We also find that a market for immoral work benefits immoral types, particularly when they compete with fewer other immoral types.

We separately use survey responses to classify the immorality of real-world firms and industries and show that industries classified as immoral pay higher wages. We also use surveys to obtain a separate measure of workers' moral types. This individual characteristic is correlated with the moral type measured in the laboratory and predicts subjects' behaviors in the laboratory labor market. Moreover, both the survey-based and lab-based measures of morality also predict stated preferences for working in firms and industries outside the laboratory that vary in their perceived morality. Using either measure, workers less concerned with morality are more willing to work for firms and industries generally perceived as less moral.

Given the significance of many social ills produced by immoral work practices, such as deceptive marketing of socially harmful products, our study sheds important new light on the interaction between individual's types, their willingness to do immoral work and the resulting labor-market outcomes. Our work also has several important policy implications.

First, in those jobs and industries with the greatest potential to do societal harm, social welfare will often be higher when workers voluntarily internalize the negative impacts of their actions and forgo potentially profitable opportunities. For instance, a weapons manufacturer may restrict sales to conflict areas if top management has a moral aversion to the social harm caused by such sales. However, our evidence suggests that it is the least moral types who will sort into these industries and that, therefore, labor market sorting will make it less likely that such internalization will occur. This also creates an important contrast between our findings and related work on sorting by mission-oriented types into firms or jobs with a pro-social orientation. In such cases, sorting may often be beneficial for society, as those who care about a cause become the ones who impact it; in our case, however, those 
who care about doing "good" may avoid the opportunity to determine how much "bad" takes place.

Second, another implication of our empirical findings is that the perception that a firm, industry or type of work is immoral may be self-reinforcing. If, as our results indicate, the perception that work involves immoral acts leads people less concerned with acting morally to differentially opt into such work, then the end result of such sorting may be a workforce more likely to commit immoral acts. Even if some of the firms and industries that we study do not actually involve any inherently immoral activities in their line of work, the fact that they are disproportionately more attractive to people more willing to do immoral things may result in a self-confirming greater prevalence for immoral behavior. Thus, firms and industries that regularly confront the perception that they involve immoral work - such as the banking sector-may need to be particularly attuned to such selection in their hiring.

Finally, our theoretical analysis predicts — in line with our experimental data - that the least moral types are overcompensated by the immorality premium. This is in stark contrast to Mankiw's (2010) "just deserts theory"-that is, everybody should receive his or her contribution to society. Our work suggests a perverse case in which those willing to do the most socially harmful acts may instead benefit from doing so. Moreover, this benefit is the direct result of the actions by others who are concerned with behaving morally. Indeed, we provide evidence that a shift in preferences toward a greater aversion to performing immoral work may reward those individuals who are least concerned with morality.

Of course, our work leaves open many important questions regarding the precise characteristics that lead some kinds of work to be differentially perceived as immoral and the specific nature of the preference underlying workers' market behavior. Nevertheless, as the above examples make clear, the differential sorting by people more or less concerned with immoral behavior into different lines of work has important implications for the extent to which market activity yields beneficial social outcomes. 


\section{References}

Ariely, D., Bracha, A. and Meier, S. (2009) "Doing Good or Doing Well? Image Motivation and Monetary Incentives in Behaving Prosocially," American Economic Review, 99(1): 544-555.

Arunachalam, R. and Shah, M. (2008) "Prostitutes and Brides?," American Economic Review, Papers and Proceedings, 98(2): 516-522.

Ashraf, N., and Bandiera, O. (2017) “Altruistic Capital,” American Economic Review, Papers and Proceedings, 107(5): 70-75.

Ashraf, N., Bandiera, O., Davenport, E. and Lee, S. S. (2019) "Losing pro sociality in the quest for talent? Sorting, Selection and Performance in Public Service Delivery," working paper.

Ashton, M.C. and Lee, K. (2009) "The HEXACO-60: A Short Measure of the Major Dimensions of Personality,” Journal of Personality Assessment, 91(4): 340-345.

Bartling, B., Weber, R. A. and Yao, L. (2015) "Do Markets Erode Social Responsibility?," Quarterly Journal of Economics, 130(1): 219-66.

Bates, C. and Rowell, A. (1998) "Tobacco explained: The truth about the tobacco industry ... in its own words." Scotland: ASH.

Becker, G. S. (1957) "The Economics of Discrimination," Chicago: University of Chicago Press.

Benedict, M.E., McClough, D and McClough, A.C. (2006) "The price of morals: An empirical investigation of industry sectors and perceptions of moral satisfaction - do business economists pay for morally satisfying employment?," The American Economist, 50(1): 21-36.

Besley, T. and Ghatak, M. (2005) "Competition and Incentives with Motivated Agents," American Economic Review, 95(3): 616-636.

Blitz, D. and Fabozzi, F. J. (2017) "Sin Stocks Revisited: Resolving the Sin Stock Anomaly," Journal of Portfolio Management, 44(1): 1-7.

Bock, O., Baetge, I., and Nicklisch, A. (2014) „Hroot: Hamburg registration and organization on-line tool," European Economic Review, 71: 117-120.

Bradley M.M. and Lang, P.J. (1994) "Measuring emotion: the self-assessment manikin and the semantic differential," Journal of Behavioral Therapy and Experimental Psychiatry, 25(1): 49-59. 
Brashear, G., Green, L., and Webb, J. (2000) "Development and validation of scales to measure attitudes influencing monetary donations to charitable organizations," Journal of the Academy of Marketing Science, 28(2): 299-309.

British American Tobacco (2015) “Annual Report 2015,” report.

Buurman, M., Delfgaauw, J., Dur, R. and Van den Bossche, S. (2012) "Public sector employees: Risk averse and altruistic?," Journal of Economic Behavior \& Organization, 83: 279-291.

Cameron, A. C., Gelbach, J. G., and Miller, D. L. (2008) "Bootstrap-Based Improvements for Inference with Clustered Errors," Review of Economics and Statistics, 90(3): 414427.

Cameron, A. C., Gelbach, J. B. and Miller, D. L. (2011) "Robust inference with multiway clustering," Journal of Business \& Economic Statistics, 29(2): 238-249.

Carpenter, J., and Myers, C. K. (2010) "Why Volunteer? Evidence on the Role of Altruism, Image, and Incentives,” Journal of Public Economics, 94(11-12): 911-20.

Carpenter, J. and Gong, E. (2016) "Motivating Agents: How Much Does the Mission Matter?," Journal of Labor Economics, 34(1): 211-236.

Carpenter, J., Matthews, P. and Robbett, A. (2017) “Compensating Differentials in Experimental Labor Markets,” Journal of Behavioral and Experimental Economics, 69: 50-60.

Carter, J. R., and Irons, M. D. (1991) “Are Economists Different, and If So, Why?” Journal of Economic Perspectives, 5(2): 171-177.

Case, A. and Deaton, A. (2015) "Rising morbidity and mortality in midlife among white nonHispanic Americans in the 21st century," Proceedings of the National Academy of Sciences, 112(49): 15078-15083.

Cassar, L. and Meier, S. (2018) "Nonmonetary Incentives and the Implications of Work as a Source of Meaning," Journal of Economic Perspectives, 32(3): 215-238.

Cassar, L. (2019) “Job Mission as a Substitute for Monetary Incentives: Benefits and Limits," Management Science, 65(2): 896-912.

CNBC (2019) "Facebook has struggled to hire talent since the Cambridge Analytica scandal, according to recruiters who worked there," accessed June 13, 2019, https://www.cnbc.com/2019/05/16/facebook-has-struggled-to-recruit-sincecambridge-analytica-scandal.html. 
Cohn, A., Fehr, E. \& Maréchal, A. (2014) "Business culture and dishonesty in the banking industry," Nature, 516: 86-89.

Colonnello, S., Curatola, G. and Gioffré, A. (2019) "Pricing Sin Stocks: Ethical Preference vs. Risk Aversion,” European Economic Review, 118: 69-100.

Dal Bó, E., Finan, F. and Rossi, M. A. (2013) "Strengthening State Capabilities: The Role of Financial Incentives in the Call to Public Service," Quarterly Journal of Economics, 128(3): 1169-1218.

Delfgaauw, J. and Dur, R. (2008) "Incentives and Workers' Motivation in the Public Sector," Economic Journal, 118(525): 171-191.

Deseranno, E. (2019) "Financial Incentives as Signals: Experimental Evidence from the Recruitment of Village Promoters in Uganda" American Economic Journal: Applied Economics, 11(1): 277-317.

Dur, R. and van Lent, M. (2019) “Socially Useless Jobs," Industrial Relations, 58(3), 543546.

Dur, R. and Zoutenbier, R. (2014) “Working for a Good Cause," Public Administration Review, 74(2): 144-155.

Edlund L. and Korn, E. (2002) “A Theory of Prostitution,” Journal of Political Economy, 110(1): 181-214.

Edlund, L., Engelberg, J. and Parsons, C. A. (2009) "The Wages of Sin,” Columbia Discussion Paper Series, Discussion Paper 0809-16.

Eriksson, T. and Kristensen, N. (2014) "Wages or Fringes? Some Evidence on Trade-Offs and Sorting," Journal of Labor Economics, 32(4): 899-928.

Fabozzi, F. J., Ma, K. C. and Oliphant B. J. (2008) "Sin stock returns," Journal of Portfolio Management, 35(1): 82-94.

Falk A. and Szech, N. (2013) “'Morals and Markets,'” Science, 340: 707-711.

Fehrler, S. and Kosfeld, M. (2014) "Pro-Social Missions and Worker Motivation: An Experimental Study,” Journal of Economic Behavior \& Organization, 100: 99-110.

Fischbacher, U. (2007) "z-Tree: Zurich toolbox for ready-made economic experiments," Experimental Economics, 10(2), 171-178.

Fisman, R., Jakiela, P., Kariv, S. and Markovits, D. (2015) “The distributional preferences of an elite," Science, 349(6254): 1300.

Frank, R. H. (1996) "What prices the moral high ground?," Southern Economic Journal, 63(1): 1-17. 
Frank, R. H., Gilovich, T. and Regan, D. T. (1993) "Does Studying Economics Inhibit Cooperation?," Journal of Economic Perspectives, 7(2): 159-171.

Friebel, G., Kosfeld, M. and Thielmann, G. (2019) "Trust the Police? Self-Selection of Motivated Agents into the German Police Force," American Economic Journal: Microeconomics, 11(4): 59-78.

Garen, J. (1988) "Compensating Wage Differentials and the Endogeneity of Job Riskiness," Review of Economics and Statistics, 70(1): 9-16.

Gertler, P., Shah, M. and Bertozzi, S. M. (2005) "Risky Business: The Market for Unprotected Commercial Sex," Journal of Political Economy, 113(3): 518-550.

Gibson, R., Tanner, C. and Wagner, A. (2013) "Preferences for truthfulness: Heterogeneity among and within individuals," American Economic Review, 103(1): 532-548.

Gneezy, U., Rockenbach, B. and Serra-Garcia, M. (2013) "Measuring lying aversion," Journal of Economic Behavior and Organization, 93: 293-300.

Gosling, S.D., Rentfrow, P.J., and Swann Jr. W.B. (2003) "A very brief measure of the BigFive personality domains," Journal of Research in Personality, 37: 504-528.

Gregg, P., Grout, P. A., Ratcliffe, A., Smith, S. and Windmeijer, F. (2011) "How important is pro-social behaviour in the delivery of public services?," Journal of Public Economics, 95: 758-766.

Hanna, R. and Wang, S. (2017) "Dishonesty and Selection into Public Service: Evidence from India,” American Economic Journal: Economic Policy, 9 (3): 262-290.

Heath, D. (2016) "Contesting The Science of Smoking," The Atlantic, https://www.theatlantic.com/politics/archive/2016/05/low-tar-cigarettes/481116/

Heidhues, P., Köszegi, B. and Murooka, T. (2016) "Inferior products and profitable deception" Review of Economic Studies, 84(1): 323-356.

Hill, C. A. (2012) "Bankers behaving badly? The limits of regulatory reform,“ Review of Banking and Financial Law, 31: 675-691.

Hong, H. and Kacperczyk, M. (2009) "The Price of Sin: The Effects of Social Norms on Markets," Journal of Financial Economics, 93: 15-36.

Hwang, H., Reed, W. R., and Hubbard, C. (1992) "Compensating Wage Differentials and Unobserved Productivity,” Journal of Political Economy, 100(4): 835-858.

Jones, D. B. (2015) “The Supply and Demand of Motivated Labor: When Should We Expect to See Nonprofit Wage Gaps?," Labour Economics 32: 1-14.

Kirchler, M., Huber, J., Stefan, M. and Sutter, M. (2016) "Market design and moral behavior," Management Science, 62: 2615-2625. 
Lazear, E. P., Malmendier, U. and Weber, R. A. (2012) "Sorting in Experiments with Application to Social Preferences,” American Economic Journal: Applied Economics, 4(1): 136-163.

Leary, M.R., Diebels, K. J. and Jongman-Sereno, K. P. (2015) "Measures of concerns with public image and social evaluation", in: Measures of Personality and Social Psychological Constructs, Elsevier Inc., 448-473. DOI: 10.1016/B978-0-12-3869159.00016-4.

Leete, L. (2001) "Whither the Nonprofit Wage Differential? Estimates from the 1990 Census,” Journal of Labor Economics 19(1): 136-170.

Levitt, S. D. and List, J. A. (2007) “What Do Laboratory Experiments Measuring Social Preferences Reveal About the Real World?, Journal of Economic Perspectives, 21(2): 153-174.

Levitt, S. D. and List, J. A. (2008) “Homo economicus Evolves," Science, 319: 909-910.

Maestas, N., Mullen, K. J, Powell, D., von Wachter, T. and Wenger, J. (2018) “The Value of Working Conditions in the United States and Implications for the Structure of Wages," working paper.

Mankiw, G. N. (2010) "Spreading the Wealth Around: Reflections Inspired by Joe the Plumber," Eastern Economic Journal, 36: 285-298.

Mas, A., and Pallais, A. (2017) "Valuing Alternative Work Arrangements," American Economic Review, 107(12): 3722-3759.

Mocan, N. H. and Tekin, E. (2003) "Nonprofit Sector and Part-Time Work: An Analysis of Employer-Employee Matched Data on Child Care Workers," Review of Economics and Statistics 85(1): 38-50.

Moffatt, P. G. and Peters, S. A. (2004) "Pricing personal services: An empirical study of earnings in the UK prostitution industry," Scottish Journal of Political Economy 51(5): 675-690.

Okie, S. (2010) "A flood of opioids, a rising tide of deaths," New England Journal of Medicine, 363(21): 1981-1985.

Philip Morris International Inc. (2015) "Form 10-K submitted to US Securities and Exchange Commission," report.

Prendergast, C. (2007) "The Motivation and Bias of Bureaucrats," American Economic Review, 97(1): 180-196.

Pörtner, C. C., Hassairi, N., and Toomim, M. (2015) "Only if You Pay Me More: Field Experiments Support Compensating Wage Differentials Theory,” working paper. 
Rosen, S. (1986) „The theory of equalizing differences“, Ed: Ashenfelter, O. and Layard, R., in: Handbook of Labor Economics, Elsevier Science Publishers BV.

Ruhm, C. J. and Borkoski, C. (2003) "Compensation in the Nonprofit Sector," Journal of Human Resources 38(4): 992-1021.

Sausgruber, R. and Tyran, J-R. (2011) "Are we taxing ourselves? How deliberation and experience shape voting on taxes", Journal of Public Economics, 95: 164-176.

Sjöberg, L. and Engelberg, E. (2009) “Attitudes to Economic Risk Taking, Sensation Seeking and Values of Business Students Specializing in Finance," Journal of Behavioral Finance, 10(1): 33-43.

Smith, A. (1776) "An Inquiry into the Nature and Causes of the Wealth of Nations," London: W. Strahan and T. Cadell.

Smith, V.L., Williams A.W., Bratton W.K. and Vannoni, M.G. (1982) "Competitive market institutions: Double auctions vs. sealed bid-offer auctions", American Economic Review, 72(1): 58-77.

Tonin, M. and Vlassopoulos, M. (2015) „Corporate Philanthropy and Productivity: Evidence from an Online Real Effort Experiment,“"Management Science, 61(8): 1795-1811.

US Department of Justice, Office of Public Affairs (2016) "Goldman Sachs Agrees to Pay More than \$5 Billion in Connection with Its Sale of Residential Mortgage Backed Securities," https://www.justice.gov/, date accessed: 21.01.2017.

Wiswall, M. and Zafar, B. (2018) "Preference for the Workplace, Investment in Human Capital, and Gender," Quarterly Journal of Economics, 133(1): 457-507. 


\section{Appendix A - Additional Analysis}

Figure A1: Labor supply for neutral and immoral work in the laboratory, last 5 periods

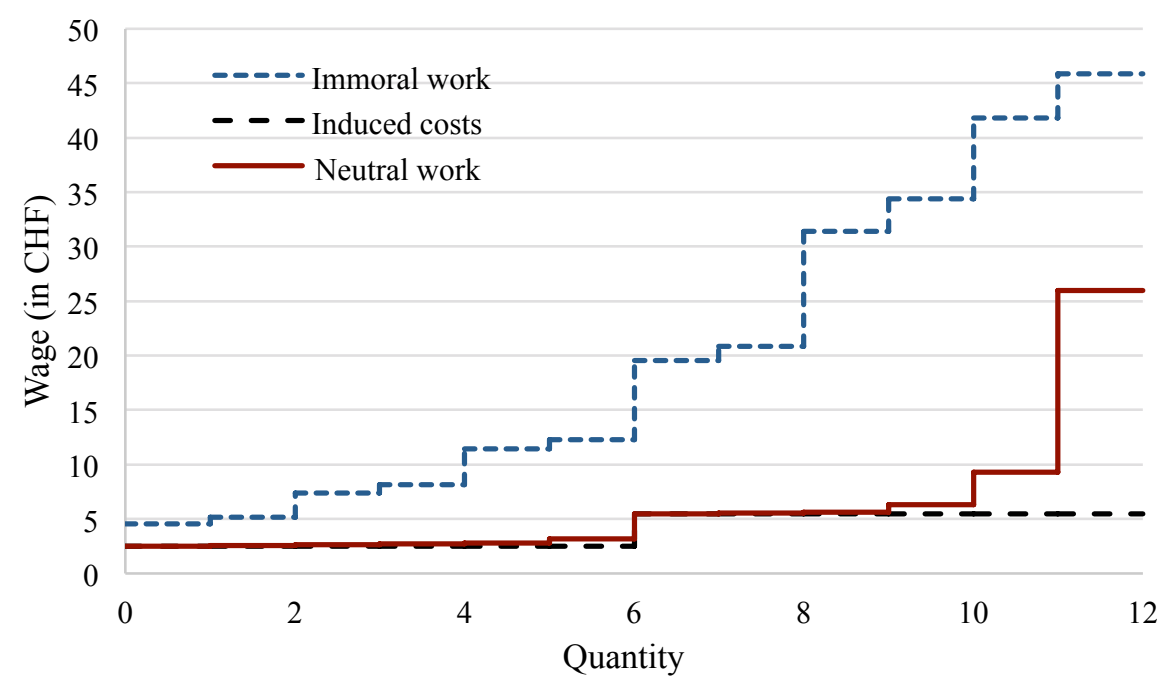

Figure A2: Labor supply for immoral work in the laboratory for different types $\left(\theta^{\operatorname{Exp}}\right)$

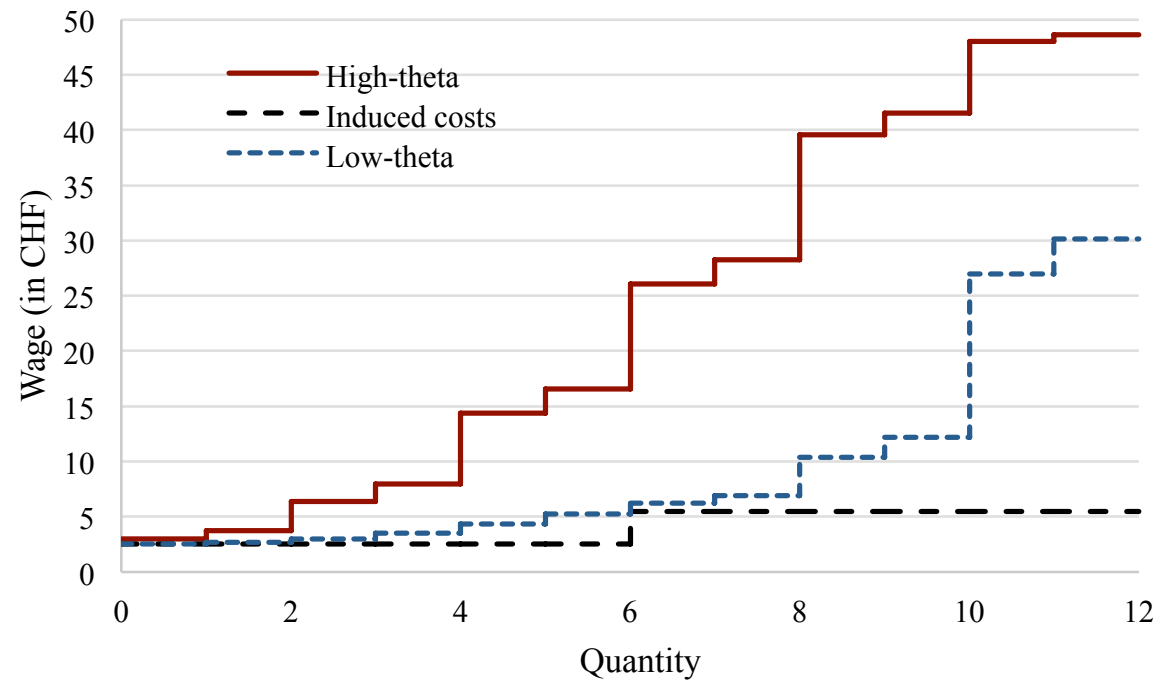

Notes: Labor supplies conditional on types are calculated with a simulation: 6 labor market decisions (first and second wage request) of high-theta (or, low-theta) types are randomly drawn (without replacement) from our sample. We then calculate the labor supply for this group of people. We repeat this 1000 times (with replacement) and take the average of these 1000 individual labor supplies. This approach differs from the one we use in Figure 4 and Figure A1, where we take the average of the actual labor supplies in the different market groups and periods. Figure 4 does not change substantially if we simulate market composition instead of using actual composition. 
Figure A3: Market quantities in laboratory labor markets

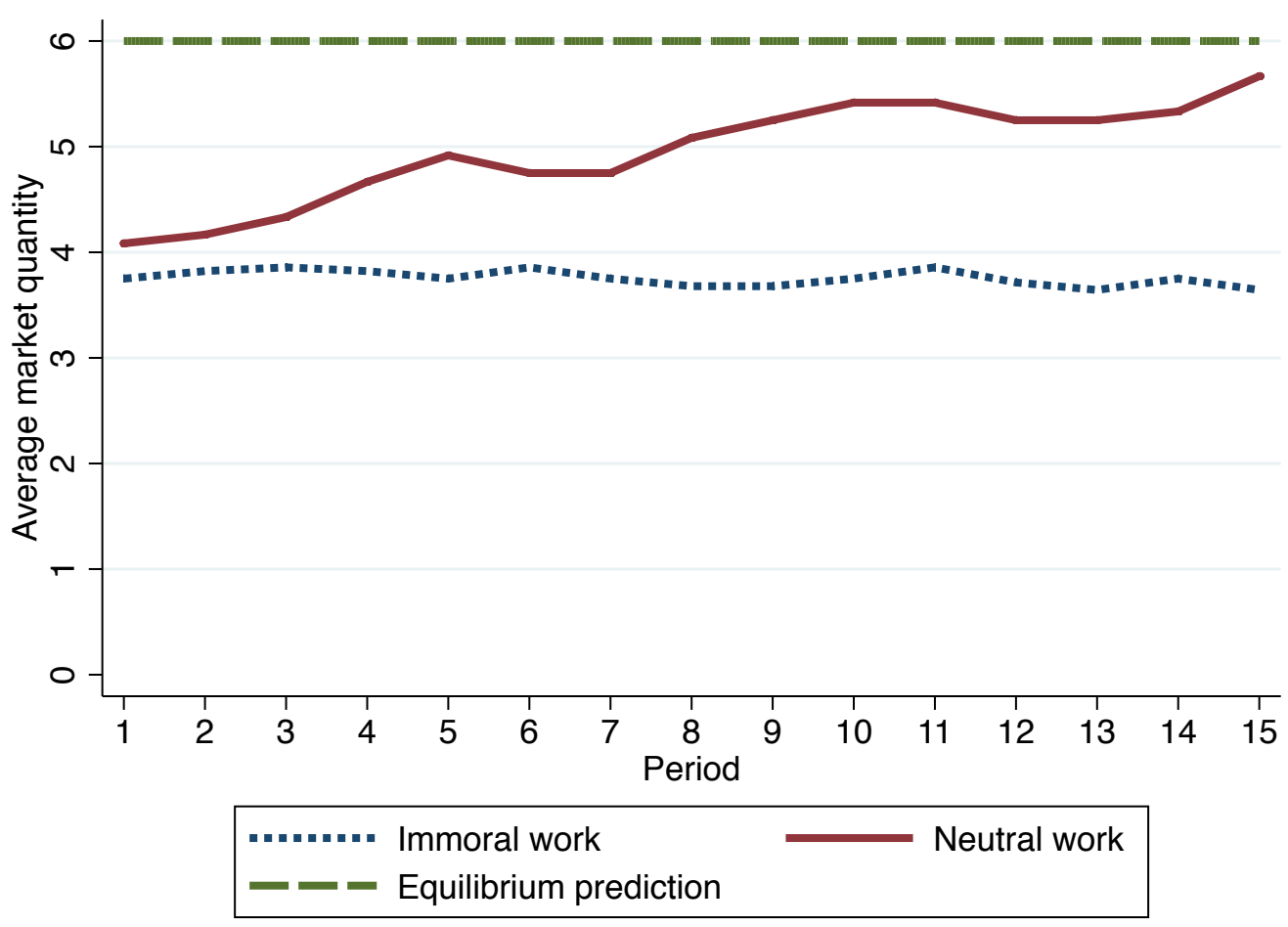

Figure A4: Employment rate by the two types in the neutral work condition

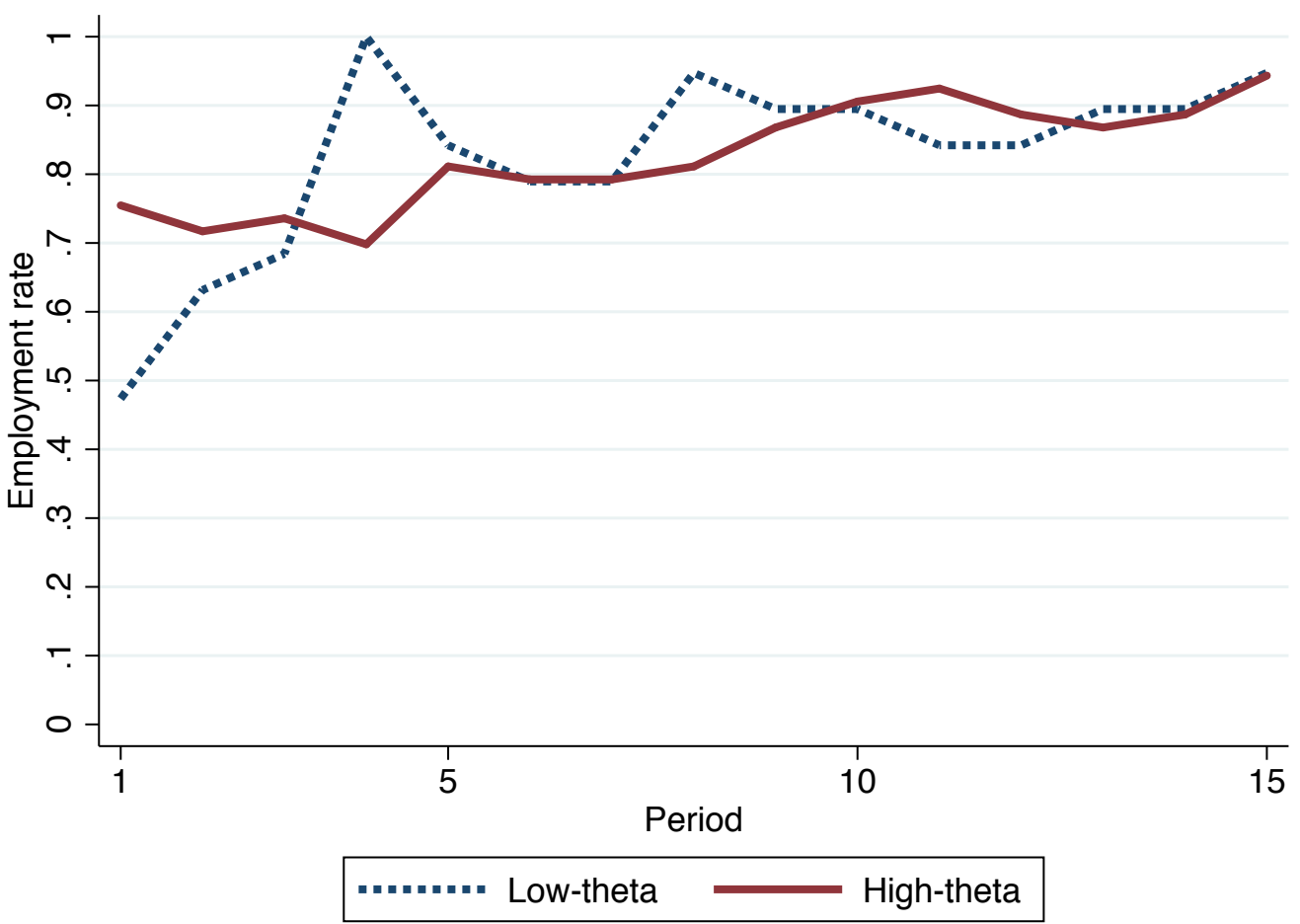


Figure A5: Income inequalities across conditions

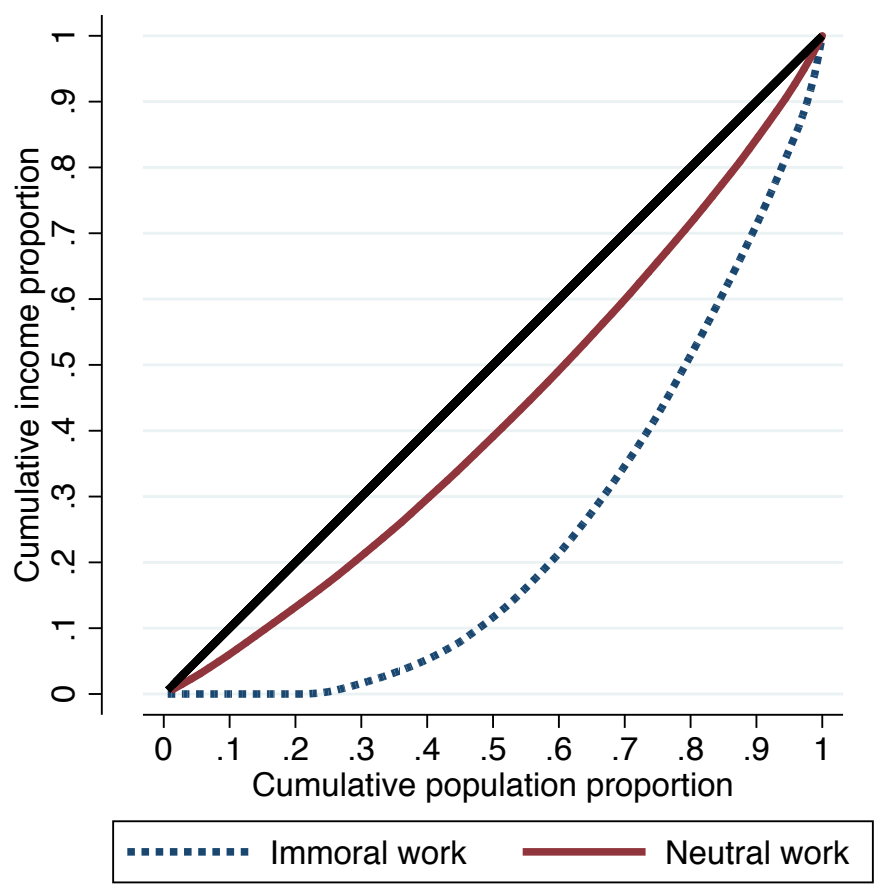

Figure A6: Probability distribution of $\theta^{\text {Sur }}$

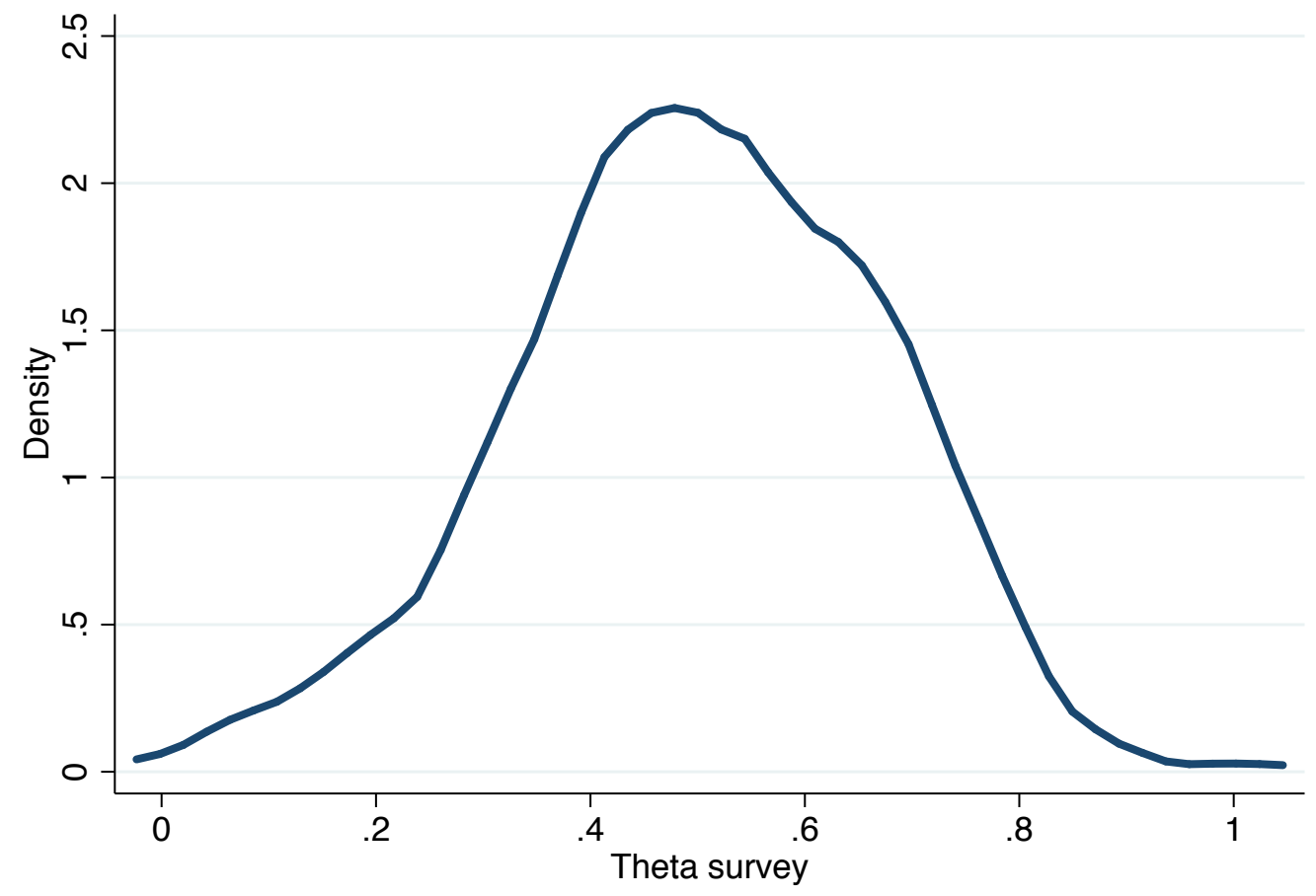

kernel $=$ epanechnikov, bandwidth $=0.0503$ 
Figure A7: Labor supply for immoral work in the laboratory for different types $\left(\theta^{\text {Sur }}\right)$

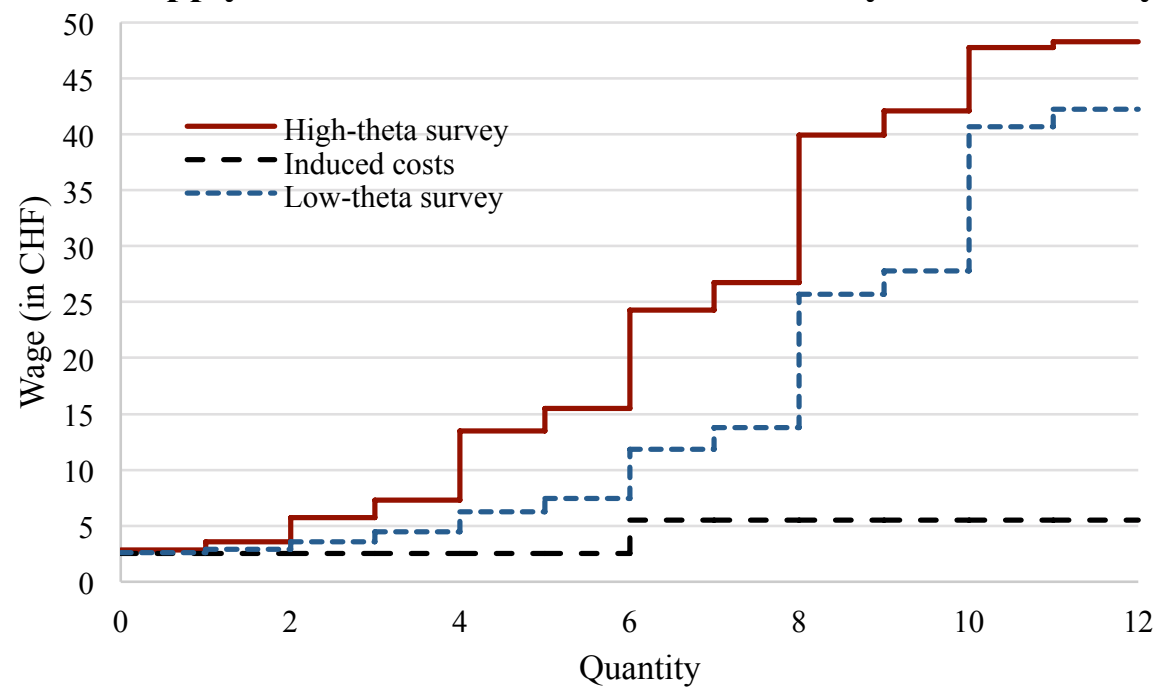

Notes: High-theta survey is 1 if $\theta^{\text {Sur }}$ is lower than the median of $\theta^{\text {Sur }}$. Labor supplies are calculated with simulations: 6 labor market decisions (first and second wage request) of high-theta survey (or, low-theta survey) types are randomly drawn (without replacement) from our sample. We then calculate the labor supply for this group of people. We repeat this 1000 times (with replacement) and take the average of these 1000 individual labor supplies. 
Table A1: Perceived immorality of industries and summary of main variables from the Swiss Labor Force Survey

\begin{tabular}{|c|c|c|c|c|c|c|c|c|c|c|c|c|c|c|c|}
\hline Industries & $\mathbf{Z}$ & 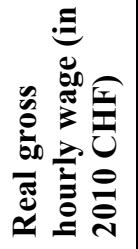 & 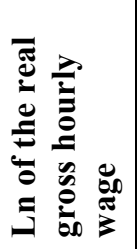 & \&્o & $\frac{0}{\sum^{\frac{N}{\Sigma}}}$ & 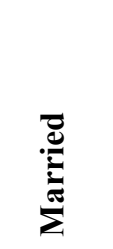 & 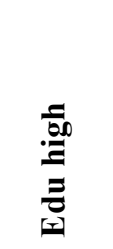 & 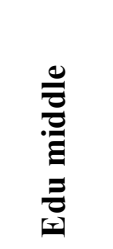 & $\overbrace{\infty}^{\infty}$ & 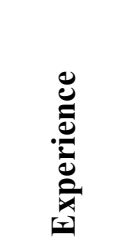 & 莺 & 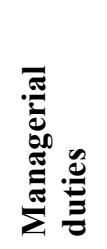 & 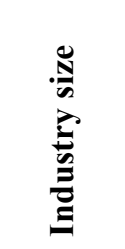 & 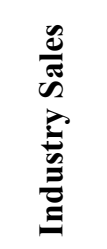 & 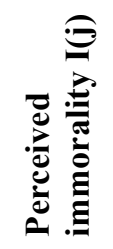 \\
\hline All industries & 32,638 & $\begin{array}{c}41.00 \\
(20.11)\end{array}$ & $\begin{array}{c}3.59 \\
(0.54)\end{array}$ & $\begin{array}{c}42.25 \\
(11.16)\end{array}$ & $\begin{array}{c}0.57 \\
(0.49)\end{array}$ & $\begin{array}{c}0.58 \\
(0.49)\end{array}$ & $\begin{array}{c}0.35 \\
(0.48)\end{array}$ & $\begin{array}{c}0.51 \\
(0.50)\end{array}$ & $\begin{array}{c}0.64 \\
(0.48)\end{array}$ & $\begin{array}{c}9.56 \\
(9.21)\end{array}$ & $\begin{array}{c}0.87 \\
(0.24)\end{array}$ & $\begin{array}{c}0.17 \\
(0.37)\end{array}$ & $\begin{array}{l}106.46 \\
(87.54)\end{array}$ & $\begin{array}{c}0.94 \\
(1.27)\end{array}$ & $\begin{array}{l}-0.18 \\
(0.22)\end{array}$ \\
\hline $\begin{array}{r}\text { Processing of tea and } \\
\text { coffee }\end{array}$ & 138 & $\begin{array}{c}38.88 \\
(14.00)\end{array}$ & $\begin{array}{c}3.60 \\
(0.35)\end{array}$ & $\begin{array}{c}41.29 \\
(10.34)\end{array}$ & $\begin{array}{c}0.66 \\
(0.47)\end{array}$ & $\begin{array}{c}0.67 \\
(0.47)\end{array}$ & $\begin{array}{c}0.24 \\
(0.43)\end{array}$ & $\begin{array}{c}0.59 \\
(0.49)\end{array}$ & $\begin{array}{c}0.55 \\
(0.50)\end{array}$ & $\begin{array}{c}8.78 \\
(8.94)\end{array}$ & $\begin{array}{c}0.93 \\
(0.20)\end{array}$ & $\begin{array}{c}0.10 \\
(0.30)\end{array}$ & $\begin{array}{c}3.10 \\
(0.43)\end{array}$ & $\begin{array}{c}0.22 \\
(0.02)\end{array}$ & $\begin{array}{l}-0.11 \\
(-0.41)\end{array}$ \\
\hline $\begin{array}{r}\text { Manufacture of tobacco } \\
\text { products }\end{array}$ & 162 & $\begin{array}{c}51.01 \\
(20.20) \\
\end{array}$ & $\begin{array}{r}3.85 \\
(0.44) \\
\end{array}$ & $\begin{array}{l}39.42 \\
(8.26) \\
\end{array}$ & $\begin{array}{c}0.59 \\
(0.49)\end{array}$ & $\begin{array}{r}0.59 \\
(0.49) \\
\end{array}$ & $\begin{array}{c}0.45 \\
(0.50)\end{array}$ & $\begin{array}{c}0.41 \\
(0.49)\end{array}$ & $\begin{array}{r}0.52 \\
(0.50) \\
\end{array}$ & $\begin{array}{c}9.63 \\
(8.84) \\
\end{array}$ & $\begin{array}{c}0.92 \\
(0.10)\end{array}$ & $\begin{array}{c}0.03 \\
(0.16)\end{array}$ & $\begin{array}{c}2.24 \\
(0.15) \\
\end{array}$ & $\begin{array}{l}11.79 \\
(0.97)\end{array}$ & $\begin{array}{c}0.47 \\
(-0.42) \\
\end{array}$ \\
\hline $\begin{array}{r}\text { Manufacture of paper and } \\
\text { paperboard }\end{array}$ & 96 & $\begin{array}{r}42.33 \\
(16.25) \\
\end{array}$ & $\begin{array}{c}3.69 \\
(0.33) \\
\end{array}$ & $\begin{array}{r}46.00 \\
(10.77) \\
\end{array}$ & $\begin{array}{c}0.78 \\
(0.42) \\
\end{array}$ & $\begin{array}{c}0.77 \\
(0.42) \\
\end{array}$ & $\begin{array}{c}0.35 \\
(0.48) \\
\end{array}$ & $\begin{array}{c}0.50 \\
(0.50) \\
\end{array}$ & $\begin{array}{c}0.57 \\
(0.50) \\
\end{array}$ & $\begin{array}{r}16.80 \\
(13.32) \\
\end{array}$ & $\begin{array}{c}0.96 \\
(0.10) \\
\end{array}$ & $\begin{array}{c}0.09 \\
(0.29) \\
\end{array}$ & $\begin{array}{c}1.58 \\
(0.22) \\
\end{array}$ & $\begin{array}{c}2.11 \\
(1.11) \\
\end{array}$ & $\begin{array}{c}-0.06 \\
(-0.37) \\
\end{array}$ \\
\hline $\begin{array}{r}\text { Manufacture of weapons } \\
\text { and ammunitions }\end{array}$ & 104 & $\begin{array}{c}53.26 \\
(20.66)\end{array}$ & $\begin{array}{c}3.91 \\
(0.37)\end{array}$ & $\begin{array}{c}48.53 \\
(10.85)\end{array}$ & $\begin{array}{c}0.95 \\
(0.22)\end{array}$ & $\begin{array}{c}0.58 \\
(0.50)\end{array}$ & $\begin{array}{c}0.57 \\
(0.50)\end{array}$ & $\begin{array}{c}0.37 \\
(0.48)\end{array}$ & $\begin{array}{c}0.83 \\
(0.38)\end{array}$ & $\begin{array}{c}16.36 \\
(13.49)\end{array}$ & $\begin{array}{c}0.96 \\
(0.06)\end{array}$ & $\begin{array}{c}0.10 \\
(0.31)\end{array}$ & $\begin{array}{c}1.44 \\
(0.10)\end{array}$ & $\begin{array}{c}0.46 \\
(0.05)\end{array}$ & $\begin{array}{c}0.71 \\
(-0.40)\end{array}$ \\
\hline $\begin{array}{r}\text { Manufacture of electronic } \\
\text { components }\end{array}$ & 1,133 & $\begin{array}{r}44.79 \\
(18.21) \\
\end{array}$ & $\begin{array}{c}3.72 \\
(0.41) \\
\end{array}$ & $\begin{array}{r}43.27 \\
(10.59) \\
\end{array}$ & $\begin{array}{c}0.68 \\
(0.47) \\
\end{array}$ & $\begin{array}{c}0.61 \\
(0.49) \\
\end{array}$ & $\begin{array}{c}0.51 \\
(0.50)\end{array}$ & $\begin{array}{c}0.37 \\
(0.48) \\
\end{array}$ & $\begin{array}{r}0.53 \\
(0.50) \\
\end{array}$ & $\begin{array}{l}10.47 \\
(9.64)\end{array}$ & $\begin{array}{c}0.93 \\
(0.14) \\
\end{array}$ & $\begin{array}{c}0.06 \\
(0.24)\end{array}$ & $\begin{array}{l}22.08 \\
(0.76)\end{array}$ & $\begin{array}{c}0.66 \\
(0.16)\end{array}$ & $\begin{array}{l}-0.01 \\
(-0.42) \\
\end{array}$ \\
\hline Construction of buildings & 3,600 & $\begin{array}{r}37.87 \\
(13.18) \\
\end{array}$ & $\begin{array}{c}3.57 \\
(0.40) \\
\end{array}$ & $\begin{array}{c}43.21 \\
(10.73) \\
\end{array}$ & $\begin{array}{c}0.91 \\
(0.28) \\
\end{array}$ & $\begin{array}{c}0.70 \\
(0.46) \\
\end{array}$ & $\begin{array}{c}0.21 \\
(0.41) \\
\end{array}$ & $\begin{array}{c}0.48 \\
(0.50) \\
\end{array}$ & $\begin{array}{r}0.48 \\
(0.50) \\
\end{array}$ & $\begin{array}{l}11.16 \\
(9.89) \\
\end{array}$ & $\begin{array}{c}0.95 \\
(0.15) \\
\end{array}$ & $\begin{array}{c}0.14 \\
(0.34) \\
\end{array}$ & $\begin{array}{l}82.97 \\
(0.79) \\
\end{array}$ & $\begin{array}{c}0.43 \\
(0.01) \\
\end{array}$ & $\begin{array}{l}-0.28 \\
(-0.39) \\
\end{array}$ \\
\hline $\begin{array}{r}\text { Maintenance and repair of } \\
\text { motor vehicles }\end{array}$ & 2,664 & $\begin{array}{r}34.64 \\
(12.89) \\
\end{array}$ & $\begin{array}{c}3.48 \\
(0.38)\end{array}$ & $\begin{array}{c}41.38 \\
(12.08)\end{array}$ & $\begin{array}{c}0.82 \\
(0.38)\end{array}$ & $\begin{array}{c}0.61 \\
(0.49)\end{array}$ & $\begin{array}{c}0.19 \\
(0.40)\end{array}$ & $\begin{array}{c}0.71 \\
(0.45)\end{array}$ & $\begin{array}{c}0.66 \\
(0.47)\end{array}$ & $\begin{array}{c}11.47 \\
(10.47)\end{array}$ & $\begin{array}{c}0.92 \\
(0.21)\end{array}$ & $\begin{array}{c}0.26 \\
(0.44)\end{array}$ & $\begin{array}{l}58.65 \\
(0.33)\end{array}$ & $\begin{array}{c}0.54 \\
(0.01)\end{array}$ & $\begin{array}{l}-0.28 \\
(-0.40)\end{array}$ \\
\hline $\begin{array}{r}\text { Wholesale of tobacco } \\
\text { products }\end{array}$ & 87 & $\begin{array}{r}58.75 \\
(27.28) \\
\end{array}$ & $\begin{array}{c}3.96 \\
(0.48) \\
\end{array}$ & $\begin{array}{l}45.10 \\
(9.98) \\
\end{array}$ & $\begin{array}{c}0.55 \\
(0.50) \\
\end{array}$ & $\begin{array}{c}0.70 \\
(0.46) \\
\end{array}$ & $\begin{array}{c}0.51 \\
(0.50) \\
\end{array}$ & $\begin{array}{c}0.49 \\
(0.50) \\
\end{array}$ & $\begin{array}{r}0.65 \\
(0.48) \\
\end{array}$ & $\begin{array}{l}11.05 \\
(7.86) \\
\end{array}$ & $\begin{array}{c}0.93 \\
(0.15) \\
\end{array}$ & $\begin{array}{c}0.13 \\
(0.33) \\
\end{array}$ & $\begin{array}{c}1.72 \\
(0.07) \\
\end{array}$ & $\begin{array}{c}1.49 \\
(0.19) \\
\end{array}$ & $\begin{array}{c}0.44 \\
(-0.38) \\
\end{array}$ \\
\hline $\begin{array}{r}\text { Wholesale of clothing and } \\
\text { footwear }\end{array}$ & 306 & $\begin{array}{c}38.92 \\
(18.97)\end{array}$ & $\begin{array}{c}3.54 \\
(0.51)\end{array}$ & $\begin{array}{c}40.21 \\
(10.73)\end{array}$ & $\begin{array}{c}0.31 \\
(0.46)\end{array}$ & $\begin{array}{c}0.45 \\
(0.50)\end{array}$ & $\begin{array}{c}0.38 \\
(0.49)\end{array}$ & $\begin{array}{c}0.53 \\
(0.50)\end{array}$ & $\begin{array}{c}0.52 \\
(0.50)\end{array}$ & $\begin{array}{c}7.16 \\
(6.70)\end{array}$ & $\begin{array}{c}0.84 \\
(0.24)\end{array}$ & $\begin{array}{c}0.16 \\
(0.37)\end{array}$ & $\begin{array}{c}6.08 \\
(0.18)\end{array}$ & $\begin{array}{c}1.80 \\
(0.22)\end{array}$ & $\begin{array}{c}0.10 \\
(-0.46)\end{array}$ \\
\hline $\begin{array}{r}\text { Wholesale of perfume and } \\
\text { cosmetics }\end{array}$ & 353 & $\begin{array}{r}53.47 \\
(28.01) \\
\end{array}$ & $\begin{array}{c}3.84 \\
(0.54)\end{array}$ & $\begin{array}{r}39.78 \\
(10.03) \\
\end{array}$ & $\begin{array}{c}0.34 \\
(0.47)\end{array}$ & $\begin{array}{c}0.60 \\
(0.49)\end{array}$ & $\begin{array}{c}0.58 \\
(0.49)\end{array}$ & $\begin{array}{c}0.36 \\
(0.48) \\
\end{array}$ & $\begin{array}{c}0.40 \\
(0.49)\end{array}$ & $\begin{array}{c}7.80 \\
(6.48) \\
\end{array}$ & $\begin{array}{c}0.89 \\
(0.19) \\
\end{array}$ & $\begin{array}{c}0.15 \\
(0.35) \\
\end{array}$ & $\begin{array}{c}6.19 \\
(0.26)\end{array}$ & $\begin{array}{c}1.89 \\
(0.22)\end{array}$ & $\begin{array}{c}0.12 \\
(-0.37) \\
\end{array}$ \\
\hline
\end{tabular}

See next page for the rest of the table. 


\begin{tabular}{|c|c|c|c|c|c|c|c|c|c|c|c|c|c|c|c|}
\hline Industries & Z & 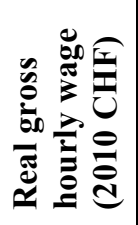 & 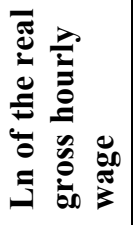 & \&્o & $\sum^{\frac{0}{J}}$ & 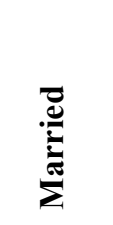 & 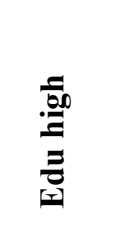 & 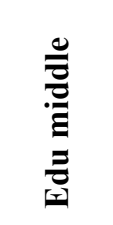 & $\frac{n}{\infty}$ & 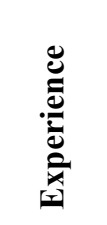 & 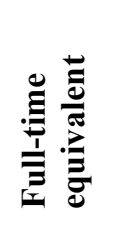 & 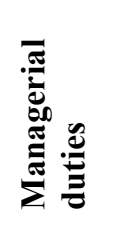 & 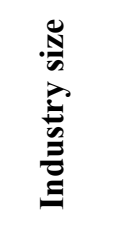 & 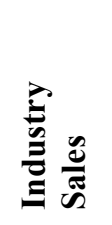 & 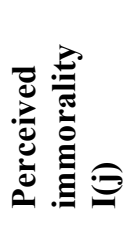 \\
\hline $\begin{array}{r}\text { Wholesale of watches and } \\
\text { jewelry }\end{array}$ & 158 & $\begin{array}{r}44.16 \\
(19.05) \\
\end{array}$ & $\begin{array}{c}3.71 \\
(0.40) \\
\end{array}$ & $\begin{array}{r}43.89 \\
(10.68) \\
\end{array}$ & $\begin{array}{c}0.42 \\
(0.49) \\
\end{array}$ & $\begin{array}{c}0.58 \\
(0.50) \\
\end{array}$ & $\begin{array}{c}0.46 \\
(0.50) \\
\end{array}$ & $\begin{array}{c}0.48 \\
(0.50) \\
\end{array}$ & $\begin{array}{c}0.55 \\
(0.50) \\
\end{array}$ & $\begin{array}{c}8.09 \\
(8.04) \\
\end{array}$ & $\begin{array}{c}0.88 \\
(0.19) \\
\end{array}$ & $\begin{array}{c}0.20 \\
(0.40) \\
\end{array}$ & $\begin{array}{c}2.65 \\
(0.17) \\
\end{array}$ & $\begin{array}{c}2.13 \\
(0.30) \\
\end{array}$ & $\begin{array}{c}0.04 \\
(-0.41) \\
\end{array}$ \\
\hline $\begin{array}{r}\text { Hotels and similar } \\
\text { accommodation }\end{array}$ & 2,658 & $\begin{array}{c}27.06 \\
(10.58) \\
\end{array}$ & $\begin{array}{c}3.22 \\
(0.48) \\
\end{array}$ & $\begin{array}{c}40.69 \\
(11.24) \\
\end{array}$ & $\begin{array}{c}0.40 \\
(0.49) \\
\end{array}$ & $\begin{array}{c}0.55 \\
(0.50) \\
\end{array}$ & $\begin{array}{c}0.19 \\
(0.39) \\
\end{array}$ & $\begin{array}{c}0.55 \\
(0.50) \\
\end{array}$ & $\begin{array}{c}0.40 \\
(0.49) \\
\end{array}$ & $\begin{array}{r}7.16 \\
(7.59) \\
\end{array}$ & $\begin{array}{c}0.85 \\
(0.26) \\
\end{array}$ & $\begin{array}{c}0.16 \\
(0.36) \\
\end{array}$ & $\begin{array}{l}59.16 \\
(0.75) \\
\end{array}$ & $\begin{array}{c}0.16 \\
(0.00) \\
\end{array}$ & $\begin{array}{c}-0.34 \\
(-0.37) \\
\end{array}$ \\
\hline $\begin{array}{r}\text { Restaurants and mobile food } \\
\text { activities }\end{array}$ & 5,560 & $\begin{array}{l}25.12 \\
(9.96)\end{array}$ & $\begin{array}{c}3.14 \\
(0.47) \\
\end{array}$ & $\begin{array}{c}40.55 \\
(11.92)\end{array}$ & $\begin{array}{c}0.43 \\
(0.49)\end{array}$ & $\begin{array}{c}0.56 \\
(0.50) \\
\end{array}$ & $\begin{array}{c}0.14 \\
(0.34) \\
\end{array}$ & $\begin{array}{c}0.57 \\
(0.50) \\
\end{array}$ & $\begin{array}{c}0.46 \\
(0.50) \\
\end{array}$ & $\begin{array}{c}6.58 \\
(7.35) \\
\end{array}$ & $\begin{array}{c}0.79 \\
(0.29)\end{array}$ & $\begin{array}{c}0.21 \\
(0.41) \\
\end{array}$ & $\begin{array}{l}94.45 \\
(1.03)\end{array}$ & $\begin{array}{c}0.15 \\
(0.00) \\
\end{array}$ & $\begin{array}{c}-0.33 \\
(-0.37) \\
\end{array}$ \\
\hline Monetary intermediations & 7,286 & $\begin{array}{c}56.00 \\
(21.87) \\
\end{array}$ & $\begin{array}{c}3.94 \\
(0.44) \\
\end{array}$ & $\begin{array}{c}42.00 \\
(10.37) \\
\end{array}$ & $\begin{array}{c}0.59 \\
(0.49) \\
\end{array}$ & $\begin{array}{c}0.55 \\
(0.50) \\
\end{array}$ & $\begin{array}{c}0.55 \\
(0.50) \\
\end{array}$ & $\begin{array}{c}0.42 \\
(0.49) \\
\end{array}$ & $\begin{array}{c}0.73 \\
(0.44) \\
\end{array}$ & $\begin{array}{l}10.65 \\
(9.42) \\
\end{array}$ & $\begin{array}{c}0.91 \\
(0.18) \\
\end{array}$ & $\begin{array}{c}0.19 \\
(0.40) \\
\end{array}$ & $\begin{array}{l}109.31 \\
(2.05) \\
\end{array}$ & $\begin{array}{c}2.26 \\
(0.88) \\
\end{array}$ & $\begin{array}{c}0.11 \\
(-0.40) \\
\end{array}$ \\
\hline Credit granting & 79 & $\begin{array}{c}53.62 \\
(22.28) \\
\end{array}$ & $\begin{array}{c}3.90 \\
(0.39) \\
\end{array}$ & $\begin{array}{l}40.00 \\
(8.59) \\
\end{array}$ & $\begin{array}{c}0.46 \\
(0.50) \\
\end{array}$ & $\begin{array}{c}0.53 \\
(0.50) \\
\end{array}$ & $\begin{array}{c}0.51 \\
(0.50) \\
\end{array}$ & $\begin{array}{c}0.48 \\
(0.50) \\
\end{array}$ & $\begin{array}{c}0.67 \\
(0.47) \\
\end{array}$ & $\begin{array}{c}5.45 \\
(5.73) \\
\end{array}$ & $\begin{array}{c}0.89 \\
(0.17) \\
\end{array}$ & $\begin{array}{c}0.11 \\
(0.31) \\
\end{array}$ & $\begin{array}{c}1.23 \\
(0.03) \\
\end{array}$ & $\begin{array}{c}1.50 \\
(0.83) \\
\end{array}$ & $\begin{array}{c}0.15 \\
(-0.41) \\
\end{array}$ \\
\hline Non-life insurance & 2,637 & $\begin{array}{c}49.20 \\
(18.82)\end{array}$ & $\begin{array}{c}3.82 \\
(0.39) \\
\end{array}$ & $\begin{array}{c}42.09 \\
(11.02)\end{array}$ & $\begin{array}{c}0.49 \\
(0.50) \\
\end{array}$ & $\begin{array}{c}0.51 \\
(0.50) \\
\end{array}$ & $\begin{array}{c}0.51 \\
(0.50) \\
\end{array}$ & $\begin{array}{c}0.47 \\
(0.50) \\
\end{array}$ & $\begin{array}{c}0.80 \\
(0.40) \\
\end{array}$ & $\begin{array}{c}9.91 \\
(9.07) \\
\end{array}$ & $\begin{array}{c}0.89 \\
(0.20) \\
\end{array}$ & $\begin{array}{c}0.09 \\
(0.29) \\
\end{array}$ & $\begin{array}{l}40.52 \\
(0.97) \\
\end{array}$ & $\begin{array}{c}1.76 \\
(0.76) \\
\end{array}$ & $\begin{array}{c}-0.13 \\
(-0.44) \\
\end{array}$ \\
\hline $\begin{array}{r}\text { General public administration } \\
\text { activities }\end{array}$ & 4,563 & $\begin{array}{r}44.42 \\
(17.24) \\
\end{array}$ & $\begin{array}{c}3.70 \\
(0.52) \\
\end{array}$ & $\begin{array}{r}45.36 \\
(10.74) \\
\end{array}$ & $\begin{array}{c}0.48 \\
(0.50) \\
\end{array}$ & $\begin{array}{c}0.60 \\
(0.49) \\
\end{array}$ & $\begin{array}{c}0.42 \\
(0.49) \\
\end{array}$ & $\begin{array}{c}0.52 \\
(0.50) \\
\end{array}$ & $\begin{array}{c}0.91 \\
(0.29) \\
\end{array}$ & $\begin{array}{l}10.71 \\
(9.53) \\
\end{array}$ & $\begin{array}{c}0.80 \\
(0.28) \\
\end{array}$ & $\begin{array}{c}0.14 \\
(0.35) \\
\end{array}$ & $\begin{array}{l}311.69 \\
(6.54) \\
\end{array}$ & $\begin{array}{c}0.02 \\
(0.00) \\
\end{array}$ & $\begin{array}{c}-0.41 \\
(-0.36) \\
\end{array}$ \\
\hline $\begin{array}{r}\text { Gambling and betting } \\
\text { activities }\end{array}$ & 153 & $\begin{array}{c}38.96 \\
(16.01) \\
\end{array}$ & $\begin{array}{c}3.59 \\
(0.40) \\
\end{array}$ & $\begin{array}{c}41.83 \\
(10.35) \\
\end{array}$ & $\begin{array}{c}0.61 \\
(0.49) \\
\end{array}$ & $\begin{array}{c}0.50 \\
(0.50) \\
\end{array}$ & $\begin{array}{c}0.31 \\
(0.46) \\
\end{array}$ & $\begin{array}{c}0.52 \\
(0.50) \\
\end{array}$ & $\begin{array}{c}0.45 \\
(0.50) \\
\end{array}$ & $\begin{array}{r}7.51 \\
(5.41) \\
\end{array}$ & $\begin{array}{c}0.89 \\
(0.20) \\
\end{array}$ & $\begin{array}{c}0.12 \\
(0.33) \\
\end{array}$ & $\begin{array}{c}2.69 \\
(0.06) \\
\end{array}$ & $\begin{array}{c}0.77 \\
(0.05) \\
\end{array}$ & $\begin{array}{c}0.42 \\
(-0.41) \\
\end{array}$ \\
\hline $\begin{array}{r}\text { Organization and operation of } \\
\text { sport facilities for indoor and } \\
\text { outdoor sports events }\end{array}$ & 502 & $\begin{array}{r}34.03 \\
(15.83) \\
\end{array}$ & $\begin{array}{r}3.40 \\
(0.66) \\
\end{array}$ & $\begin{array}{r}44.03 \\
(12.42) \\
\end{array}$ & $\begin{array}{r}0.50 \\
(0.50) \\
\end{array}$ & $\begin{array}{r}0.53 \\
(0.50) \\
\end{array}$ & $\begin{array}{r}0.27 \\
(0.44) \\
\end{array}$ & $\begin{array}{r}0.57 \\
(0.50) \\
\end{array}$ & $\begin{array}{r}0.70 \\
(0.46) \\
\end{array}$ & $\begin{array}{r}7.63 \\
(8.20) \\
\end{array}$ & $\begin{array}{r}0.72 \\
(0.34) \\
\end{array}$ & $\begin{array}{r}0.11 \\
(0.32) \\
\end{array}$ & $\begin{array}{r}3.69 \\
(0.13) \\
\end{array}$ & $\begin{array}{r}0.24 \\
(0.01) \\
\end{array}$ & $\begin{array}{r}-0.49 \\
(-0.40) \\
\end{array}$ \\
\hline Fitness facilities & 399 & $\begin{array}{c}30.76 \\
(16.32)\end{array}$ & $\begin{array}{c}3.29 \\
(0.56) \\
\end{array}$ & $\begin{array}{c}40.82 \\
(11.22)\end{array}$ & $\begin{array}{c}0.28 \\
(0.45) \\
\end{array}$ & $\begin{array}{c}0.58 \\
(0.49) \\
\end{array}$ & $\begin{array}{c}0.28 \\
(0.45) \\
\end{array}$ & $\begin{array}{c}0.62 \\
(0.49)\end{array}$ & $\begin{array}{c}0.67 \\
(0.47) \\
\end{array}$ & $\begin{array}{r}6.06 \\
(6.72) \\
\end{array}$ & $\begin{array}{c}0.54 \\
(0.34) \\
\end{array}$ & $\begin{array}{c}0.19 \\
(0.39) \\
\end{array}$ & $\begin{array}{c}4.61 \\
(0.38)\end{array}$ & $\begin{array}{c}0.15 \\
(0.00)\end{array}$ & $\begin{array}{c}-0.35 \\
(-0.38) \\
\end{array}$ \\
\hline
\end{tabular}

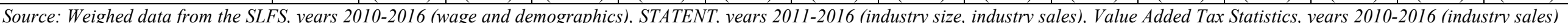

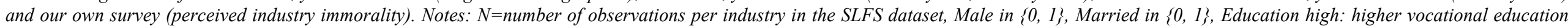

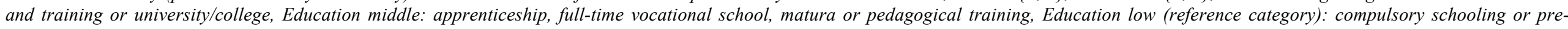

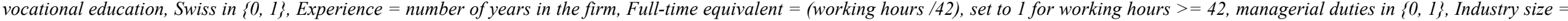

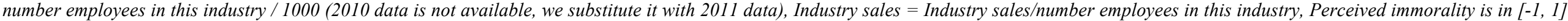
where -1 means very moral, 0 means neutral and 1 means very immoral. Standard deviations in parentheses. 
Table A2: Perceived immorality of firms

\begin{tabular}{|l|c|l|c|}
\hline \multicolumn{1}{|c|}{ Firms } & $\begin{array}{c}\text { Perceived } \\
\text { immorality I(j) }\end{array}$ & \multicolumn{1}{|c|}{ Firms } & $\begin{array}{c}\text { Perceived } \\
\text { immorality I(j) }\end{array}$ \\
\hline Marlboro & 0.54 & Swisscom & -0.07 \\
\hline Monsanto & 0.52 & Firmenich & -0.09 \\
\hline Glencore & 0.46 & Winterthur Assurance & -0.1 \\
\hline Philip Morris & 0.46 & Swiss Life & -0.13 \\
\hline Nestlé & 0.39 & Swatch & -0.17 \\
\hline Tamoil & 0.37 & Adecco & -0.18 \\
\hline Syngenta & 0.23 & ABB & -0.2 \\
\hline UBS & 0.19 & Migros & -0.38 \\
\hline Novartis & 0.18 & WWF & -0.66 \\
\hline Credit Suisse & 0.17 & Pro Juventute & -0.66 \\
\hline Roche & 0.13 & Pro Natura & -0.67 \\
\hline Holcim & 0.03 & UNICEF & -0.72 \\
\hline Ernst and Young & -0.05 & Red cross & -0.81 \\
\hline
\end{tabular}

Source: own survey.

Notes: Perceived immorality is in $[-1,1]$ where -1 means very moral, 0 means neutral and 1 means very immoral. 
Table A3: Distribution of behavior regarding the behavioral measure of concern for morality

\begin{tabular}{|c|c|c|c|c|c|c|c|c|}
\hline \multirow[t]{2}{*}{ Number of lies } & \multicolumn{4}{|c|}{$\begin{array}{l}\text { Reported number } \\
\text { for state } \mathrm{r} \text { : }\end{array}$} & \multirow{2}{*}{$\begin{array}{c}\text { Expected } \\
\text { payoff lying }\end{array}$} & \multirow[t]{2}{*}{ Frequency } & \multirow[t]{2}{*}{ Share } & \multirow[t]{2}{*}{ Classification } \\
\hline & 123 & 4 & 5 & 6 & & & & \\
\hline 0 (Honest) & 123 & 4 & 5 & 6 & 0 & 161 & 0.671 & High-theta \\
\hline \multirow{2}{*}{1} & 623 & 4 & 5 & 6 & 0.83 & 6 & \multirow{2}{*}{0.038} & \multirow{2}{*}{ Low-theta } \\
\hline & 223 & 4 & 5 & 6 & 0.17 & 3 & & \\
\hline \multirow{8}{*}{2} & 663 & 4 & 5 & 6 & 1.5 & 12 & \multirow{8}{*}{0.104} & \multirow{8}{*}{ Low-theta } \\
\hline & 123 & 6 & 6 & 6 & 0.5 & 2 & & \\
\hline & 133 & 5 & 5 & 6 & 0.33 & 1 & & \\
\hline & 144 & 4 & 5 & 6 & 0.5 & 1 & & \\
\hline & 563 & 4 & 5 & 6 & 1.33 & 2 & & \\
\hline & 653 & 4 & 5 & 6 & 1.33 & 1 & & \\
\hline & 323 & 5 & 5 & 6 & 0.5 & 1 & & \\
\hline & 333 & 4 & 5 & 6 & 0.5 & 5 & & \\
\hline \multirow{2}{*}{3} & 666 & 4 & 5 & 6 & 2 & 11 & \multirow{2}{*}{0.050} & \multirow{2}{*}{ Low-theta } \\
\hline & 423 & 6 & 6 & 6 & 1 & 1 & & \\
\hline \multirow{2}{*}{4} & 666 & 6 & 5 & 6 & 2.33 & 3 & \multirow{2}{*}{0.017} & \multirow{2}{*}{ Low-theta } \\
\hline & 655 & 5 & 5 & 6 & 1.83 & 1 & & \\
\hline \multirow{2}{*}{5} & 666 & 6 & 6 & 6 & 2.5 & 15 & \multirow{2}{*}{0.067} & \multirow{2}{*}{ Low-theta } \\
\hline & 234 & 5 & 6 & 6 & 0.83 & 1 & & \\
\hline \multirow{13}{*}{$\begin{array}{l}\text { Lied in a } \\
\text { self-harmful } \\
\text { manner }\end{array}$} & 123 & 4 & 3 & 3 & -0.83 & 1 & \multirow{13}{*}{0.054} & \multirow{13}{*}{ High-theta } \\
\hline & 123 & 4 & 4 & 4 & -0.5 & 1 & & \\
\hline & 123 & 4 & 5 & 5 & -0.17 & 1 & & \\
\hline & 132 & 5 & 4 & 6 & 0 & 1 & & \\
\hline & 142 & 4 & 5 & 6 & 0.17 & 1 & & \\
\hline & 146 & 3 & 5 & 6 & 0.67 & 1 & & \\
\hline & 213 & 4 & 5 & 6 & 0 & 1 & & \\
\hline & 345 & 4 & 6 & 2 & 0.5 & 1 & & \\
\hline & $\begin{array}{lll}5 & 1 & 3\end{array}$ & 6 & 4 & 2 & 0 & 1 & & \\
\hline & 523 & 4 & 1 & 6 & 0 & 1 & & \\
\hline & 546 & 4 & 6 & 5 & 1.5 & 1 & & \\
\hline & 625 & 5 & 1 & 3 & 0.17 & 1 & & \\
\hline & $6 \quad 66$ & 6 & 6 & 5 & 2.33 & 1 & & \\
\hline
\end{tabular}

Notes: Expected payoff from lying $=\frac{1}{6} \sum_{r=1}^{6}\left(m_{i r}-r\right)$, where $m_{i r}$ is the number that individual $i$ reports if the actual die roll is $r$. 


\section{Table A4: Relationship participation decision/reservation wage and $\boldsymbol{\theta}^{\text {Exp }}$ (Hurdle model)}

\begin{tabular}{|c|c|c|c|}
\hline Dependent variable: & Participate & $\begin{array}{l}\text { Reservation } \\
\text { wage }\end{array}$ & $\begin{array}{l}\text { Reservation } \\
\text { wage }\end{array}$ \\
\hline & (1) & $(2)$ & (3) \\
\hline Low-theta $\left(\theta_{L}^{E x p}\right)$ & $\begin{array}{l}0.925 * * * \\
(4.64)\end{array}$ & $\begin{array}{l}-0.362 \\
(-0.99)\end{array}$ & $\begin{array}{l}-0.060 \\
(-0.39)\end{array}$ \\
\hline Period (t) & $\begin{array}{l}-0.019 * * \\
(-2.40)\end{array}$ & $\begin{array}{l}-0.047 \\
(-1.64)\end{array}$ & $\begin{array}{l}-0.050 * * * \\
(-5.74)\end{array}$ \\
\hline Period $* \theta_{L}^{E x p}$ & $\begin{array}{l}0.012 \\
(1.14)\end{array}$ & $\begin{array}{l}-0.015 \\
(-0.40)\end{array}$ & $\begin{array}{l}0.005 \\
(0.54)\end{array}$ \\
\hline Constant & $\begin{array}{l}0.449 * * * \\
(3.86)\end{array}$ & $\begin{array}{l}4.425 * * * \\
(14.76)\end{array}$ & $\begin{array}{l}3.312 * * * \\
(25.63)\end{array}$ \\
\hline Sigma & & $\begin{array}{l}2.630 * * * \\
(7.69)\end{array}$ & $\begin{array}{l}0.571 * * * \\
(10.58)\end{array}$ \\
\hline Condition & Immoral work & Immoral work & Neutral work \\
\hline $\mathbf{N}$ & 2520 & 1755 & 1077 \\
\hline LL (pseudo) & -1424.0 & -4187.4 & -924.3 \\
\hline p-value: $\mathrm{t}+\mathrm{t}^{*} \theta_{L}^{E x p}=0$ & 0.422 & 0.001 & 0.0000 \\
\hline
\end{tabular}

Notes: Estimates from Craggs double-hurdle model: (1) is a probit model; (2) and (3) are truncated linear regressions (truncated from above at $50 \mathrm{CHF}$ ). Models (1) and (2) use only data from the immoral work condition; model (3) uses only data from the neutral work condition. For neutral work, we do not report the regression of market participation as we have only 3 incidences where a subject did not participate. Independent variables: Lowtheta in $\{0,1\}$, Period between 1 and 15. Standard errors clustered at market level; z-statistics in parentheses; * $p$ $<0.1 ; * *-p<0.05 ; * * *-p<0.01$. 
Table A5: Relationship between the behavioral measures of concern for morality and outcomes in the experimental labor markets, robustness

\begin{tabular}{|c|c|c|c|c|c|c|c|c|}
\hline \multirow[t]{2}{*}{$\begin{array}{l}\text { Dependent } \\
\text { variable: }\end{array}$} & \multicolumn{8}{|c|}{ Employment rate } \\
\hline & (1) & (2) & (3) & (4) & (5) & (6) & (7) & (8) \\
\hline \multicolumn{9}{|l|}{ Number of lies } \\
\hline 1 lie & $\begin{array}{l}0.201 \\
(1.05)\end{array}$ & $\begin{array}{l}0.128 \\
(0.53)\end{array}$ & & & $\begin{array}{l}0.004 \\
(0.11)\end{array}$ & $\begin{array}{l}-0.008 \\
(-0.12)\end{array}$ & & \\
\hline 2 lies & $\begin{array}{l}0.220 * * \\
(2.17)\end{array}$ & $\begin{array}{l}0.182 \\
(1.39)\end{array}$ & & & $\begin{array}{l}-0.011 \\
(-0.21)\end{array}$ & $\begin{array}{l}-0.049 \\
(-0.84)\end{array}$ & & \\
\hline 3 lies & $\begin{array}{l}0.398^{* * *} \\
(5.29)\end{array}$ & $\begin{array}{l}0.351 * * * \\
(3.57)\end{array}$ & & & $\begin{array}{l}-0.296 * * * \\
(-12.89)\end{array}$ & $\begin{array}{l}-0.326^{* * *} \\
(-15.52)\end{array}$ & & \\
\hline 4 lies & $\begin{array}{l}0.392 * * * \\
(4.94)\end{array}$ & $\begin{array}{l}0.279 * * \\
(2.61)\end{array}$ & & & $\begin{array}{l}0.171^{* * *} \\
(7.43)\end{array}$ & $\begin{array}{l}0.167 * * * \\
(7.18)\end{array}$ & & \\
\hline 5 lies & $\begin{array}{l}0.286^{* * *} \\
(3.26)\end{array}$ & $\begin{array}{l}0.233^{* *} \\
(2.48)\end{array}$ & & & $\begin{array}{l}0.037 \\
(0.49)\end{array}$ & $\begin{array}{l}0.018 \\
(0.17)\end{array}$ & & \\
\hline $\begin{array}{l}\text { self-harmful } \\
\text { lies }\end{array}$ & $\begin{array}{l}0.252 * * \\
(2.53)\end{array}$ & $\begin{array}{l}0.182 \\
(1.37)\end{array}$ & & & $\begin{array}{l}-0.0516 \\
(-1.25)\end{array}$ & $\begin{array}{l}-0.001 \\
(-0.04)\end{array}$ & & \\
\hline $\begin{array}{l}\text { Expected payoff } \\
\text { lying }\end{array}$ & & & $\begin{array}{l}0.127 * * * \\
(5.04)\end{array}$ & $\begin{array}{l}0.105^{* * *} \\
(3.18)\end{array}$ & & & $\begin{array}{l}0.006 \\
(0.18)\end{array}$ & $\begin{array}{l}-0.001 \\
(-0.03)\end{array}$ \\
\hline Constant & $\begin{array}{l}0.475^{* * *} \\
(11.6)\end{array}$ & $\begin{array}{l}0.517 * * * \\
(32.97)\end{array}$ & $\begin{array}{l}0.510 * * * \\
(13.79)\end{array}$ & $\begin{array}{l}0.512 * * * \\
(37.01)\end{array}$ & $\begin{array}{l}0.829 * * * \\
(36.11)\end{array}$ & $\begin{array}{l}0.806^{* * * *} \\
(35.35)\end{array}$ & $\begin{array}{l}0.824 * * * \\
(35.65)\end{array}$ & $\begin{array}{l}0.801 * * * \\
(36.06)\end{array}$ \\
\hline Condition & Immoral & Immoral & Immoral & $\begin{array}{l}\text { Immoral } \\
168\end{array}$ & $\begin{array}{l}\text { Neutral } \\
72\end{array}$ & $\begin{array}{l}\text { Neutral } \\
72\end{array}$ & $\begin{array}{l}\text { Neutral } \\
72\end{array}$ & Neutral \\
\hline $\begin{array}{l}\mathbf{N} \\
\mathbf{R}^{2}\end{array}$ & $\begin{array}{l}168 \\
0.121\end{array}$ & $\begin{array}{l}168 \\
0.263\end{array}$ & $\begin{array}{l}168 \\
0.0752\end{array}$ & $\begin{array}{l}168 \\
0.238\end{array}$ & $\begin{array}{l}72 \\
0.085\end{array}$ & $\begin{array}{l}72 \\
0.250\end{array}$ & $\begin{array}{l}72 \\
0.001\end{array}$ & $\begin{array}{l}72 \\
0.162\end{array}$ \\
\hline Market FE & No & Yes & No & Yes & No & Yes & No & Yes \\
\hline
\end{tabular}

Notes: Coefficient estimates of linear regression models. Models (1)-(4) use only data from the immoral work condition, models (5)-(8) use only data from the neutral work condition. Expected payoff from lying $=\frac{1}{6} \sum_{r=1}^{6} m_{i r}-$ $r(\in[-2.5,2.5])$, where $m_{i r}$ is the number that individual $i$ reports if the actual die roll is $r$. Standard errors clustered at market level; $t$-statistics in parentheses; * $-p<0.1 ; * *-p<0.05$; *** $-p<0.01$. 
Table A6: Relationship between $\theta^{\text {Exp }}$ and market income, depending on the behavior of other market participants

\begin{tabular}{|c|c|}
\hline Dependent variable: & Market income \\
\hline Low-theta $\left(\theta_{L}^{E x p}\right)$ & $\begin{array}{l}-3.679 \\
(-1.05)\end{array}$ \\
\hline Many $\theta_{H}$ types & $\begin{array}{l}4.334^{*} \\
(2.05)\end{array}$ \\
\hline$\theta_{L}^{E x p} *$ Many $\theta_{\mathrm{H}}$ types & $\begin{array}{l}16.348 * * * \\
(3.53)\end{array}$ \\
\hline Constant & $\begin{array}{l}18.046^{* * *} \\
(11.61)\end{array}$ \\
\hline $\begin{array}{l}\mathbf{N} \\
\mathbf{P}^{2}\end{array}$ & 168 \\
\hline $\begin{array}{l}\mathbf{R}^{2} \\
\text { p-value: Many } \theta_{\mathrm{H}} \text { types }+ \\
\theta_{J}^{E x p} * \operatorname{Many} \theta_{\mathrm{H}} \text { types }=0\end{array}$ & 0.0002 \\
\hline
\end{tabular}

Notes: Coefficient estimates of linear regression models. Sample incudes only subjects from the immoral work condition. Low-theta in $\left\{\begin{array}{ll}0,1 & 1\end{array}\right.$, Many $\theta_{H}$ types: $0=$ number of (other) low-theta type workers is lower than 2 , $1=$ number of (other) low-theta type workers is 2 or more. Standard errors clustered at market level; $t$-statistics in parentheses; * $p<0.1 ; * *-p<0.05 ; * * *-p<0.01$.

Table A7: Description and summary statistics of survey scales

\begin{tabular}{|l|c|c|l|}
\hline Variable & $\begin{array}{l}\text { Number } \\
\text { of items }\end{array}$ & $\begin{array}{c}\text { Mean } \\
\text { (Sd) }\end{array}$ & Interpretation \\
\hline $\begin{array}{l}\text { Protected } \\
\text { value 1 }\end{array}$ & 5 & $\begin{array}{c}0.75 \\
(0.19)\end{array}$ & $\begin{array}{l}\text { 1=the person finds that the behavior of a banker who recommends sub- } \\
\text { optimal assets to his clients because he has larger margins on them is: } \\
\text { very outrageous, very blameworthy, very immoral, not at all acceptable } \\
\text { and notl praiseworthy. }\end{array}$ \\
\hline $\begin{array}{l}\text { Protected } \\
\text { value 2 }\end{array}$ & 4 & $\begin{array}{c}0.63 \\
(0.18)\end{array}$ & $\begin{array}{l}1=\text { the person thinks that truthfulness is a value that cannot be } \\
\text { sacrificed. }\end{array}$ \\
\hline $\begin{array}{l}\text { Work } \\
\text { ethics 1 }\end{array}$ & 1 & $\begin{array}{c}0.38 \\
(0.29)\end{array}$ & $1=$ the person thinks that people are generally honest. \\
\hline $\begin{array}{l}\text { Work } \\
\text { ethics 2 }\end{array}$ & 1 & $\begin{array}{c}0.55 \\
(0.36)\end{array}$ & $\begin{array}{l}1=\text { the person thinks that calling sick to have a free day at work is really } \\
\text { bad. }\end{array}$ \\
\hline $\begin{array}{l}\text { HEXACO } \\
\text { sincerity }\end{array}$ & 3 & $\begin{array}{c}0.59 \\
(0.19)\end{array}$ & $1=$ the person is very sincere. \\
\hline $\begin{array}{l}\text { HEXACO } \\
\text { fairness }\end{array}$ & 3 & $\begin{array}{c}0.68 \\
(0.22)\end{array}$ & $1=$ the person is very fair. \\
\hline $\begin{array}{l}\text { HEXACO } \\
\text { greed } \\
\text { avoidance }\end{array}$ & 2 & $\begin{array}{c}0.58 \\
(0.23)\end{array}$ & $1=$ the person is not at all greedy. \\
\hline $\begin{array}{l}\text { HEXACO } \\
\text { modesty }\end{array}$ & 2 & $\begin{array}{c}0.66 \\
(0.22)\end{array}$ & 1 the person is very modest. \\
\hline $\begin{array}{l}\text { Charity } \\
\text { attitude } \\
\text { index }\end{array}$ & 9 & $\begin{array}{c}0.69 \\
(0.13)\end{array}$ & $1=$ the person's attitude towards charities is very positive. \\
\hline
\end{tabular}

Notes: Each subscale is constructed by taking averages over all items of the scale, and then normalized such that it lies between 0 and 1 . 
Table A8: Relationship between $\theta^{\text {Sur }}$ and outcomes in the experimental labor market

\begin{tabular}{|c|c|c|c|c|c|c|}
\hline \multirow[t]{2}{*}{ Dependent variable: } & \multicolumn{6}{|c|}{ Employment rate } \\
\hline & (1) & (2) & (3) & (4) & (5) & (6) \\
\hline Type survey $\left(\theta^{\text {Sur }}\right)$ & $\begin{array}{l}-0.008 \\
(-0.06)\end{array}$ & $\begin{array}{l}0.036 \\
(0.22)\end{array}$ & $\begin{array}{l}0.104 \\
(0.45)\end{array}$ & $\begin{array}{l}0.150 \\
(0.75)\end{array}$ & $\begin{array}{l}0.0103 \\
(0.06)\end{array}$ & $\begin{array}{l}0.015 \\
(0.06)\end{array}$ \\
\hline Immoral work (IW) & $\begin{array}{l}-0.046 \\
(-0.37)\end{array}$ & & $\begin{array}{l}0.013 \\
(0.07)\end{array}$ & & $\begin{array}{l}0.133 \\
(0.59)\end{array}$ & \\
\hline$\theta^{\text {Sur }} * \mathbf{I W}$ & $\begin{array}{l}-0.431 \\
(-1.64)\end{array}$ & $\begin{array}{l}-0.366 \\
(-1.14)\end{array}$ & $\begin{array}{c}-0.558 \\
(-1.53)\end{array}$ & $\begin{array}{l}-0.537 \\
(-1.26)\end{array}$ & $\begin{array}{l}-0.648^{*} \\
(-1.69) \\
\end{array}$ & $\begin{array}{l}-0.505 \\
(-1.05)\end{array}$ \\
\hline Aggregation $\theta^{\text {Sur }}$ & $\begin{array}{l}\text { Factor } \\
\text { Analysis }\end{array}$ & $\begin{array}{l}\text { Factor } \\
\text { Analysis }\end{array}$ & $\begin{array}{l}\text { Equal } \\
\text { weight }\end{array}$ & $\begin{array}{l}\text { Equal } \\
\text { weight }\end{array}$ & $\begin{array}{l}\text { Theta- } \\
\text { Exp }\end{array}$ & $\begin{array}{l}\text { Theta- } \\
\text { Exp }\end{array}$ \\
\hline $\mathbf{N}$ & 237 & 237 & 237 & 237 & 237 & 237 \\
\hline $\mathbf{R}^{2}$ & 0.137 & 0.294 & 0.132 & 0.291 & 0.133 & 0.293 \\
\hline p-value: $\theta^{\text {Sur }}+\theta^{\text {Sur } *} \mathbf{I m}=\mathbf{0}$ & 0.0569 & 0.237 & 0.0924 & 0.311 & 0.0708 & 0.252 \\
\hline Market FE & No & Yes & No & Yes & No & Yes \\
\hline
\end{tabular}

Notes: Coefficient estimates of linear regression models. Models differ in how we construct $\theta^{\text {Sur }}$ from the nine psychological survey measures. Columns (1) and (2) report our main results, using factor analysis to aggregate the psychological measures. Columns (3) and (4) give the result if equal weight is given to each measure instead. Columns (5) and (6) give the results if weights are determined by a regression of the survey measures on $\theta^{\text {Exp }}$. Other independent variables: Immoral work is in $\{0,1\}, \theta^{\text {Sur }}$ is in $[0,1]$, where higher numbers indicate more morality. Standard errors clustered at market level; $t$-statistics in parentheses; ${ }^{*}-p<0.1 ; *^{*}-p<0.05 ; * * *-p<$ 0.01 .

Table A9: Relationship between participation decision/reservation wage and $\theta^{\text {Sur }}$ (Hurdle model) in the immoral work condition

\begin{tabular}{lllllll}
\hline $\begin{array}{l}\text { Dependent } \\
\text { variable: }\end{array}$ & Participate & $\begin{array}{l}\text { Reservation } \\
\text { wage }\end{array}$ & Participate & $\begin{array}{l}\text { Reservation } \\
\text { wage }\end{array}$ & Participate & $\begin{array}{l}\text { Reservation } \\
\text { wage }\end{array}$ \\
\hline & \multicolumn{1}{c}{$(1)$} & \multicolumn{1}{c}{$(2)$} & $(3)$ & $(4)$ & $(5)$ & $(6)$ \\
\hline \multirow{2}{*}{ Type survey $\left(\boldsymbol{\theta}^{\text {Sur }}\right)$} & $-1.614^{* *}$ & 0.432 & $-1.971^{* *}$ & 0.571 & $-2.177^{* *}$ & 0.373 \\
& $(-2.44)$ & $(0.60)$ & $(-2.08)$ & $(0.61)$ & $(-2.13)$ & $(0.33)$ \\
Constant & $1.326^{* * *}$ & $3.674^{* * *}$ & $1.806^{* * *}$ & $3.515^{* * *}$ & $1.841^{* * *}$ & $3.657^{* * *}$ \\
& $(3.98)$ & $(10.39)$ & $(2.99)$ & $(6.12)$ & $(3.01)$ & $(5.25)$ \\
Sigma & & $2.679^{* * *}$ & & $2.679^{* * *}$ & & $2.680^{* * *}$ \\
& & $(7.71)$ & & $(7.72)$ & & $(7.70)$ \\
\hline \multirow{2}{*}{ Aggregation $\boldsymbol{\theta}^{\text {Sur }}$} & Factor & Factor & Equal & Equal & Theta- & Theta- \\
N & Analysis & Analysis & weight & weight & Exp & Exp \\
LL (pseudo) & 2475 & 1711 & 2475 & 1711 & 2475 & 1711 \\
\hline
\end{tabular}

Notes: Estimates from Craggs double-hurdle model: Regressions (1), (3) and (5) are probit models, regressions (2), (4) and (6) are truncated linear regressions (truncated from above at $50 \mathrm{CHF}$ ). Regressions differ in how $\theta^{\text {Sur }}$ is constructed from the nine psychological survey measures. Columns (1) and (2) report our main results, using factor analysis to aggregate the psychological measures. Columns (3) and (4) give the result if equal weight is given to each measure instead. Columns (5) and (6) give the results if weights are determined by a regression of the survey measures on $\theta^{\text {Exp }} . \theta^{\text {Sur }}$ is in $[0,1]$, where higher numbers indicate more morality. Sample incudes only subjects from the immoral work condition. (In the neutral work condition, the coefficient of $\theta^{\text {Sur }}$ is not significant for any of the above specifications.) Standard errors clustered at market level; z-statistics in parentheses; $*_{-} p<0.1 ; *^{*}-p<0.05 ; * * *_{-} p<0.01$. 
Table A10: Regressions of willingness to work for diverse industries and firms on perceived immorality and moral types, robustness checks aggregation $\theta^{\text {Sur }}$

\begin{tabular}{lcccccccc}
\hline Dependent variable: & \multicolumn{4}{c}{ Willingness to work for industry $\boldsymbol{j}$} & \multicolumn{4}{c}{ Willingness to work for firm $\boldsymbol{j}$} \\
\hline & $(1)$ & $(2)$ & $(3)$ & $(4)$ & $(5)$ & $(6)$ & $(7)$ & $(8)$ \\
\hline Perceived & 0.089 & 0.096 & 0.122 & 0.129 & $0.396^{* * *}$ & $0.391^{* * *}$ & $0.337^{* * *}$ & $0.327^{* * *}$ \\
immorality $(\mathbf{I}(\mathbf{j}))$ & $(1.00)$ & $(1.17)$ & $(1.33)$ & $(1.43)$ & $(3.65)$ & $(3.58)$ & $(4.16)$ & $(4.00)$ \\
Type survey $\left(\boldsymbol{\theta}^{\text {Sur }}\right)$ & $-0.154^{*}$ & $-0.149^{*}$ & -0.131 & $-0.158^{*}$ & $-0.200^{*}$ & $-0.267^{* * *}$ & $-0.243^{* *}$ & $-0.298^{* * *}$ \\
& $(-1.93)$ & $(-1.77)$ & $(-1.49)$ & $(-1.68)$ & $(-1.84)$ & $(-2.58)$ & $(-2.21)$ & $(-2.69)$ \\
$\boldsymbol{\theta}^{\text {Sur }} * \mathbf{I}(\mathbf{j})$ & $-0.583^{* * *}$ & $-0.583^{* * *}$ & $-0.671^{* * *}$ & $-0.671^{* * *}$ & $-0.998^{* * *}$ & $-0.990^{* * *}$ & $-0.961^{* * *}$ & $-0.944^{* * *}$ \\
& $(-5.05)$ & $(-5.06)$ & $(-4.95)$ & $(-4.98)$ & $(-7.83)$ & $(-7.60)$ & $(-8.54)$ & $(-8.26)$ \\
\hline Aggregation $\boldsymbol{\theta}^{\text {Sur }}$ & Equal & Equal & Theta- & Theta- & Equal & Equal & Theta- & Theta- \\
& weight & weight & Exp & Exp & weight & weight & Exp & Exp \\
$\mathbf{N}$ & 4715 & 4715 & 4715 & 4715 & 5064 & 5064 & 5064 & 5064 \\
Control variables & No & Yes & No & Yes & No & Yes & No & Yes \\
\hline
\end{tabular}

Notes: Coefficient estimates of linear regression models. Observations where subjects did not know the firm ("I don't know this organization") or did not fill out the questionnaire are excluded. Independent variables: Models differ in how we construct $\theta^{\text {Sur }}$ from the nine psychological survey measures. Columns (1), (2), (5) and (6) give the result if equal weight is given to each measure. Columns (3), (4), (7) and (8) give the results if weights are determined by a regression of the survey measures on $\theta_{L}^{\text {Exp }} . \theta^{\text {Sur }}$ is in $[0,1]$ where higher numbers indicate more morality. Willingness to work is in $\{0,0.25,0.5,0.75,1\}$ where 0 means not at all willing to work, 0.5 means indifferent and 1 means really much willing to work. Perceived immorality is in $[-1,1]$ where -1 means very moral, 0 means neutral and 1 means very immoral. Control variables: age, gender, Swiss nationality, subject of study, average wage industry 2016 (SLFS; only for industries), industry size 2016 (STATENT; only for industries), industry sales 2015 (Value Added Tax Statistics; only for industries). Standard errors clustered at individual and industry/firm level (Cameron, Gelbach and Miller, 2011); z-statistics in parentheses; ${ }^{*} p<0.1 ;{ }^{* *} p<0.05 ; * * * p$ $<0.01$.

Table A11: Regressions of willingness to work for diverse industries and firms on perceived immorality and moral types, robustness checks classification firms immorality

\begin{tabular}{|c|c|c|c|c|}
\hline \multirow[t]{2}{*}{ Dependent variable: } & \multicolumn{4}{|c|}{ Willingness to work for firm $j$} \\
\hline & (1) & (2) & (3) & (4) \\
\hline $\begin{array}{l}\text { Perceived } \\
\text { immorality }\left(I_{\text {Alt }}(j)\right)\end{array}$ & $\begin{array}{l}0.141 \\
(1.63)\end{array}$ & $\begin{array}{l}0.138 \\
(1.59)\end{array}$ & $\begin{array}{c}-0.157^{* *} \\
(-1.96)\end{array}$ & $\begin{array}{c}-0.156^{* *} \\
(-1.96)\end{array}$ \\
\hline Type survey $\left(\theta^{\text {Sur }}\right)$ & $\begin{array}{c}-0.184 * * \\
(-2.42)\end{array}$ & $\begin{array}{c}-0.222 * * * \\
(-2.99)\end{array}$ & & \\
\hline $\boldsymbol{\theta}^{\text {Sur } * \mathbf{I}_{\text {Alt }}(\mathbf{j})}$ & $\begin{array}{c}-0.848 * * * \\
(-9.22)\end{array}$ & $\begin{array}{c}-0.840 * * * \\
(-9.10)\end{array}$ & & \\
\hline $\begin{array}{l}\text { Type experiment } \\
\left(\theta^{\operatorname{Exp}}\right)\end{array}$ & & & $\begin{array}{c}-0.045^{*} \\
(-1.65)\end{array}$ & $\begin{array}{c}-0.053 * * \\
(-2.04)\end{array}$ \\
\hline 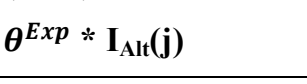 & & & $\begin{array}{c}-0.174 * * * \\
(-4.06) \\
\end{array}$ & $\begin{array}{c}-0.175^{* * * *} \\
(-4.15) \\
\end{array}$ \\
\hline $\mathbf{N}$ & 5064 & 5064 & 5064 & 5064 \\
\hline Control variables & No & Yes & No & Yes \\
\hline
\end{tabular}

Notes: Coefficient estimates of linear regression models. Perceived immorality is calculated different then in our main analysis: Clients that choose "I don't know this organization" are classified as giving neutral ratings. Dependent variable: Willingness to work is in $\{0,0.25,0.5,0.75,1\}$ where 0 means not at all willing to work, 0.5 means indifferent and 1 means really much willing to work. Observations where subjects did not know the firm ("I don't know this organization") or did not fill out the questionnaire are excluded. Independent variables: (1) and (2) use $\theta^{\text {Sur }}$ (in [0,1]), while (3) and (4) use $\theta^{\text {Exp }}$ to classify participants, where $\theta^{\text {Exp }}=0$ for low-theta types and $\theta^{E x p}=1$ for high-theta types. Perceived immorality is in $[-1,1]$ where -1 means very moral, 0 means neutral and 1 means very immoral. Control variables: age, gender, Swiss nationality, subject of study. Standard errors clustered at individual and industry/firm level (Cameron, Gelbach and Miller, 2011); z-statistics in parentheses; * $p<0.1$; ** $p<0.05 ; * * * p<0.01$. 
Table A12: Regressions of willingness to work for diverse industries and firms on perceived immorality and moral types, robustness checks "I don't know this organization"

\begin{tabular}{|c|c|c|c|c|c|c|c|c|}
\hline \multirow{2}{*}{ Dependent variable: } & \multicolumn{8}{|c|}{ Willingness to work for firm $\boldsymbol{j}$} \\
\hline & (1) & (2) & (3) & (4) & (5) & (6) & (7) & (8) \\
\hline $\begin{array}{l}\text { Perceived } \\
\quad \text { immorality (I(j)) }\end{array}$ & $\begin{array}{l}0.088 \\
(1.48)\end{array}$ & $\begin{array}{l}0.088 \\
(1.47)\end{array}$ & $\begin{array}{c}0.159 * * * \\
(2.70)\end{array}$ & $\begin{array}{c}0.159 * * * \\
(2.71)\end{array}$ & $\begin{array}{c}-0.123 * * \\
(-2.21)\end{array}$ & $\begin{array}{c}-0.123 * * \\
(-2.20)\end{array}$ & $\begin{array}{l}-0.092 \\
(-1.49)\end{array}$ & $\begin{array}{l}-0.092 \\
(-1.46)\end{array}$ \\
\hline Type survey $\left(\theta^{\text {Sur }}\right)$ & $\begin{array}{c}-0.127 * * \\
(-2.01)\end{array}$ & $\begin{array}{c}-0.165^{* * * *} \\
(-2.58)\end{array}$ & $\begin{array}{l}-0.156 \\
(-1.11)\end{array}$ & $\begin{array}{l}-0.204 \\
(-1.15)\end{array}$ & & & & \\
\hline$\theta^{\text {Sur * }} \mathbf{I}(\mathbf{j})$ & $\begin{array}{c}-0.613^{* * *} \\
(-7.46)\end{array}$ & $\begin{array}{c}-0.613^{* * * *} \\
(-7.39)\end{array}$ & $\begin{array}{c}-0.792 * * * \\
(-5.49)\end{array}$ & $\begin{array}{c}-0.792 * * * \\
(-5.46)\end{array}$ & & & & \\
\hline $\begin{array}{l}\text { Type experiment } \\
\left(\theta^{\operatorname{Exp}}\right)\end{array}$ & & & & & $\begin{array}{l}-0.034 \\
(-1.54)\end{array}$ & $\begin{array}{c}-0.040^{*} \\
(-1.91)\end{array}$ & $\begin{array}{l}-0.039 \\
(-0.58)\end{array}$ & $\begin{array}{l}-0.056 \\
(-0.90)\end{array}$ \\
\hline$\theta^{E x p} * \mathbf{I}(\mathbf{j})$ & & & & & $\begin{array}{c}-0.131 * * * \\
(-4.47)\end{array}$ & $\begin{array}{c}-0.131 * * * \\
(-4.43)\end{array}$ & $\begin{array}{c}-0.158 * * * \\
(-2.98)\end{array}$ & $\begin{array}{c}-0.158 * * * \\
(-2.87)\end{array}$ \\
\hline $\mathbf{N}$ & 6162 & 6162 & 1352 & 1352 & 6162 & 6162 & 1352 & 1352 \\
\hline Control variables & No & Yes & No & Yes & No & Yes & No & Yes \\
\hline
\end{tabular}

Notes: Coefficient estimates of linear regression models. Dependent variable: Willingness to work is in $\{0,0.25$, $0.5,0.75,1\}$ where 0 means not at all willing to work, 0.5 means indifferent and 1 means really much willing to work. Observations where subjects did not fill out the questionnaire are excluded. Columns (1), (2), (5) and (6): Observations where subjects did not know the firm ("I don't know this organization") are classified as having willingness to work of 0.5. Columns (3), (4), (7) and (8): only participants that did know all firms $(N=52)$ are included. Independent variables: (1) - (4) use $\theta^{\text {Sur }}$ (in [0,1]), while (5) - (8) use $\theta^{\text {Exp }}$ to classify participants, where $\theta^{E x p}=0$ for low-theta types and $\theta^{\text {Exp }}=1$ for high-theta types. Perceived immorality is in $[-1,1]$ where -1 means very moral, 0 means neutral and 1 means very immoral. Control variables: age, gender, Swiss nationality, subject of study. Standard errors clustered at individual and industry/firm level (Cameron, Gelbach and Miller, 2011); zstatistics in parentheses; * $p<0.1 ; * * p<0.05 ; * * * p<0.01$.

Table A13: Regressions of willingness to work for diverse industries and firms on employment rate in the immoral work condition

\begin{tabular}{|c|c|c|c|c|}
\hline \multirow[t]{2}{*}{ Dependent variable: } & \multicolumn{2}{|c|}{$\begin{array}{c}\text { Willingness to } \\
\text { work for industry } \boldsymbol{j}\end{array}$} & \multicolumn{2}{|c|}{$\begin{array}{l}\text { Willingness to } \\
\text { work for firm } \boldsymbol{j}\end{array}$} \\
\hline & (1) & (2) & $(5)$ & (6) \\
\hline $\begin{array}{l}\text { Perceived } \\
\text { immorality (I(j)) }\end{array}$ & $\begin{array}{c}-0.332 * * * \\
(-6.64)\end{array}$ & $\begin{array}{c}-0.399 * * * \\
(-6.74)\end{array}$ & $\begin{array}{c}-0.311 * * * \\
(-6.42)\end{array}$ & $\begin{array}{c}-0.310^{* * *} \\
(-6.33)\end{array}$ \\
\hline Employment rate (E) & $\begin{array}{l}0.029 \\
(1.07)\end{array}$ & $\begin{array}{l}0.044^{*} \\
(1.79)\end{array}$ & $\begin{array}{l}0.048 \\
(1.36)\end{array}$ & $\begin{array}{l}0.055 \\
(1.54)\end{array}$ \\
\hline $\mathbf{E} * \mathbf{I}(\mathbf{j})$ & $\begin{array}{c}0.073^{* *} \\
(2.03)\end{array}$ & $\begin{array}{l}0.073^{* *} \\
(2.00)\end{array}$ & $\begin{array}{l}0.114^{* *} \\
(2.49)\end{array}$ & $\begin{array}{c}0.114 * * * \\
(2.44)\end{array}$ \\
\hline $\mathbf{N}$ & 3275 & 3275 & 3561 & 3561 \\
\hline Control variables & No & Yes & No & Yes \\
\hline
\end{tabular}

Notes: Coefficient estimates of linear regression models. Sample incudes only subjects from the immoral work condition. Dependent variable: Willingness to work is in $\{0,0.25,0.5,0.75,1\}$ where 0 means not at all willing to work, 0.5 means indifferent and 1 means really much willing to work. Observations where subjects did not know the firm ("I don't know this organization") or did not fill out the questionnaire are excluded. Independent variables: Employment rate is the share of market periods in which the worker was employed. Perceived immorality is in [-1, $1]$ where -1 means very moral, 0 means neutral and 1 means very immoral. Control variables: age, gender, Swiss nationality, subject of study, average wage industry 2016 (SLFS; only for industries), industry size 2016 (STATENT; only for industries), industry sales 2015 (Value Added Tax Statistics; only for industries). Standard errors clustered at individual and industry/firm level (Cameron, Gelbach and Miller, 2011); z-statistics in parentheses; * $p<0.1 ; * *$ $p<0.05 ; * * * p<0.01$. 


\section{Appendix B - Robustness checks for analysis using Swiss Labor Force Survey}

A potential critique of our analysis of wage premiums using the Swiss Labor Force Survey data in Section 4 is that we selected the potential immoral industries and the control industries ourselves. In this Appendix, we report results from two robustness checks that address this issue.

\section{1) We use all industries in the Swiss Labor Force survey as control industries}

In a first robustness check, we use all non-immoral industries in the Swiss Labor Force survey as control industries. We do not have a measure of the perceived industry immorality, I(j), for most industries. Instead of relying on such a measure, we define a set of industries as "immoral industries" and calculate wage premiums (or, wage discounts) for these industries, controlling for worker, job and industry characteristics. This approach is commonly used in the literature that studies stock returns for "sin industries" (e.g., Fabozzi, Ma and Oliphant, 2008; Hong and Kacperczyk, 2009; Blitz and Fabozzi, 2017; Colonnello, Curatola and Gioffré, 2019). We expect immoral industries to pay a positive wage premium, a compensating differential for the immoral nature of the work.

Set of immoral industries: We select the set of immoral industries based on the industry ratings. Most participants that rated the immorality of the industries agreed that it is immoral to work in the following four industries: manufacture of weapons and ammunitions, manufacture of tobacco products, wholesale of tobacco products and gambling and betting activities (see Table A1). These four industries are also typically considered to be "sin industries" in the literature on sin stocks. We focus on these four industries. ${ }^{39}$ Given that we use the industry ratings to select the immoral industries, this robustness check still depends on our selection of potentially immoral industries in Section 4. Note, however, that we use the entire dataset as control industries and therefore do not rely on our selection of control industries.

Results: Figure B1 (i) shows the average gross hourly wages for each of the four immoral industries and the average wage in all other industries. Table B1 reports regressions of the

\footnotetext{
${ }^{39}$ In Section 4, we select two other industries, monetary intermediations and credit granting, that might potentially be perceived as immoral. As there was disagreement on the immorality of these two industries among survey respondents (see Table A1), we do not include them in the set of immoral industries. Note, however, that both industries pay substantial wage premiums. If we add dummies for working in these industries to Model 3, coefficients are $0.263(\mathrm{t}=11.12, \mathrm{p}<0.001)$ for monetary intermediation and $0.282(\mathrm{t}=20.51, \mathrm{p}<0.001)$ for credit granting.
} 
natural logarithm of real gross hourly wages on the dummies for working in each of the four immoral industries, along with several additional control variables (Model 1, 2 and 3). All four immoral industries pay substantial wage premiums, in line with an immorality premium for immoral work. According to Model 3, individuals working in the immoral industries have (geometric) mean hourly earnings of between 12 percent and 29 percent higher than people working in other industries.

\section{2) We elicited perceived industry immorality for a second set of industries}

As a second robustness check, we elicit the perceived industry immorality for a second set of industries, but in this case we do not select the industries. Instead, we ask research assistants unaware of our hypotheses to select moral and immoral industries. We then provide evidence for an immorality premium in this second set of industries.

Set of industries: We created a list with all industries that had at least 50 observations in the Swiss Labor Force Survey. This resulted in a list of 394 industries. We then asked five research assistants to select up to ten industries in which they think it is most immoral to work and up to ten industries in which they think it is most moral to work. They ranked the selected industries from most immoral (moral) to least immoral (moral). The research assistants were unaware of our research question. The five industries that the research assistants thought to be the most immoral and the five industries that they thought to be the most moral are included in the set of industries used in this robustness test. ${ }^{40}$ In addition to these ten industries, we randomly selected a set of 40 other industries that had at least 50 observations in the Swiss Labor Force Survey. Table B2 gives all selected industries.

Industry ratings: We elicited a measure of perceived immorality for the set of 50 industries. We recruited 45 participants drawn from the same subject pool from which we recruit participants for our laboratory experiment (but that did not participate in our experiment). These participants rated how immoral they think it is to work for each of the 50 industries on a 7-point Likert scale ranging from very immoral to very moral. We re-scaled the responses to lie on the -1 to 1 interval. Table B2 gives the ratings for all industries.

\footnotetext{
${ }^{40} \mathrm{We}$ calculated the average rank of each industry as follows. We first allocated points to each industry according to its rank: if an in industry was rated the most immoral industry it received 10 points, the second most immoral industry received 9 points, and so on. We then added up points for every industry and selected the five immoral and the five moral industries with the highest number of points.
} 
Results: Figure B1 (ii) shows the correlation between average industry wages and the new collected measure of perceived industry immorality. Table B1 reports regressions of the natural logarithm of real gross hourly wages on the new collected measure of perceived industry immorality, along with several additional control variables (Model 4 to 6). ${ }^{41} \mathrm{We}$ find a substantial and statistically significant immorality wage premium. According to Model 6, individuals working in an industry as immoral as manufacture of weapons and ammunition (i.e., Perceived immorality $=0.47$ ) have (geometric) mean hourly earnings approximately 17 percent higher than people working in an industry with the median industry immorality rating (i.e., Perceived immorality $=-0.14) .^{42}$

Figure B1: Correlation between wages and perceived industry immorality, robustness

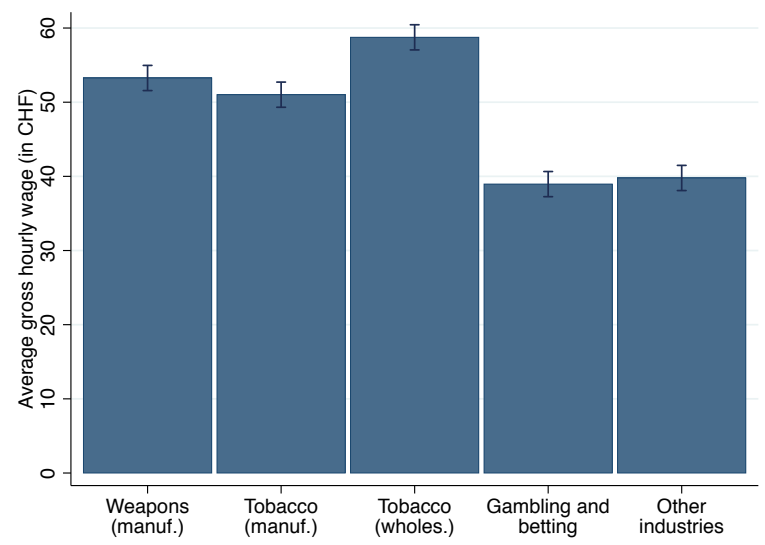

(i) All industries as control industries

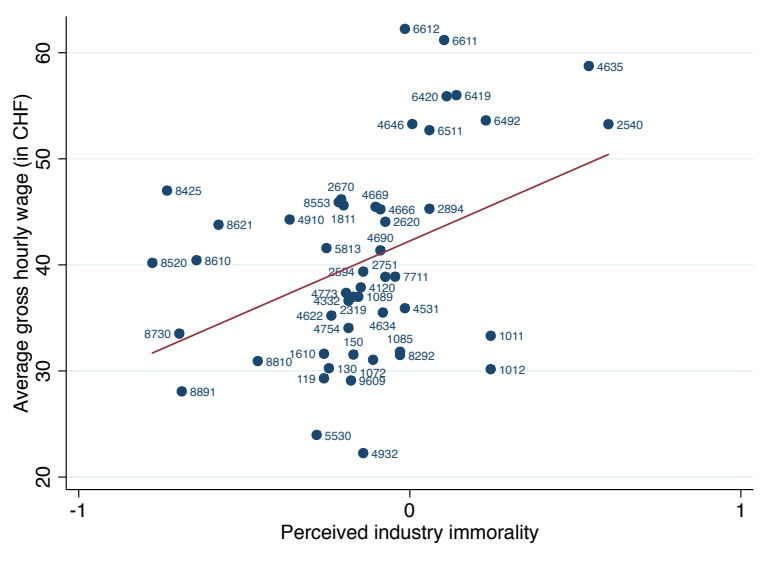

(ii) Second set of industries

Source: Weighted data from the SLFS, years 2010-2016 (wage) and our own survey for the second set of industries (panel (ii), perceived industry immorality). Notes: Real gross hourly wage in 2010 CHF. Panel (i) gives the average gross hourly wages for Manufacture weapons and ammunitions (Weapons (manuf.)), manufacture tobacco (Tobacco (manuf.)), Wholesale tobacco (Tobacco (wholes.)), Gambling and betting and all other industries. $N=239,313$. Panel (ii) gives the correlation between average industry wages and perceived industry immorality. Perceived immorality is in $[-1,1]$ where -1 means very moral, 0 means neutral and 1 means very immoral. The numbers in the figure give the industry code of each dot (see Table B2). $N=47,935$.

\footnotetext{
${ }^{41}$ Numbers of observations differ substantially between industries. If we weight observations by industry size (instead of using survey weights), estimates for perceived immorality are similar (Model 4: 0.342, Model 5: 0.281, Model 6: 0.266$)$ and statistically significant $(\mathrm{t}=2.83, \mathrm{t}=3.21, \mathrm{t}=3.39$, respectively).

${ }^{42}$ We obtain this number by doing the following calculation: $e^{0.209^{*} 0.74}-1 \approx 0.167$.
} 
Table B1: Relationship between wages and industry immorality, robustness

\begin{tabular}{|c|c|c|c|c|c|c|}
\hline \multicolumn{7}{|c|}{ Dependent variable: In of real gross hourly wage (in $2010 \mathrm{CHF}$ ) } \\
\hline & $(1)$ & $(2)$ & (3) & (4) & $(5)$ & $(6)$ \\
\hline $\begin{array}{l}\text { Manufacture weapons and } \\
\text { ammunitions }\end{array}$ & $\begin{array}{c}0.345 * * * \\
(14.98)\end{array}$ & $\begin{array}{c}0.154 * * * \\
(10.31)\end{array}$ & $\begin{array}{l}0.147 * * * \\
(8.24)\end{array}$ & & & \\
\hline Manufacture tobacco & $\begin{array}{c}0.285 * * * \\
(12.37)\end{array}$ & $\begin{array}{c}0.237 * * * \\
(7.61)\end{array}$ & $\begin{array}{l}0.288 * * * \\
(9.16)\end{array}$ & & & \\
\hline Wholesale tobacco & $\begin{array}{c}0.402 * * * \\
(17.47)\end{array}$ & $\begin{array}{c}0.327 * * * \\
(23.49)\end{array}$ & $\begin{array}{c}0.280 * * * \\
(16.29)\end{array}$ & & & \\
\hline Gambling and betting & $\begin{array}{l}0.025 \\
(1.08)\end{array}$ & $\begin{array}{l}0.087 * * * \\
(7.26)\end{array}$ & $\begin{array}{l}0.123 * * * \\
(9.44)\end{array}$ & & & \\
\hline $\begin{array}{l}\text { Perceived industry } \\
\text { immorality }\end{array}$ & & & & $\begin{array}{c}0.327 * * \\
(2.34)\end{array}$ & $\begin{array}{l}0.242 * * * \\
(2.94)\end{array}$ & $\begin{array}{l}0.209 * * * \\
(2.77)\end{array}$ \\
\hline Age & & $\begin{array}{c}0.006 * * * \\
(12.66)\end{array}$ & $\begin{array}{c}0.006 * * * \\
(12.58)\end{array}$ & & $\begin{array}{l}0.008 * * * \\
(7.20)\end{array}$ & $\begin{array}{l}0.007 * * * \\
(6.94)\end{array}$ \\
\hline Male & & $\begin{array}{c}0.194 * * * \\
(17.26)\end{array}$ & $\begin{array}{c}0.195 * * * \\
(17.81)\end{array}$ & & $\begin{array}{l}0.152 * * * \\
(7.50)\end{array}$ & $\begin{array}{c}0.155^{* * * *} \\
(7.62)\end{array}$ \\
\hline Married & & $\begin{array}{c}0.035^{* * *} \\
(4.57)\end{array}$ & $\begin{array}{l}0.039 * * * \\
(5.00)\end{array}$ & & $\begin{array}{l}0.030 \\
(1.26)\end{array}$ & $\begin{array}{l}0.032 \\
(1.33)\end{array}$ \\
\hline Education high & & $\begin{array}{l}0.586^{* * *} \\
(31.24)\end{array}$ & $\begin{array}{c}0.564 * * * \\
(32.32)\end{array}$ & & $\begin{array}{c}0.602 * * * \\
(13.69)\end{array}$ & $\begin{array}{c}0.580 * * * \\
(12.91)\end{array}$ \\
\hline Education middle & & $\begin{array}{c}0.247 * * * \\
(17.07)\end{array}$ & $\begin{array}{c}0.241^{* * *} \\
(16.99)\end{array}$ & & $\begin{array}{c}0.297 * * * \\
(6.93)\end{array}$ & $\begin{array}{c}0.288 * * * \\
(6.60)\end{array}$ \\
\hline Swiss & & $\begin{array}{r}0.0024 \\
(0.20)\end{array}$ & $\begin{array}{l}0.011 \\
(1.01)\end{array}$ & & $\begin{array}{l}-0.011 \\
(-0.63)\end{array}$ & $\begin{array}{l}-0.002 \\
(-0.11)\end{array}$ \\
\hline Experience & & $\begin{array}{l}0.004 * * * \\
(5.75)\end{array}$ & $\begin{array}{l}0.005^{* * *} \\
(6.24)\end{array}$ & & $\begin{array}{c}0.004 * * \\
(2.49)\end{array}$ & $\begin{array}{l}0.005^{* * *} * \\
(2.77)\end{array}$ \\
\hline Full-time equivalent & & $\begin{array}{c}-0.076^{* * * *} \\
(-2.59)\end{array}$ & $\begin{array}{c}-0.078 * * * \\
(-2.73)\end{array}$ & & $\begin{array}{c}-0.166^{* *} \\
(-2.35)\end{array}$ & $\begin{array}{c}-0.168^{* *} \\
(-2.44)\end{array}$ \\
\hline Managerial duties & & $\begin{array}{l}-0.025 \\
(-0.91)\end{array}$ & $\begin{array}{l}-0.020 \\
(-0.74)\end{array}$ & & $\begin{array}{l}0.063 \\
(0.85)\end{array}$ & $\begin{array}{l}0.066 \\
(0.93)\end{array}$ \\
\hline Industry sales & & $\begin{array}{c}0.006^{* * *} \\
(2.15)\end{array}$ & $\begin{array}{c}0.005^{* *} * \\
(2.04)\end{array}$ & & $\begin{array}{l}0.020 \\
(1.17)\end{array}$ & $\begin{array}{l}0.021 \\
(1.22)\end{array}$ \\
\hline Industry size (employees) & & $\begin{array}{c}0.0004 \\
(1.59)\end{array}$ & $\begin{array}{c}0.0004 * \\
(1.83)\end{array}$ & & $\begin{array}{c}0.001 * * * \\
(3.80)\end{array}$ & $\begin{array}{c}0.001 * * * \\
(4.08)\end{array}$ \\
\hline Constant & $\begin{array}{c}3.561 * * * \\
(154.57)\end{array}$ & $\begin{array}{c}2.832 * * * \\
(79.63)\end{array}$ & & $\begin{array}{c}3.737 * * * \\
(52.83)\end{array}$ & $\begin{array}{c}2.876^{* * *} * \\
(32.09)\end{array}$ & \\
\hline $\mathrm{N}$ & 239,313 & 236,625 & 236,625 & 47,935 & 47,935 & 47,935 \\
\hline Adjusted $\mathrm{R}^{2}$ & 0.001 & 0.206 & 0.221 & 0.041 & 0.248 & 0.263 \\
\hline Year and Region FE & No & No & Yes & No & No & Yes \\
\hline
\end{tabular}

Source: Weighed data from the SLFS, years 2010-2016 (wage and demographics), STATENT, years 2011-2016 (industry size, industry sales), Value Added Tax Statistics, years 2010-2016 (industry sales) and our own online-survey (perceived industry immorality). Notes: Manufacture weapons and ammunitions, Manufacture tobacco, Wholesale tobacco and Gambling and betting are binary variables where 1 means that the individual works in the respective industry. Perceived immorality is in [-1, 1] where -1 means very moral, 0 means neutral and 1 means very immoral. Control variables: Male in $\{0,1\}$, Married in $\{0,1\}$, Education high: higher vocational education and training or university/college, Education middle: apprenticeship, full-time vocational school, matura or pedagogical training, Education low (reference category): compulsory schooling or pre-vocational education, Swiss in $\{0,1\}$, Experience $=$ number of years in the firm, Full-time equivalent $=($ working hours /42), set to 1 for working hours $>=42$, managerial duties in $\{0,1\}$, Industry size $=$ number employees in this industry / 1000 (2010 data is not available, we substitute it with 2011 data), Industry sales = Industry sales/number employees in this industry. Model 3 and 6 control for company region fixed effects (26 Swiss cantons) and year fixed effects (2010-2016). Standard errors clustered at the industry level, $t$-statistics in parentheses; $* p<0.1 ; * *<<0.05 ; * * *<0.01$. 
Table B2: Set of industries and industry ratings

\begin{tabular}{|c|c|c|c|}
\hline & Industry & $\begin{array}{l}\text { Industry } \\
\text { Code }\end{array}$ & $\begin{array}{l}\text { Perceived } \\
\text { immorality }\end{array}$ \\
\hline \multirow{5}{*}{$\begin{array}{l}\text { Immoral } \\
\text { industries }\end{array}$} & Manufacture of weapons and ammunition & 2540 & 0.60 \\
\hline & Wholesale of tobacco products & 4635 & 0.54 \\
\hline & Processing and preserving of meat (except poultry meat) & 1011 & 0.24 \\
\hline & Credit granting & 6492 & 0.23 \\
\hline & Processing and preserving of poultry meat & 1012 & 0.24 \\
\hline \multirow[t]{5}{*}{ Moral industries } & $\begin{array}{l}\text { Social work activities without accommodation for the elderly and } \\
\text { disabled }\end{array}$ & 8810 & -0.46 \\
\hline & Residential care activities for the elderly and disabled & 8730 & -0.70 \\
\hline & Fire service activities & 8425 & -0.73 \\
\hline & Primary education & 8520 & -0.78 \\
\hline & Hospital activities & 8610 & -0.64 \\
\hline \multirow{17}{*}{ Other Industries } & Manufacture of prepared meals and dishes & 1085 & -0.03 \\
\hline & $\begin{array}{l}\text { Wholesale of office machinery and equipment, except computers } \\
\text { and computer peripheral equipment }\end{array}$ & 4666 & -0.09 \\
\hline & Publishing of newspapers & 5813 & -0.25 \\
\hline & $\begin{array}{l}\text { Monetary intermediation (cantonal banks, commercial banks, } \\
\text { stock exchange banks, private bankers; banks with a special field } \\
\text { of business; regional banks; Raiffeisen banks; Foreign-controlled } \\
\text { banks) }\end{array}$ & 6419 & 0.14 \\
\hline & Passenger rail transport & 4910 & -0.36 \\
\hline & $\begin{array}{l}\text { Support activities for crop production (preparation of fields; } \\
\text { establishing a crop; treatment of crops; crop spraying; trimming of } \\
\text { fruit trees and vines; transplanting of rice; thinning of beets; } \\
\text { harvesting; pest control; provision of agricultural machinery with } \\
\text { operators and crew) }\end{array}$ & 1610 & -0.26 \\
\hline & Driving school & 8553 & -0.21 \\
\hline & Security and commodity contracts brokerage & 6612 & -0.01 \\
\hline & Printing of newspapers & 1811 & -0.2 \\
\hline & $\begin{array}{l}\text { Growing of other non-perennial crops (growing of swedes, } \\
\text { mangolds, fodder roots, clover, alfalfa, sainfoin, fodder maize and } \\
\text { other grasses; buckwheat; potted and bedding plants; beet seeds } \\
\text { (excluding sugar beet seeds); seeds of forage plants and flower } \\
\text { seeds; forage kale and similar forage products; production of cut } \\
\text { flowers) }\end{array}$ & 119 & -0.26 \\
\hline & Plant propagation & 130 & -0.24 \\
\hline & $\begin{array}{l}\text { Packaging activities (bottling of liquids; packaging of solids; } \\
\text { security packaging of pharmaceutical preparations; labelling, } \\
\text { stamping and imprinting; parcel-packing and gift-wrapping) }\end{array}$ & 8292 & -0.03 \\
\hline & Manufacture of fasteners and screw machine products & 2594 & -0.14 \\
\hline & Construction of residential and non-residential buildings & 4120 & -0.15 \\
\hline & $\begin{array}{l}\text { Manufacture of machinery for textile, apparel and leather } \\
\text { production }\end{array}$ & 2894 & 0.06 \\
\hline & General medical practice activities & 8621 & -0.58 \\
\hline & Activities of holding companies & 6420 & 0.11 \\
\hline
\end{tabular}

See next page for the rest of the table. 


\begin{tabular}{|c|c|c|c|}
\hline & Industry & $\begin{array}{l}\text { Industry } \\
\text { Code }\end{array}$ & $\begin{array}{l}\text { Perceived } \\
\text { immorality }\end{array}$ \\
\hline \multirow{23}{*}{ Other Industries } & Retail sale of electrical household appliances in specialised stores & 4754 & -0.19 \\
\hline & Wholesale trade of motor vehicle parts and accessories & 4531 & -0.01 \\
\hline & Wholesale of flowers and plants & 4622 & -0.24 \\
\hline & Dispensing chemist in specialised stores & 4773 & -0.19 \\
\hline & Administration of financial markets & 6611 & 0.10 \\
\hline & $\begin{array}{l}\text { Manufacture of other food products (soups and broths; artificial } \\
\text { honey and caramel; perishable prepared foods; food supplements; } \\
\text { yeast; extracts and juices; non-dairy milk and cheese substitutes; } \\
\text { egg products; artificial concentrates) }\end{array}$ & 1089 & -0.16 \\
\hline & $\begin{array}{l}\text { Other personal service activities (astrological and spiritualists' } \\
\text { activities; social activities; pet care services; genealogical } \\
\text { organisations; tattooing and piercing studios; shoe shiners; } \\
\text { porters; valet car parkers; concession operation of coin-operated } \\
\text { personal service machines) }\end{array}$ & 9609 & -0.18 \\
\hline & Manufacture of computers and peripheral equipment & 2620 & -0.07 \\
\hline & Joinery installation & 4332 & -0.19 \\
\hline & Wholesale of beverages & 4634 & -0.08 \\
\hline & Camping grounds, recreational vehicle parks and trailer parks & 5530 & -0.28 \\
\hline & Manufacture of optical instruments and photographic equipment & 2670 & -0.21 \\
\hline & Renting and leasing of cars and light motor vehicles & 7711 & -0.04 \\
\hline & $\begin{array}{l}\text { Wholesale of other machinery and equipment (transport } \\
\text { equipment except motor vehicles; production-line robots; wires } \\
\text { and switches; other electrical material; machinery for use in trade, } \\
\text { navigation and industry [except mining, construction, civil } \\
\text { engineering and textile industry]; measuring instruments and } \\
\text { equipment) }\end{array}$ & 4669 & -0.10 \\
\hline & Non-specialised wholesale trade & 4690 & -0.09 \\
\hline & Mixed Farming & 150 & -0.17 \\
\hline & Manufacture of electric domestic appliances & 2751 & -0.07 \\
\hline & Life insurance & 6511 & 0.06 \\
\hline & $\begin{array}{l}\text { Manufacture and processing of other glass, including technical } \\
\text { glassware (laboratory, hygienic or pharmaceutical glassware; } \\
\text { clock or watch glasses, optical glass and optical elements not } \\
\text { optically worked; glassware used in imitation jewellery; glass } \\
\text { insulators and glass insulating fittings; glass envelopes for lamps; } \\
\text { glass figurines; glass paving blocks; glass in rods or tubes) }\end{array}$ & 2319 & -0.17 \\
\hline & Wholesale of pharmaceutical goods & 4646 & 0.01 \\
\hline & Taxi operation & 4932 & -0.14 \\
\hline & Child day-care activities & 8891 & -0.69 \\
\hline & $\begin{array}{l}\text { Manufacture of rusks and biscuits; manufacture of preserved } \\
\text { pastry goods and cakes }\end{array}$ & 1072 & -0.11 \\
\hline
\end{tabular}

Notes: Immoral (Moral) industries are the industries that the research assistants selected as the most immoral (moral) industries. Other industries are 40 randomly selected industries that have at least 50 observations in the Swiss Labor Force Survey. 


\section{Appendix C - Welfare measure}

In the model, accepting an immoral job has "moral costs," $\theta_{i} * I(j)$. According to Proposition 3, the types with the lowest moral concerns nevertheless benefit from an increase in immorality because the increase of the market wage exceeds the increase of these moral costs. In the analysis in Section 5, we focused on subjects' market incomes, thereby ignoring these costs. The market mechanism that we apply allows us to measure subjects' moral costs. In the following, we account for moral costs and reconsider whether the predictions of our model (Proposition 3 and 4) are in line with the data.

In the experimental labor markets, subjects submit reservation wages. The differences between reservation wages and induced costs measure individuals' moral costs (together with potential real effort costs, though the reservation wages in the neutral work condition suggest that these are minimal). The difference between the market wage and the reservation wage is then a subject's benefits from market participation. Based on this reasoning, we calculate the following welfare measure for each participant $i$ :

$$
\begin{aligned}
\text { welfare }_{i}= & \sum_{r=1}^{15} \mathbf{1}\left(\underline{w}_{1}(i, r)<w(i, r)\right) *\left(w(i, r)-\underline{w}_{1}(i, r)\right) \\
& +\sum_{r=1}^{15} \mathbf{1}\left(\underline{w}_{2}(i, r)<w(i, r)\right) *\left(w(i, r)-\underline{w}_{2}(i, r)\right)
\end{aligned}
$$

where $w(i, r)$ is the market wage in round $r$ in the market of individual $i, \underline{w}_{1}(i, r)$ is individual $i$ 's wage request for the doing a first job in round $r, \underline{w}_{2}(i, r)$ is individual $i$ 's wage request for

doing the second job in round $r$ and $\mathbf{1}\left(\underline{w}_{j}(i, r)<w(i, r)\right)$ measures whether individual $i$ is hired for job $j$ (first or second job) in round $r$.

Table C1, columns (1) and (2) presents evidence in support of Proposition 3: in the immoral work condition, the low-theta types have a CHF 7.05 higher welfare than the high-theta types ( $p=0.007$ ). In the neutral work condition, the difference between types is very small (and even in the opposite direction).

However, this welfare measure has two potential shortcomings:

i) In the uniform-price sealed-offer auction, workers have incentives to submit their true reservation wage for the first job (Smith et al., 1982). For the second job, however, participants can have incentives to overstate their wage request. As a 
result, the second wage requests should be interpreted as upper bounds of subjects' true reservation wages, and, as a result, the welfare measures should be interpreted as a lower bound of the "true" welfare.

ii) If some subjects do not understand the market mechanism, they might make errors in reporting their reservation wages.

We address this issue in Table C1, columns (3) - (6). First, we replicate the analysis for the welfare generated trough the first job only, for which elicitation is incentive compatible. That is, we look at $\sum_{r=1}^{15} \mathbf{1}\left(\underline{w}_{1}(i, r)<w(i, r)\right) *\left(w(i, r)-\underline{w}_{1}(i, r)\right)$. Table C1, columns (3) and (4) provide the estimates for this second welfare measure. We again find support for Proposition 3. In columns (5) and (6), we look at the welfare generated in the last five market periods only, that is, $\quad \sum_{r=11}^{15} \mathbf{1}\left(\underline{w}_{1}(i, r)<w(i, r)\right) *\left(w(i, r)-\underline{w}_{1}(i, r)\right)+\sum_{r=11}^{15} \mathbf{1}\left(\underline{w}_{2}(i, r)<w(i, r)\right) *$ $\left(w(i, r)-\underline{w}_{2}(i, r)\right)$. Subjects already participated in 10 market rounds, which gave them time to learn how the market works. We again find support for Proposition 3. (Given that the dependent variable only aggregates welfare from 5 periods, effect sizes are, if anything, bigger than in the other specifications.)

We also have a second welfare measure: subjects' self-report happiness, which we elicit after the final market period. We do not find a statistically significant difference in happiness between the types in both treatment conditions (see Table C1, columns (7) and (8)).

\section{Table C1: Relationship between $\theta^{\operatorname{Exp}}$ and welfare}

\begin{tabular}{|c|c|c|c|c|c|c|c|c|}
\hline \multirow[t]{2}{*}{$\begin{array}{l}\text { Dependent } \\
\text { variable: }\end{array}$} & \multicolumn{2}{|l|}{ Welfare } & \multicolumn{2}{|c|}{ Welfare, first job } & \multicolumn{2}{|c|}{$\begin{array}{l}\text { Welfare, last } 5 \\
\text { periods }\end{array}$} & \multicolumn{2}{|c|}{$\begin{array}{l}\text { Self-reported } \\
\text { happiness }\end{array}$} \\
\hline & $(1)$ & $(2)$ & (3) & $(4)$ & (5) & (6) & $(7)$ & $(8)$ \\
\hline Low-theta $\left(\theta_{L}^{E x p}\right)$ & $\begin{array}{l}-1.07 * * \\
(-2.42)\end{array}$ & $\begin{array}{l}-0.99 * \\
(-1.89)\end{array}$ & $\begin{array}{l}-1.07 * * \\
(-2.42)\end{array}$ & $\begin{array}{l}-0.99 * \\
(-1.89)\end{array}$ & $\begin{array}{l}-0.22 \\
(-1.45)\end{array}$ & $\begin{array}{l}-0.26 \\
(-1.63)\end{array}$ & $\begin{array}{l}0.64 \\
(1.03)\end{array}$ & $\begin{array}{l}0.43 \\
(0.60)\end{array}$ \\
\hline $\begin{array}{l}\text { Immoral work } \\
\text { (IW) }\end{array}$ & $\begin{array}{l}8.83 * * * \\
(9.93)\end{array}$ & & $\begin{array}{l}7.93 * * * \\
(8.77)\end{array}$ & & $\begin{array}{l}3.02 * * * \\
(7.80)\end{array}$ & & $\begin{array}{l}-0.07 \\
(-0.25)\end{array}$ & \\
\hline$\theta_{L}^{E x p} * \mathbf{I W}$ & $\begin{array}{l}8.12 * * * \\
(3.22)\end{array}$ & $\begin{array}{l}9.92 * * * \\
(3.57)\end{array}$ & $\begin{array}{l}8.60 * * * \\
(3.45)\end{array}$ & $\begin{array}{l}9.82 * * * \\
(3.56)\end{array}$ & $\begin{array}{l}3.04 * * * \\
(3.14)\end{array}$ & $\begin{array}{l}3.77 * * * \\
(3.79)\end{array}$ & $\begin{array}{l}-0.48 \\
(-0.64)\end{array}$ & $\begin{array}{l}-0.20 \\
(-0.22)\end{array}$ \\
\hline $\mathbf{N}$ & 240 & 240 & 240 & 240 & 240 & 240 & 240 & 240 \\
\hline $\mathbf{R}^{2}$ & 0.134 & 0.235 & 0.151 & 0.264 & 0.136 & 0.276 & 0.006 & 0.113 \\
\hline $\begin{array}{l}\text { p-value: } \theta_{L}^{E x p} \\
+\theta_{L}^{E x p} *_{*} I W=0\end{array}$ & 0.007 & 0.002 & 0.004 & 0.002 & 0.005 & 0.001 & 0.719 & 0.670 \\
\hline Market FE & No & Yes & No & Yes & No & Yes & No & Yes \\
\hline
\end{tabular}

Notes: Coefficient estimates of linear regression models. Independent variables: Low-theta in $\{0,1\}$, Immoral work in $\{0,1\}$. Standard errors clustered at market level; t-statistics in parentheses; $*_{-} p<0.1 ; *_{-}-p<0.05 ; *^{* *}-p<$ 0.01 . 
According to Proposition 4, the least moral types benefit from the presence of more moral types in immoral labor markets. Table C2 replicates the analysis from Section 5 for all welfare measures. We find support for Proposition 4. However, there is no effect of the typecomposition of the market on self-reported happiness.

Table C2: Relationship between $\theta^{\operatorname{Exp}}$ and welfare, depending on the behavior of other market participants

\begin{tabular}{|c|c|c|c|c|}
\hline Dependent variable: & Welfare & $\begin{array}{l}\text { Welfare, } \\
\text { first job }\end{array}$ & $\begin{array}{l}\text { Welfare, } \\
\text { last } 5 \\
\text { periods } \\
\end{array}$ & $\begin{array}{l}\text { Self-reported } \\
\text { happiness }\end{array}$ \\
\hline Low-theta $\left(\theta_{L}^{E x p}\right)$ & $\begin{array}{l}-1.455 \\
(-0.39)\end{array}$ & $\begin{array}{l}-1.381 \\
(-0.37)\end{array}$ & $\begin{array}{l}-0.243 \\
(-0.15)\end{array}$ & $\begin{array}{l}-0.383 \\
(-1.16)\end{array}$ \\
\hline Many $\theta_{H}$ types & $\begin{array}{l}0.480 \\
(0.27)\end{array}$ & $\begin{array}{l}-0.987 \\
(-0.55)\end{array}$ & $\begin{array}{l}-0.011 \\
(-0.01)\end{array}$ & $\begin{array}{l}-0.221 \\
(-0.58)\end{array}$ \\
\hline $\begin{array}{l}\theta_{L}^{E x p} * \operatorname{Many} \theta_{H} \\
\text { types }\end{array}$ & $\begin{array}{l}13.270 * * * \\
(2.85)\end{array}$ & $\begin{array}{l}14.082 * * * \\
(3.00)\end{array}$ & $\begin{array}{l}4.792 * * \\
(2.34)\end{array}$ & $\begin{array}{l}0.868 \\
(1.58)\end{array}$ \\
\hline Constant & $\begin{array}{l}13.993 * * * \\
(10.09)\end{array}$ & $\begin{array}{l}3.919 * * * \\
(2.81)\end{array}$ & $\begin{array}{l}-5.484 * * * \\
(-10.12)\end{array}$ & $\begin{array}{l}4.736 * * * \\
(16.66)\end{array}$ \\
\hline $\mathbf{N}$ & 168 & 168 & 168 & 168 \\
\hline $\mathbf{R}^{2}$ & 0.072 & 0.090 & 0.077 & 0.007 \\
\hline $\begin{array}{l}\text { p-value: Many } \theta_{\mathrm{H}} \\
\text { types }+\boldsymbol{\theta}_{L}^{E x p} * \text { Many } \\
\theta_{\mathrm{H}} \text { types }=0\end{array}$ & 0.0068 & 0.0086 & 0.0221 & 0.2969 \\
\hline
\end{tabular}

Notes: Coefficient estimates of linear regression models. Sample incudes only subjects from the immoral work condition. Low-theta in $\{0,1\}$, Many $\theta_{H}$ types: $0=$ number of (other) low-theta type workers is lower than 2, $1=$ number of (other) low-theta type workers is 2 or more. Standard errors clustered at market level; $t$-statistics in parentheses; * $-p<0.1 ; * *-p<0.05$; *** $-p<0.01$. 


\section{Appendix D - A simple model of heterogeneous moral concern in labor markets}

In this section, we introduce a simple stylized model of labor markets with varying degrees of perceived job immorality and heterogeneity in concern for moral behavior among workers.

We examine a single labor market for a job, $j \in J$, which might involve doing immoral work. Firms decide whether to hire a worker to do $j$ at the market wage, $w$, and workers decide whether to accept work $j$ for the market wage. Workers differ in their concerns for morality. We investigate how the equilibrium wage and selection in this labor market change with the immorality of $j$. Our framework is a simplification of the theoretical literature on compensating wage differentials (see, e.g., Rosen, 1986). ${ }^{43}$ We do not seek to expand this literature, but rather to apply it to a context in which the relevant job dimension is immorality.

The immorality of $j$ is measured by a function $I: J \rightarrow[0, \infty)$, where $I\left(j^{\prime}\right)>I(j)$ means that job $j^{\prime}$ is more immoral than job $j$, and $I(j)=0$ means that $j$ involves no immoral acts. The set of immoral jobs is $J^{I M}=\{j \in J: I(j)>0\}$.

Labor demand is represented by an interval of firms, $k \in[0,1]$. Firms' behavior is given by the labor demand function, $D: \mathbb{R} \times J \rightarrow[0,1]$, with $\lim _{w \rightarrow \infty} D(w, j)=0, D(w, j)=1$ for $w \leq 0, D$ continuous in $w$ and $D$ strictly decreasing in $w$ on $[0, \infty)$. In addition, we assume that an increase in the immorality of the job does not decrease the profitability of employing labor, that is, $I\left(j^{\prime}\right)>I(j)$ implies $D\left(w, j^{\prime}\right) \geq D(w, j)$ for all $w .^{44}$

Labor supply consists of an interval of workers, $i \in[0,1]$. Each worker has reservation utility $\underline{u} \geq 0$, and the utility of accepting job $j$ for a worker of type $i$ is given by: ${ }^{45}$

$$
u_{i}^{a c c e p t}(j, w)=w-c-\theta_{i} * I(j)
$$

\footnotetext{
${ }^{43}$ Unlike most models of compensating wage differentials, we do not have multiple labor markets, rather one and a fixed outside option. In our laboratory experiment, we also assign subjects to one labor market. This abstraction simplifies both the theory and the experiment. However, we show in Appendix E that the model allows for an interpretation with two jobs, an immoral job and a neutral job. Our results also apply to such a context.

${ }^{44}$ In our experiment, we vary the immorality of the job, but fix labor demand, that is, $D\left(w, j^{\prime}\right)=D(w, j)$ for all $w$ and all $j, j^{\prime} \in J$. If an increase in immorality were to decrease profitability, there would be no incentives for firms to operate in immoral industries. Heidhues, Kőszegi and Murooka (2017) provide a basis for why deceptively marketed socially harmful products may be more profitable in the presence of naïve consumers. In Appendix E, we provide a behavioral foundation for the labor demand.

${ }^{45}$ Models about "mission-oriented" employees commonly assume very similar additive utility functions (e.g. Cassar and Meier, 2018), with the main difference that $-I(j) * \theta_{i}$ is replaced by a positive term, the "meaningfulness of work" multiplied by how much the individual cares about meaning.
} 
where $c \geq 0$ is the worker's cost of effort, which is independent of $j$. The parameter $\theta_{i} \geq 0$ measures the worker's aversion to immoral work and is distributed according to a cumulative density function $F \in \mathcal{F}_{\theta}$. The set $\mathcal{F}_{\theta}$ consists of all density functions $F$ that are continuous, strictly increasing on $[0, \infty)$, and with $F(0)=0$, meaning that no worker likes immoral work. ${ }^{46}$ The indirect utility of a worker of type $i$ is then given by $v_{i}(j, w)=\max \left\{\underline{u}, u_{i}^{a c c e p t}(j, w)\right\}$. Workers' behavior determines the labor supply, $S: \mathbb{R} \times J \rightarrow[0,1]$. If $j \in J^{I M}$, every worker with $\theta_{i} \leq \frac{w-\underline{u}-c}{I(j)}$ accepts the job. Labor supply is therefore $S(w, j)=F\left(\frac{w-\underline{u}-c}{I(j)}\right) .^{47}$

We next consider the equilibrium properties of this type of market. The equilibrium wage, $w^{*}(j)$, is implicitly defined by $S\left(w^{*}(j), j\right)-D\left(w^{*}(j), j\right)=0 .{ }^{48}$ The following Lemma states that for every $j \in J, w^{*}(j)$ exists and is unique.

Lemma. For all $j \in J^{I M}, w^{*}(j)$ exists, is unique and is in $(\underline{u}+c, \infty)$. For all $j \in J \backslash J^{I M}$, $w^{*}(j)=\underline{u}+c$.

Proof. Suppose $j \in J^{I M}$. Existence: Define $f(w, j)=S(w, j)-D(w, j)$. Note that $f(\underline{u}+c, j)=$ $0-(+)<0, \lim _{w \rightarrow \infty} f(w, j)=1-0=1$ and $f(w, j)$ is continuous in $w$. By the intermediate value theorem there exists $w^{*}(j) \in(\underline{u}+c, \infty)$ such that $f\left(w^{*}(j), j\right)=0$.

Uniqueness: Follows from $f(w, j)$ being strictly increasing in $w$ on $[0, \infty)$. Suppose $j \in J \backslash J^{I M}$. Then, $S(w, j)=\left\{\begin{array}{c}0, w<\underline{u}+c \\ {[0,1], w=\underline{u}+c \text {. Note that for any } w<\underline{u}+c \text {, we have }} \\ 1, w>\underline{u}+c\end{array}\right.$ $D(w, j)>0$ but $S(w, j)=0$, and for any $w>\underline{u}+c$ we have $D(w, j)<1$, but $S(w, j)=1$. For $w=\underline{u}+c, S(w, j)=[0,1]$ and $D(w, j) \in[0,1]$, so $D(w, j) \in S(w, j)$.

In the following, we derive four properties of labor markets with immoral jobs. While straightforward, we use these results to make predictions for our empirical work. In particular, the first two propositions derive the primary hypotheses that we test across all of our analysis.

\footnotetext{
${ }^{46}$ Note that $F(0)=0$ implies that no worker likes to do immoral jobs.

${ }^{47}$ The assumptions on $F$ (together with the properties of a cdf) imply that $S$ is continuous and strictly increasing in $w$ on $[\underline{u}+c, \infty), \lim _{w \rightarrow \infty} S(w, j)=1$, and $S(w, j)=0$ for all $w \leq \underline{u}+c$.

${ }^{48}$ Note that for $j \in J \backslash J^{I M}, S$ is a correspondence. For this case, $w^{*}(\bar{j})$ is defined by $D\left(w^{*}(j), j\right) \in S\left(w^{*}(j), j\right)$. Moreover, $w^{*}(j)$ depends on $F$. When necessary (Corollary, Proposition 4) we will make this explicit by writing $w^{*}(j, F)$ instead of $w^{*}(j)$.
} 
Proposition 1 shows that there is an immorality premium for immoral jobs: an increase in the immorality of a job decreases supply and therefore increases the equilibrium wage.

Proposition 1. (Immorality premium) For all $j, j^{\prime} \in J$ with $I(j)<I\left(j^{\prime}\right), w^{*}(j)<w^{*}\left(j^{\prime}\right)$.

Proof. $w^{*}(j)<w^{*}\left(j^{\prime}\right)$ : Suppose $I(j)=0$. Then, $w^{*}(j)=\underline{u}+c$ and $w^{*}\left(j^{\prime}\right)>\underline{u}+c$ (see Lemma). Suppose $I(j)>0$. Suppose that $w^{*}(j) \geq w^{*}\left(j^{\prime}\right)$. Then $S\left(w^{*}(j), j\right)>S\left(w^{*}\left(j^{\prime}\right), j^{\prime}\right)$ and $D\left(w^{*}(j), j\right) \leq D\left(w^{*}\left(j^{\prime}\right), j\right)$ because $F$ and $-D$ are strictly increasing in $w$ on $[0, \infty), \mathrm{I}(j)<I\left(j^{\prime}\right)$ and therefore $D\left(w, j^{\prime}\right) \geq D(w, j)$ for all $w$. So $S\left(w^{*}(j), j\right)-S\left(w^{*}\left(j^{\prime}\right), j^{\prime}\right)+D\left(w^{*}\left(j^{\prime}\right), j^{\prime}\right)-$ $D\left(w^{*}(j), j\right)>0$, a contradiction to the definition of $w^{*}(j)$ and $w^{*}\left(j^{\prime}\right)$.

The following Corollary further shows that this wage premium will be insignificant if workers do not sufficiently care about morality. ${ }^{49}$

Corollary. For all $j, j^{\prime} \in J$ with $I(j)<I\left(j^{\prime}\right)$ and $\varepsilon>0$, there exists $G \in \mathcal{F}_{\theta}$ such that $w^{*}\left(j^{\prime}, G\right)-w^{*}(j, G) \leq \varepsilon$.

Proof. Suppose that there exists a $G \in \mathcal{F}_{\theta}$ such that

$$
G\left(\frac{\varepsilon}{I\left(j^{\prime}\right)}\right)=D\left(\underline{\mathrm{u}}+\mathrm{c}+\varepsilon, j^{\prime}\right)
$$

Then, $w^{*}\left(j^{\prime}, G\right)=\underline{u}+c+\varepsilon$. The Lemma and Proposition 1 then imply that $w^{*}(j, G) \in[\underline{u}+$ $\mathrm{c}, \underline{\mathrm{u}}+\mathrm{c}+\varepsilon)$, and, as a result, $w^{*}\left(j^{\prime}, G\right)-w^{*}(j, G) \leq \varepsilon$.

To proof that such a $G \in \mathcal{F}_{\theta}$ exist, take any $H \in \mathcal{F}_{\theta}$ and construct $G$ as follows:

$$
G(\mathrm{x})=\left\{\begin{array}{cc}
0 & \text { if } \mathrm{x}<0 \\
x \frac{I\left(j^{\prime}\right)}{\varepsilon} D\left(\underline{\mathrm{u}}+\mathrm{c}+\varepsilon, j^{\prime}\right) & \text { if } x \in\left[0, \frac{\varepsilon}{I\left(j^{\prime}\right)}\right] \\
D\left(\underline{\mathrm{u}}+\mathrm{c}+\varepsilon, j^{\prime}\right)+\left(1-D\left(\underline{\mathrm{u}}+\mathrm{c}+\varepsilon, j^{\prime}\right)\right) H\left(x-\frac{\varepsilon}{I\left(j^{\prime}\right)}\right) & \text { if } \mathrm{x}>\frac{\varepsilon}{I\left(j^{\prime}\right)}
\end{array}\right.
$$

The assumptions on $D$ imply that $D\left(\underline{\mathrm{u}}+\mathrm{c}+\varepsilon, \mathrm{j}^{\prime}\right) \in(0,1)$. Note that $G$ is continuous, strictly increasing on $[0, \infty)$, and with $G(0)=0$. Therefore $G \in \mathcal{F}_{\theta}$.

\footnotetext{
${ }^{49}$ Becker (1957) made a very similar point in his analysis of discrimination: discrimination will only affect wages if there is sufficiently large share of discriminating employers.
} 
Formally, the Corollary shows that there are distributions of moral types such that the wage differentials are arbitrary small.

Second, the types that care least about the immorality of a job $\left(\theta_{i} \leq \frac{w^{*}(j)-\underline{u}-c}{I(j)}\right)$, sort into accepting immoral jobs, while those more concerned with morality $\left(\theta_{i}>\frac{w^{*}(j)-\underline{u}-c}{I(j)}\right)$, refuse to do the job for the equilibrium wage. ${ }^{50}$ This is formally shown in Proposition 2.

Proposition 2. (Sorting) For all $j \in J^{I M}$, worker $i$ is hired iff $\theta_{i} \leq \frac{w^{*}(j)-\underline{u}-c}{I(j)} \equiv \underline{\theta}(j)>0$.

Proof. A worker accepts job $j$ iff $u_{i}^{a c c e p t}=w^{*}(j)-c-\theta_{i} * I(j) \geq \underline{u} \Leftrightarrow \theta_{i} \leq \frac{w^{*}(j)-c-\underline{u}}{I(j)}$. $\underline{\theta}(j)>0$ : Follows from $w^{*}(j)>\underline{u}+c$ (see Lemma).

Proposition 2 is critical to the notion that immorality wage premiums are driven by those who find immoral work most distasteful opting out of such jobs. This important relationship has, to our knowledge, not been previously empirically tested.

Our next two propositions are less central, but nevertheless provide some useful and testable insights into behavior in immoral labor markets. Proposition 3 shows that the most immoral types profit from an increase in the immorality of work.

Proposition 3. For all $j, j^{\prime} \in J$ with $I(j)<I\left(j^{\prime}\right)$, there exists $\tilde{\theta}\left(j, j^{\prime}\right)>0$ such that $v_{i}\left(j^{\prime}, w^{*}\left(j^{\prime}\right)\right)>v_{i}\left(j, w^{*}(j)\right)$ iff $\theta_{i}<\tilde{\theta}\left(j, j^{\prime}\right)$.

Proof. Suppose $I(j)=0$. Then $v_{i}\left(j, w^{*}(j)\right)=v_{i}(j, \underline{u}+c)=\underline{u}$ (see Lemma). Note that $u_{i}^{a c c e p t}\left(j^{\prime}, w^{*}\left(j^{\prime}\right)\right)>\underline{u}$ iff $\theta_{i}<\frac{w^{*}\left(j^{\prime}\right)-\underline{u}-c}{I\left(j^{\prime}\right)}=\underline{\theta}\left(j^{\prime}\right)$, so $v_{i}\left(j^{\prime}, w^{*}\left(j^{\prime}\right)\right)=u_{i}^{a c c e p t}\left(j^{\prime}, w^{*}\left(j^{\prime}\right)\right)>$ $\underline{u}=v_{i}\left(j, w^{*}(j)\right)$ iff $\theta_{i}<\underline{\theta}\left(j^{\prime}\right) \equiv \tilde{\theta}\left(j, j^{\prime}\right)$. Note that $\tilde{\theta}\left(j, j^{\prime}\right)>0$ by Proposition 2.

Suppose $I(j)>0$. Note that $v_{i}\left(j^{\prime}, w^{*}\left(j^{\prime}\right)\right)>v_{i}\left(j, w^{*}(j)\right)=\max \left\{u_{i}^{a c c e p t}\left(j, w^{*}(j)\right), \underline{u}\right\}$ if and only if:

i) $\quad u_{i}^{a c c e p t}\left(j^{\prime}, w^{*}\left(j^{\prime}\right)\right)>u_{i}^{a c c e p t}\left(j, w^{*}(j)\right)$

ii) $\quad u_{i}^{a c c e p t}\left(j^{\prime}, w^{*}\left(j^{\prime}\right)\right)>\underline{u}$

\footnotetext{
${ }^{50}$ This perfect sorting according to $\theta$ is an extreme case. Heterogeneity in the costs of effort, reservation utility or productivity implies partial sorting according to $\theta$ (see Garen (1988) and Hwang, Reed and Hubbard (1992) for related examples). We incorporate only one dimension of heterogeneity in the model for simplicity.
} 
Inequality i) holds iff $\theta_{i}<\frac{w^{*}\left(j^{\prime}\right)-w^{*}(j)}{I\left(j^{\prime}\right)-I(j)}$ and inequality ii) holds iff $\theta_{i}<\underline{\theta}\left(j^{\prime}\right)$. Therefore, we have $\tilde{\theta}\left(j, j^{\prime}\right)=\min \left\{\frac{w^{*}\left(j^{\prime}\right)-w^{*}(j)}{I\left(j^{\prime}\right)-I(j)}, \underline{\theta}\left(j^{\prime}\right)\right\}$. Note that $\tilde{\theta}\left(j, j^{\prime}\right)>0 \quad$ (see Proposition 1 and Proposition 2).

More precisely, there are always some types who are sufficiently unconcerned with morality who are hired in a market for immoral work and are overcompensated by the immorality premium.

Finally, Proposition 4 shows that moral behavior (refusing to do the immoral job) can have positive externalities for the most immoral types. If the distribution of types shifts toward more concern for morality - in the sense of stochastic dominance - then the supply at any given wage decreases, thereby increasing the equilibrium wage and the utility of those least concerned with morality. For instance, any completely immoral types (i.e., $\theta_{i}=0$ ) will always benefit from a higher wage produced by increased moral concerns.

Proposition 4. For all $j \in J^{I M}$ and $F, G \in \mathcal{F}_{\theta}$ with $F(x)<G(x)$ for all $x>0$, there exists $\hat{\theta}(j, F)>0$ such that $v_{i}\left(j, w^{*}(j, F)\right)>v_{i}\left(j, w^{*}(j, G)\right)$ iff $\theta_{i}<\hat{\theta}(j, F)$.

Proof. First, we will proof that $w^{*}(j, G) \leq w^{*}(j, F)$. Suppose not, then $w^{*}(j, G)>w^{*}(j, F)$. But then $S\left(w^{*}(j, G), j, G\right)>S\left(w^{*}(j, F), j, F\right)$ and $D\left(w^{*}(j, G), j\right)<D\left(w^{*}(j, F), j\right)$ because $F, G$ and $-D$ are strictly increasing in $w$ on $[0, \infty)$, and $F$ first-order stochastically dominates $G$. But then $S\left(w^{*}(j, G), j, G\right)-S\left(w^{*}(j, F), j, F\right)+D\left(w^{*}(j, F), j\right)-D\left(w^{*}(j, G), j\right)>0$, a contradiction to the definition of $w^{*}$.

Second, define $\hat{\theta}(j, F)=\frac{w^{*}(j, F)-\underline{u}-c}{I(j)} \equiv \underline{\theta}(j, F)$, and note that under this definition $w^{*}(j, F)-$ $c-S(j) * \theta_{i}>\underline{u}$ iff $\theta_{i}<\hat{\theta}(j, F) .(\hat{\theta}(j, F)>0$ follows from Proposition 2.)

To finish the proof, note that $v_{i}\left(j, w^{*}(j, F)\right)=w^{*}(j, F)-c-I(j) * \theta_{i}>\max \left\{\underline{u}, w^{*}(j, G)-\right.$ $\left.c-I(j) * \theta_{i}\right\}=v_{i}\left(j, w^{*}(j, G)\right)$ for all $\theta_{i}<\hat{\theta}(j, F)$, and $v_{i}\left(j, w^{*}(j, F)\right)=\underline{u}=v_{i}\left(j, w^{*}(j, G)\right)$ for all $\theta_{i} \geq \hat{\theta}(j, F)$. 


\section{Appendix E - Alternative model interpretation}

The results in Section 3 and Appendix D also apply for a context with 2 jobs, a neutral job $j^{N}\left(I\left(j^{N}\right)=0\right)$ and an immoral job $j^{I M} \in J^{I M}\left(I\left(j^{I M}\right)>0\right)$. In the following, we show that, under some assumptions, labor demand and labor supply correspond to their counterparts in Appendix D. Therefore, all results derived in Appendix D also hold in the context with 2 jobs.

Labor supply: Labor supply consists of an interval of workers, $i \in[0,1]$. As in Appendix $\mathrm{D}$, we assume that the utility of accepting job $j$ of a worker of type $i$ is given by:

$$
u_{i}(j, w(j))=w(j)-c-\theta_{i} * I(j)
$$

where the parameter $\theta_{i}$ is distributed according to a distribution with cdf, $F \in \mathcal{F}_{\theta}$. The set $\mathcal{F}_{\theta}$ consists of all density functions $F$ that are continuous, strictly increasing on $[0, \infty)$, and with $F(0)=0$. Workers choose between the neutral and the immoral job. Note that every worker with $\theta_{i} \leq \frac{w\left(j^{I M}\right)-w\left(j^{N}\right)}{I\left(j^{I M}\right)}$ chooses the immoral job. The labor supply for the immoral job is then given by $S\left(w, j^{I M}\right)=F\left(\frac{w}{I\left(j^{I M}\right)}\right)$, where $w=w\left(j^{I M}\right)-w\left(j^{N}\right)$ is the immorality premium. Note that the labor supply for the immoral job corresponds to the labor supply in Appendix D with $\underline{u}=c=0$.

Labor demand: Labor demand consists of an interval of firms, $k \in[0,1]$. Each firm can either produce a neutral product or an immoral product. Firms that produce immoral products offer immoral jobs; firms that produce neutral products offer neutral jobs. Firms' profits are:

$$
\pi_{k}(j, w)=a_{k}(j)-w(j)
$$

where $a_{k}(j)$ measures firm $k$ 's earnings when producing good $j$. Firms choose to produce the immoral product if $\Delta a_{k}\left(j^{I M}\right)=a_{k}\left(j^{I M}\right)-a_{k}\left(j^{N}\right) \geq w$. This term, $\Delta a_{k}\left(j^{I M}\right)$, is distributed according to a distribution with $\operatorname{cdf} G_{j} I M$. An increase in immorality of the job does not decrease firms earnings, ${ }^{51}$ that is, i) $G_{j}(0)=0$ for all $j \in J^{I M}$, and ii) for all $j, j^{\prime} \in J^{I M}$ with $I\left(j^{\prime}\right)>I(j)$, $G_{j \prime}(x) \leq G_{j}(x)$ for all $x \in \mathbb{R}$. In addition, $G_{j} I M$ is continuous and strictly increasing on $[0, \infty)$. The labor demand for the immoral job is then given by $D\left(w, j^{I M}\right)=1-G_{j} I M(w)$. Note that $D$ is

\footnotetext{
${ }^{51}$ One interpretation is, for example, that $I(j)$ measures negative externalities in production. Avoiding these externalities is costly; decreasing the immorality therefore increases production costs (see also Rosen, 1986).
} 
continuous in $w$, strictly decreasing in $w$ on $[0, \infty)$, with $\lim _{w \rightarrow \infty} D\left(w, j^{I M}\right)=0$ and $D\left(w, j^{I M}\right)=1$ for $w \leq 0$. In addition, $I\left(j^{\prime}\right)>I(j)$ implies $D\left(w, j^{\prime}\right) \geq D(w, j)$ for all $w \in \mathbb{R}$. Note that the labor demand satisfies all assumptions made for the labor demand in Appendix D.

The equilibrium wage, $w^{*}\left(j^{I M}\right)$, is implicitly defined by $S\left(w^{*}\left(j^{I M}\right), j^{I M}\right)-D\left(w^{*}\left(j^{I M}\right), j^{I M}\right)=0 .{ }^{52}$ As both labor demand and labor supply satisfy all assumptions made in Appendix D, the Lemma, Corollary and Proposition 1 to 4 apply (with $\left.j \in J^{I M}\right)$. In particular, $w^{*}\left(j^{I M}\right)$ is strictly positive (Lemma), so there is an immorality premium, and this immorality premium is increasing in the immorality of $j^{I M}, I\left(j^{I M}\right)$ (Proposition 1). The immoral types sort into accepting the immoral jobs, while the moral types sort into accepting the neutral jobs (Proposition 2).

${ }^{52}$ Note that market clearance in the immoral job market implies market clearance in the neutral job market, $\left(1-S\left(w^{*}\left(j^{I M}\right), j^{I M}\right)\right)-\left(1-D\left(w^{*}\left(j^{I M}\right), j^{I M}\right)\right)=0$. 


\section{Appendix F - Instructions}

\section{F.1 Survey study with "clients"}

\section{F.1.1 Option choice with recommendation}

\section{Thank you for volunteering!}

Worldwide, malaria is one of the top killers of children under 5 years of age, causing the death of 1900 children each day, mostly in developing countries. ${ }^{1}$ This is equivalent to 7 jumbo jets full of children disappearing, every day. However, children infected with malaria do not have to die. If they receive antimalarial drugs, their chances for survival are good. Donating antimalarial drugs greatly increases the likelihood that infected children can be saved from death.

You can now influence the number of infected children that will receive antimalarial drugs by choosing one of ten options: A, B, C, D, E, F, G, H, I or J.

Each option influences the number of antimalarial drugs that are donated. Your choice will also determine your payment for participating. Your payment is always higher if you select an option that saves more children.

You have no additional information about these options, except for a recommendation that is attached to this page. This recommendation was written by your advisor-a participant in another study who has been paired with you and who had full information about the consequences of each option.

Please put a cross in the following table, under the option you would like to choose. The option you choose will be implemented.

\begin{tabular}{|c|c|c|c|c|c|c|c|c|c|}
\hline \multicolumn{10}{|c|}{ Options } \\
\hline$A$ & B & C & D & $E$ & $\mathrm{~F}$ & G & $\mathrm{H}$ & I & J \\
\hline .............. & .............. & .............. & ............... & ……....... & ............. & .............. & .............. & ............. & ............. \\
\hline
\end{tabular}

The recommendation from your advisor is:

\footnotetext{
${ }^{1}$ Source: Dutch Malaria Foundation, a charity organization that fights malaria.
} 


\section{F.1.2 Option choice without recommendation}

\section{Thank you for volunteering!}

Worldwide, malaria is one of the top killers of children under 5 years of age, causing the death of 1900 children each day, mostly in developing countries. ${ }^{2}$ This is equivalent to 7 jumbo jets full of children disappearing, every day. However, children infected with malaria do not have to die. If they receive antimalarial drugs, their chances for survival are good. Donating antimalarial drugs greatly increases the likelihood that infected children can be saved from death.

You can now influence the number of infected children that will receive antimalarial drugs by choosing one of ten options: A, B, C, D, E, F, G, H, I or J.

Each option influences the number of antimalarial drugs that are donated. Your choice will also determine your payment for participating. Your payment is always higher if you select an option that saves more children.

\section{You have no additional information about these options.}

Please put a cross in the following table, under the option you would like to choose. The option you choose will be implemented.

\begin{tabular}{|c|c|c|c|c|c|c|c|c|c|}
\hline \multicolumn{10}{|c|}{ Options } \\
\hline$A$ & B & $C$ & $D$ & $E$ & $F$ & G & $\mathrm{H}$ & 1 & $\mathrm{~J}$ \\
\hline .............. & ............ & ............. & ................... & ................. & ............. & ............. & ................... & ................. & ................... \\
\hline
\end{tabular}

\footnotetext{
${ }^{2}$ Source: Dutch Malaria Foundation, a charity organization that fights malaria.
} 


\section{F.1.3 Perceived industry/firm immorality}

How immoral do you think it is to work in each of the following industry in Switzerland?

\begin{tabular}{|c|c|c|c|c|c|}
\hline & $\begin{array}{c}\text { Very } \\
\text { immoral }\end{array}$ & $\begin{array}{l}\text { Quite } \\
\text { immoral }\end{array}$ & $\begin{array}{c}\text { Neither } \\
\text { immoral } \\
\text { nor moral }\end{array}$ & $\begin{array}{l}\text { Quite } \\
\text { moral }\end{array}$ & $\begin{array}{l}\text { Very } \\
\text { moral }\end{array}$ \\
\hline $\begin{array}{c}\text { Monetary intermediation (cantonal banks, } \\
\text { commercial banks, stock exchange banks, private } \\
\text { bankers...) }\end{array}$ & $\mathrm{O}$ & $\mathrm{O}$ & O & $\mathrm{O}$ & $\mathrm{O}$ \\
\hline Gambling and betting activities & $\mathrm{O}$ & O & O & $\mathrm{O}$ & $\mathrm{O}$ \\
\hline $\begin{array}{c}\text { Non-life insurance (accident insurance, health } \\
\text { insurance...) }\end{array}$ & $\mathrm{O}$ & $\mathrm{O}$ & $\mathrm{O}$ & $\mathrm{O}$ & $\mathrm{O}$ \\
\hline Manufacture of tobacco products & $\mathrm{O}$ & $\mathrm{O}$ & O & O & $\mathrm{O}$ \\
\hline Wholesale of perfume and cosmetics & $\mathrm{O}$ & $\mathrm{O}$ & O & $\mathrm{O}$ & $\mathrm{O}$ \\
\hline Manufacture of paper and paperboard & $\mathrm{O}$ & $\mathrm{O}$ & $\mathrm{O}$ & $\mathrm{O}$ & O \\
\hline Wholesale of tobacco products & $\mathrm{O}$ & $\mathrm{O}$ & O & O & $\mathrm{O}$ \\
\hline Manufacture of electronic components & $\mathrm{O}$ & $\mathrm{O}$ & O & O & O \\
\hline Manufacture of weapons and ammunition & $\mathrm{O}$ & O & $\mathrm{O}$ & $\mathrm{O}$ & $\mathrm{O}$ \\
\hline Maintenance and repair of motor vehicles & $\mathrm{O}$ & $\mathrm{O}$ & O & $\mathrm{O}$ & $\mathrm{O}$ \\
\hline Hotels and similar accommodation & $\mathrm{O}$ & $\mathrm{O}$ & O & $\mathrm{O}$ & O \\
\hline Construction of buildings & O & $\mathrm{O}$ & O & O & $\mathrm{O}$ \\
\hline General public administration activities & $\mathrm{O}$ & O & O & O & $\mathrm{O}$ \\
\hline Restaurants and mobile food service activities & $\mathrm{O}$ & O & O & $\mathrm{O}$ & O \\
\hline $\begin{array}{l}\text { Organization and operation of sport facilities for } \\
\text { indoor or outdoor sports events }\end{array}$ & O & O & O & $\mathrm{O}$ & O \\
\hline Credit granting & O & O & O & O & $\mathrm{O}$ \\
\hline Processing of tea and coffee & $\mathrm{O}$ & O & $\mathrm{O}$ & $\mathrm{O}$ & $\mathrm{O}$ \\
\hline Wholesale of clothing and footwear & O & O & O & $\mathrm{O}$ & O \\
\hline Wholesale of watches and jewellery & O & O & $\mathrm{O}$ & $\mathrm{O}$ & $\mathrm{O}$ \\
\hline Fitness facilities & 0 & O & O & $\mathrm{O}$ & O \\
\hline
\end{tabular}


How immoral do you think it is to work for one of the following organization?

\begin{tabular}{|c|c|c|c|c|c|c|}
\hline & $\begin{array}{c}\text { Very } \\
\text { immoral }\end{array}$ & $\begin{array}{l}\text { Quite } \\
\text { immoral }\end{array}$ & $\begin{array}{l}\text { Neither } \\
\text { immoral } \\
\text { nor moral }\end{array}$ & $\begin{array}{l}\text { Quite } \\
\text { moral }\end{array}$ & $\begin{array}{l}\text { Very } \\
\text { moral }\end{array}$ & $\begin{array}{c}\text { I don't know } \\
\text { this } \\
\text { organization }\end{array}$ \\
\hline Glencore & O & $\mathrm{O}$ & O & $\mathrm{O}$ & $\mathrm{O}$ & 0 \\
\hline Novartis & O & 0 & 0 & 0 & 0 & O \\
\hline Roche & $\mathrm{O}$ & $\mathrm{O}$ & O & $\mathrm{O}$ & $\mathrm{O}$ & $\mathrm{O}$ \\
\hline ABB & O & 0 & 0 & 0 & O & 0 \\
\hline UNICEF & O & $\mathrm{O}$ & 0 & O & 0 & O \\
\hline Adecco & 0 & $\mathrm{O}$ & 0 & 0 & 0 & 0 \\
\hline Migros & 0 & 0 & 0 & 0 & $\mathrm{O}$ & O \\
\hline Holcim & O & 0 & 0 & 0 & 0 & O \\
\hline Pro Juventute & $\mathrm{O}$ & $\mathrm{O}$ & $\mathrm{O}$ & $\mathrm{O}$ & $\mathrm{O}$ & $\mathrm{O}$ \\
\hline Credit Suisse & 0 & $\mathrm{O}$ & $\mathrm{O}$ & $\mathrm{O}$ & 0 & $\mathrm{O}$ \\
\hline Swisscom & O & $\mathrm{O}$ & $\mathrm{O}$ & $\mathrm{O}$ & $\mathrm{O}$ & $\mathrm{O}$ \\
\hline Swatch & $\mathrm{O}$ & $\mathrm{O}$ & O & $\mathrm{O}$ & $\mathrm{O}$ & $\mathrm{O}$ \\
\hline UBS & O & $\mathrm{O}$ & $\mathrm{O}$ & $\mathrm{O}$ & $\mathrm{O}$ & $\mathrm{O}$ \\
\hline Red Cross & $\mathrm{O}$ & $\mathrm{O}$ & $\mathrm{O}$ & $\mathrm{O}$ & $\mathrm{O}$ & $\mathrm{O}$ \\
\hline Marlboro & $\mathrm{O}$ & $\mathrm{O}$ & $\mathrm{O}$ & $\mathrm{O}$ & $\mathrm{O}$ & $\mathrm{O}$ \\
\hline Monsanto Co. & 0 & $\mathrm{O}$ & $\mathrm{O}$ & $\mathrm{O}$ & $\mathrm{O}$ & 0 \\
\hline Nestlé & $\mathrm{O}$ & $\mathrm{O}$ & $\mathrm{O}$ & $\mathrm{O}$ & $\mathrm{O}$ & $\mathrm{O}$ \\
\hline WWF & 0 & 0 & 0 & 0 & O & 0 \\
\hline Tamoil & O & $\mathrm{O}$ & O & O & $\mathrm{O}$ & $\mathrm{O}$ \\
\hline Ernst \& Young & O & 0 & 0 & 0 & 0 & 0 \\
\hline Pro natura & $\mathrm{O}$ & O & O & O & O & $\mathrm{O}$ \\
\hline $\begin{array}{l}\text { Winterthur } \\
\text { assurance }\end{array}$ & 0 & O & O & $\mathrm{O}$ & O & O \\
\hline Syngenta & $\mathrm{O}$ & O & O & O & O & O \\
\hline Firmenich & 0 & 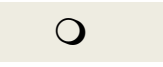 & O & O & 0 & O \\
\hline $\begin{array}{l}\text { Phillip Morris } \\
\text { International inc. }\end{array}$ & $\mathrm{O}$ & O & O & O & O & O \\
\hline Swiss Life & O & 0 & 0 & 0 & O & O \\
\hline
\end{tabular}




\section{F.2 Laboratory experiment}

\section{F.2.1 General Instructions}

\section{General instructions}

Thank you for participating. During this experiment, you will be asked to make several decisions that will impact the amount of money that you will earn today. Everyone who completes the experiment will earn 20 Swiss francs for doing so, in addition to the 10 Swiss francs you receive for completing the online survey. Each participant will also earn an additional amount determined by the decisions made in the experiment. It is thus very important that you read the instructions carefully, and that you make your decisions with care. If you have any questions, please raise your hand and wait for a staff member to come and help you.

Communication with the other participants is strictly forbidden during the study. The use of your mobile phone is also forbidden. Violation of the rules will lead to exclusion from the study and loss of all of the associated payments.

According to the scientific standards for lab experiments at the Decision Science Laboratory, we are not allowed to lie to you or deceive you at any point in time. Also note that all the information gathered during this experiment is stored in a strictly anonymous manner. The experimenters will not link your behavior to your identity.

During the study, your income will first be calculated in points, which will be converted to Swiss francs at the end of the study at a rate of:

$$
20 \text { points }=1 \text { Swiss franc }
$$

The study lasts about two and a half hours and is divided in three parts. In Part I you will make decisions in a choice situation. In Part II you will participate in a Market for 15 rounds. In Part III you will make additional decisions that are unrelated to Part II.

You can earn money in all three parts. You will receive your total payment privately and in cash at the end of the experiment.

Parts I and III are completely independent from Part II. In other words, your choices in Parts I and III will not influence the procedures or outcomes of Part II.

You will now start with Part I. You find the Instructions for Part I on the next page. 


\section{Part I: Instructions}

For the first decision in Part I, some of you will be assigned the role of Participant A, and some of you will be assigned the role of Participant $B$.

The computer will randomly assign a number, 1, 2, 3, 4, 5 or 6 , to each Participant A. Each number has the same probability to be selected. Each Participant A then has to send a message to a Participant $\mathrm{B}$, claiming what number was assigned by the computer. Participant A may claim that the assigned number was either " 1, ," "2," " 3 ," " 4 ," " 5 " or " 6 ," regardless of the actual number assigned. Participant $\mathrm{B}$, who is not informed about the actual number assigned to Participant A, has to decide whether or not to follow the message sent by Participant A. The decision you make as Participant A is public. That is, every participant in today's session will see the decision of every other participant, along with his or her portrait, at the very end of the experiment.

All Participants A will first indicate what number they intend to send to Participant B for each of the 6 numbers the computer might assign. Later, the computer will randomly select an actual assigned number for each Participant A and only the message corresponding to that number will be sent to Participant B.

Participants' decisions in this part will determine their resulting payments, as described below. Their decisions will also determine the amount of a donation to UNICEF. With the money donated, UNICEF will buy antimalarial drugs to save infected children who will otherwise almost certainly die. The box, "Malaria, UNICEF and Antimalarial Drugs" on the next page, provides information about malaria, UNICEF and how antimalarial drugs can save infected children. 


\section{Malaria, UNICEF and Antimalarial Drugs}

\section{What is Malaria?}

Malaria is a disease transmitted by infected mosquitos. Their bite introduces parasites from the mosquito's saliva into a person's blood, where they mature and reproduce. The classic symptoms of malaria consist of bouts of fever and convulsions, chills and sweats, headaches, severe anemia, nausea and vomiting, leading to coma and death if left untreated. ${ }^{3}$ Worldwide, malaria is one of the top killers of children under 5 years of age, causing the death of 1900 children each day, mostly in developing countries. ${ }^{4}$ This is equivalent to 7 jumbo jets full of children disappearing, every day.

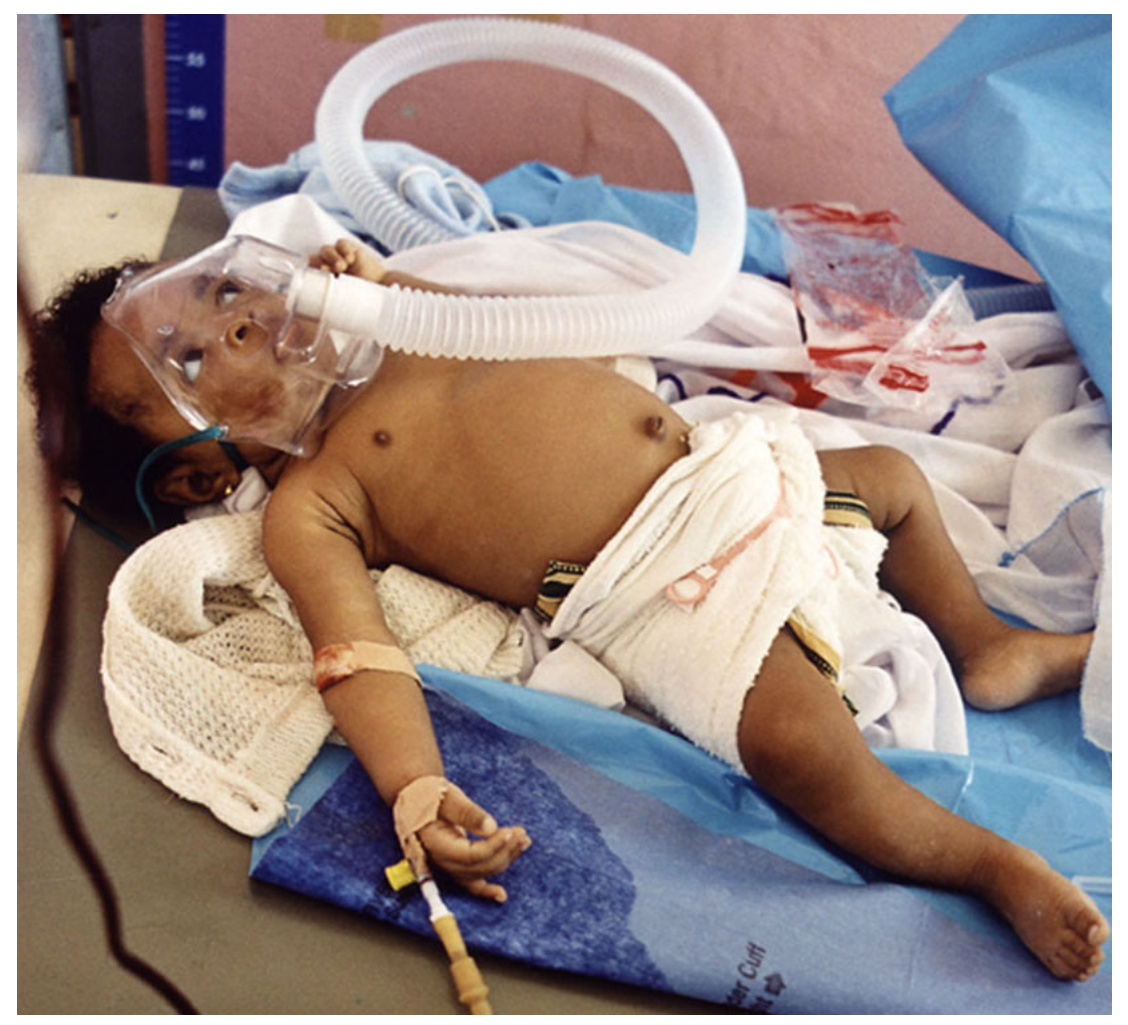

Child suffering from Malaria in a local hospital (Source: Nationales

Genomforschungsnetz).

\section{UNICEF and antimalarial drugs}

Children infected with malaria do not have to die. If they receive antimalarial drugs, their chances for survival are good. Donating antimalarial drugs greatly increases the likelihood that an infected child can be saved from death. The United Nations Children's Fund (UNICEF) is a United Nations program that provides humanitarian and developmental assistance to children and mothers in developing countries. UNICEF helps fight malaria by distributing antimalarial drugs in developing countries.

The determination of payments to participants and to UNICEF is explained further below.

First, let's describe the decisions Participants A and B have to make in more detail:

\footnotetext{
${ }^{3}$ Source: Malaria Consortium, a world leading non-profit organization in the prevention, control and treatment of malaria.

${ }^{4}$ Source: Dutch Malaria Foundation, a charity organization that fights malaria.
} 


\section{Decisions}

- For every possible number assigned by the computer, Participant A has to choose a message to send to Participant B, with a claim regarding what the number is. Participant A is free to claim any of the six possible numbers. Figure 1 illustrates how Participant A indicates which message to send for every possible assigned number.

\section{Figure 1:}

\begin{tabular}{|c|c|c|c|c|c|c|}
\hline If your assigned number is & 1 & 2 & 3 & 4 & 5 & 6 \\
\hline then your message to participant $\mathrm{B}$ is: & 1 & & & & \\
\hline
\end{tabular}

Depending on the actual number assigned to the pair, one message is then sent to Participant B.

- Participant B must then decide whether or not to follow the message sent by Participant A. Figure 2 illustrates Participant B's decision screen.

\section{Figure 2:}

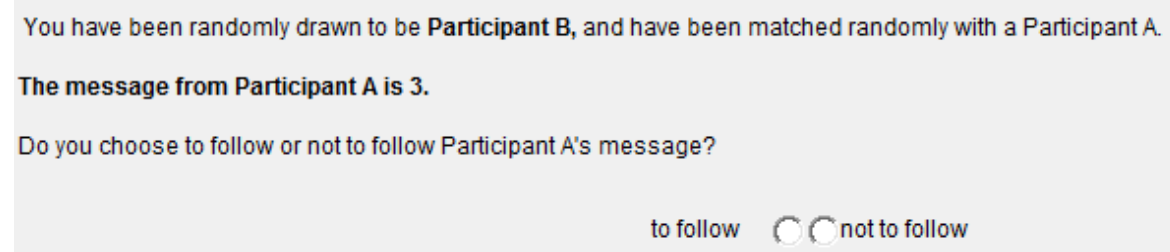

\section{$\underline{\text { Payments }}$}

- Payment for Participant A:

First, remember that, based on what Participant A enters on the screen shown in Figure 1 and the computer's random choice of an actual assigned number, only one message is actually sent. Participant A receives 100 points, plus 20 times the number sent in this message. Thus, regardless of the actual assigned number, Participant A receives 120 points if he sends a message claiming that the assigned number is " $1 ; " 140$ points if he sends a message claiming that the assigned number is " $2 ; " 160$ points if he sends a message claiming that the assigned number is " 3 ;" and so on, up to 220 points if he sends a message claiming that the assigned number is " $6 . "$

- Payment for Participant B: Participant B's payment depends on his decision whether to follow Participant A's message (and on Participant A's message).

- If Participant B does not follow the message from Participant A, then Participant B receives 30 points.

- If Participant B follows the message from Participant A and the message is the same as the actual number assigned to Participant A, then Participant B receives 100 points. 
- If Participant $B$ follows the message from Participant $A$ and the message is different from the actual number assigned to Participant A, then Participant B receives 0 points.

- Payment for UNICEF: We provide UNICEF with an initial amount that allows saving 5 infected children. However, the final number of children saved may be higher or lower than 5 . It depends on Participant B's decision (and on Participant A's message).

- If Participant $B$ does not follow the message from Participant A, then UNICEF receives money to buy antimalarial drugs to save $\mathbf{0}$ additional infected children.

- If Participant B follows the message from Participant A and the message is the same as the actual number assigned to Participant A, then UNICEF receives money to buy antimalarial drugs to save 1 additional infected child.

- If Participant $B$ follows the message from Participant A and the message is different from the actual number assigned to Participant A, then the amount of money UNICEF receives is reduced, and 1 less infected child is saved.

Figure 3 summarizes the consequences of the different payments that UNICEF and Participant B [in brackets] may receive.

Figure 3. Consequences of Participant A's and B's decisions for donation to UNICEF [and for reward for Participant B]

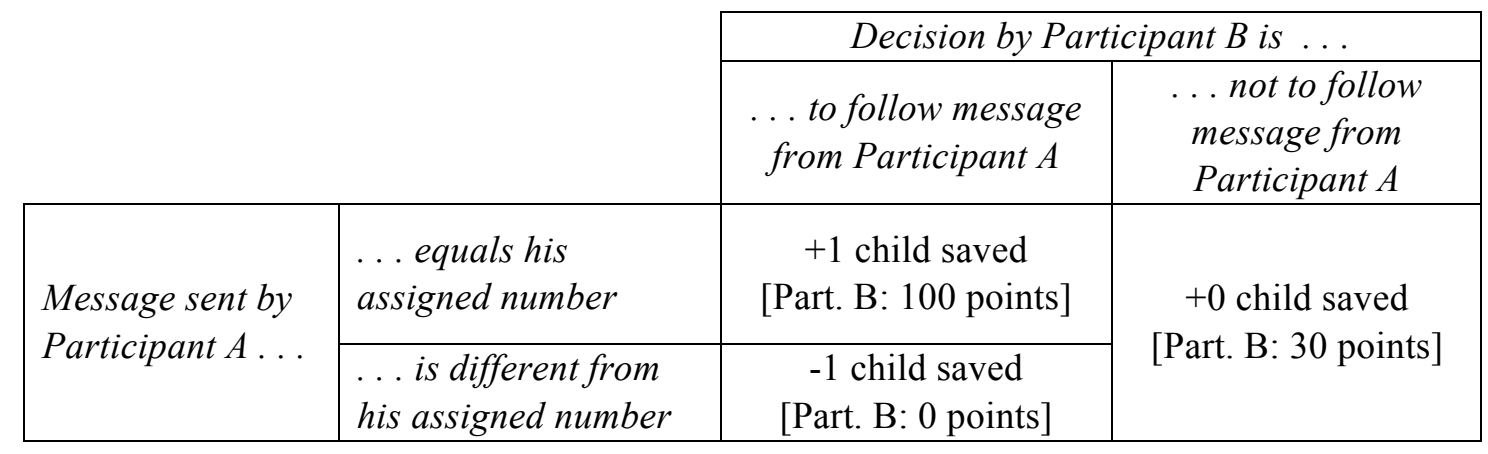

Display of your decisions and portraits:

The choices you make as Participant A will be shown to all other participants in the experiment, together with your portrait. Figure 4 below shows how the other participants will see your decisions and your portrait. In the same manner, you will see the choices made by all other participants and their respective portraits. This information will be displayed to all participants at the very end of the experiment. 
Figure 4:

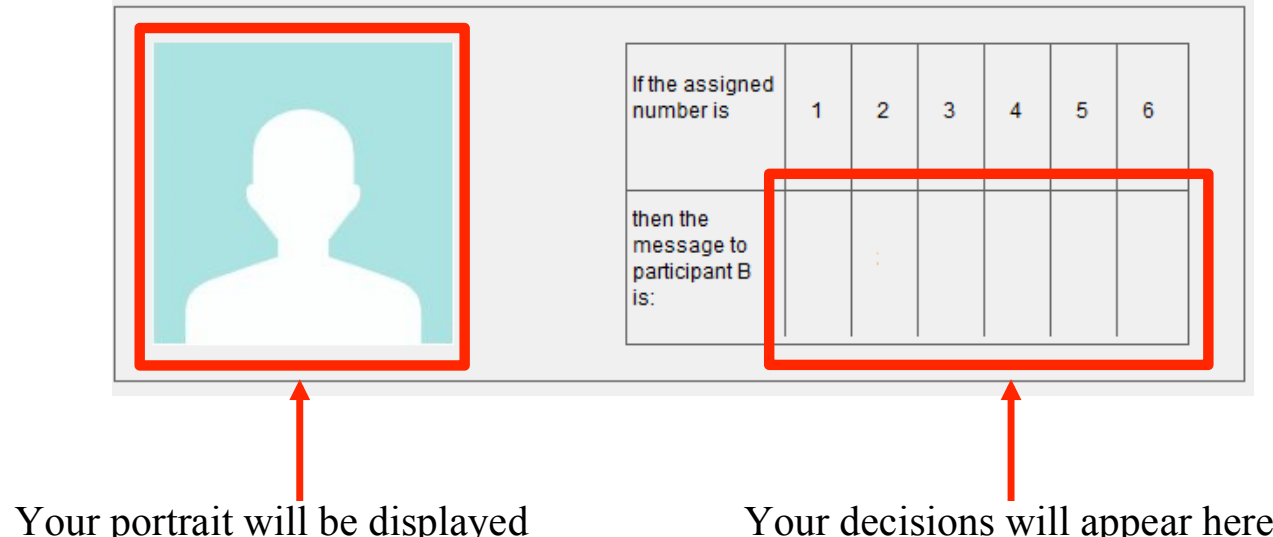

Role allocation:

All subjects in the lab will make a decision as Participant A. This will be the only decision you will make at this point.

At the end of the experiment, 5 subjects will be randomly selected to become Participant B. The 5 Participants B will be randomly matched with 5 of the remaining Participants A and will make an additional decision regarding whether to follow or not to follow the message received from Participant A.

To summarize, one of three scenarios will occur at the end of the experiment:

- You remain Participant A and you are not matched to one of the 5 randomly selected Participants B: the computer will not send your message to a Participant B.

- You remain Participant A and you are matched to one of the 5 Participants B: the computer will use your actual assigned number to determine which corresponding message to send to Participant B.

- Your role switches from Participant A to Participant B: the computer will match you with a Participant A and will show you this Participant A's message. You will then have to decide whether or not to follow it.

The Participants A (whose role was not switched to Participant B) will be paid according to their choice, independently of whether or not they are matched to one of the 5 Participants $B$. The 5 subjects who were initially Participants A and are then assigned the role of Participant B will be paid according to their decision as Participant B (and their matched Participant A's message).

Note that the 5 Participants A and the 5 Participants B who are matched at the end of the study will make choices that determine how many infected children actually receive an antimalarial drug from UNICEF.

After the subjects in the role of Participant B have made their decisions we will tell you your earnings. If you had the role of Participant A, we will also tell you whether or not your message was sent to a Participant B. Finally, the decisions of all participants as Participant A and their respective portrait will be shown. Note that your decisions as Participant A will be shown to all other participants along with your portrait, independently of your final role. Similarly, you will see all of the other participants' decisions as Participant A along with their respective portrait. 
Please click "OK" on the screen once you are done reading these instructions. If you have any questions, please raise your hand.

\section{F.2.3 Market instructions}

\section{Part II: Market Instructions}

\section{Please do not click the OK button on the screen until the experimenter asks you to do so.}

In Part II you will participate in 15 rounds of a market activity. Through the market, each participant has the possibility to be hired as an Advisor in exchange for a wage. As an Advisor, you will make a recommendation to another participant regarding a decision. The wage for those who are hired will be determined by the choices of participants in the market, as described below.

You can earn money based on the outcomes of each market round. At the end of the experiment, you will be paid the earnings you accumulate over the 15 rounds.

\section{What participants do in a market round:}

- The job of an Advisor involves writing a recommendation for a client of a firm. In each market round, you can be hired by firms to write up to two recommendations. Writing one recommendation is called one job, so you can provide up to two jobs in every round. We will provide more details on the jobs before starting the market.

- At the beginning of every market round, you can state, for each job, the lowest wage at which you would agree to do that job. Since you can do up to two jobs, you can enter two numbers. We call these two numbers your wage requests. Your wage requests can differ between the two jobs, but the second wage request has to be at least as high as the first wage request.

- You have a cost for each job that you provide. Specifically, performing one job means you incur a cost of $\mathbf{5 0}$ points. Performing a second job means you incur an additional cost of $\mathbf{1 1 0}$ points. Later in the instructions, we will describe how these costs are used to determine your earnings in a round.

- You can also decide not to participate in the market, meaning you are unwilling to do the job for any wage. In this case, your earnings will be 0 in a round. 
The following figure illustrates how to enter your wage requests on the screen:

Enter your wage request for the first job

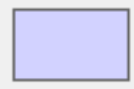

Enter your wage request for the second job

$\Gamma$ I do not participate in the market.

Before we give you more details about the job, let us explain how the market works.

\section{How the market works:}

The market consists of 6 workers (you and 5 other randomly selected participants) and 6 firms. In every market round, the workers submit wage requests, and firms submit wage offers. Then a market wage is calculated.

The firms are automated. That is, the computer will make and submit the firms' choices automatically.

The 6 workers in your market consist of 6 participants in the experiment. For the duration of Part II, you will be matched with the same 5 other participants as workers in a market. Throughout the 15 market rounds, you will see the portrait of every other worker in your market. This also means that other workers will see your portrait.

Each firm needs to hire one worker to produce a recommendation for one client, and the firms compete for hiring workers. For each firm, there is a highest wage offer that the firm is willing to pay to a worker for providing a recommendation. The highest wage offer differs for each firm, but stays constant across the market rounds. The computer automatically makes the firms' choices by submitting these highest wage offers.

Therefore, in a market round, there will be 6 firms that automatically submit how much they are willing to pay for a worker and 6 workers who can each submit up to 2 wage requests in order to compete for being hired. Note that each firm can only hire one worker, but each worker can be hired by up to two firms.

In every market round, after all workers submit their wage requests and firms submit their highest wage offers, a market wage is calculated. All wage requests that are lower than the market wage are accepted, meaning that these workers are hired. Every worker who is hired is paid the same market wage for each job. Since a worker can perform 0,1 or 2 jobs, a worker can receive 0,1 or 2 times the market wage. Note that if you are hired to do a job, the market wage you receive for that job will be at least as high as your wage request for that job. 


\section{The market wage:}

We will now explain to you exactly how the computer determines the market wage:

- The wage offers of the firms are ranked from high to low. This means that the highest wage offer has the $1^{\text {st }}$ rank, the second highest has the $2^{\text {nd }}$ rank, and so on.

- The wage requests that you and other workers in your market submit are ranked from low to high. The lowest wage has the $1^{\text {st }}$ rank, the second lowest has the $2^{\text {nd }}$ rank, and so on. If two or more wage requests are equal, the computer assigns ranks randomly. Subjects that do not participate in the market are excluded from the ranking.

- If the $1^{\text {st }}$ (the lowest) wage request is lower than the $1^{\text {st }}$ (the highest) wage offer, then the worker who submitted this wage request is hired to do this job. If the same is true for the $2^{\text {nd }}$ lowest wage request and $2^{\text {nd }}$ highest wage offer, then this worker is also hired, and so on. Let's call the last wage offer for which this holds (that is, for which the wage offer is higher than the wage request of the same rank) the "market wage candidate 1" and the first wage request for which this does not hold anymore (that is, for which the wage request is higher than the wage offer of the same rank) the "market wage candidate 2." The market wage is the lowest of these two market wage candidates. (If candidate 2 does not exist because every wage request has been accepted, candidate 1 is the market wage.)

This procedure guarantees that: 1) all wage requests that are lower than the market wage are accepted, and 2) for this market wage, the amount of jobs the workers want to do and the amount of jobs the firms want to be done are exactly the same.

Workers do not know the wage requests of other workers, nor do they know the firms' wage offers.

\section{Example:}

We will now go through an example. This example is purely hypothetical. The numbers used do not correspond to numbers in the experiment.

Suppose that we have a market with 4 workers, called $\mathrm{W}, \mathrm{X}, \mathrm{Y}$ and $\mathrm{Z}$, and 7 firms. Note that these numbers are different than in the market in Part II, where there are 6 workers and 6 firms.

In a market round, the 4 workers submit the following wage requests:

- W does not participate in the market

- X's wage requests are 60 and 100

- Y's wage requests are 77 and 160

- Z's wage requests are 145 and 170

Table 1 below summarizes the market situation and ranks the wage requests and wage offers. The wage requests are ranked from lowest to highest: the lowest wage request is 60 , the $2^{\text {nd }}$ lowest one is 77 , the $3^{\text {rd }}$ lowest one is 100 , the $4^{\text {th }}$ lowest one is 145 , the $5^{\text {th }}$ lowest one is 160 and the highest one is 170 .

Table 1 also ranks the wage offers, but from highest to lowest. Suppose that the highest wage offer from a firm is 120 , the $2^{\text {nd }}$ highest one is 115 , the 3 rd highest one is 105 , the $4^{\text {th }}$ highest one is 95 , the $5^{\text {th }}$ highest one is 60 , the $6^{\text {th }}$ highest one is 50 , and the lowest one is 40 . 


\begin{tabular}{|r|c|c|c|c|c|c|c|c|}
\hline \multicolumn{9}{|c|}{ Table 1 } \\
\hline Worker: & $\mathrm{X}$ & $\mathrm{Y}$ & $\mathrm{X}$ & $\mathrm{Z}$ & $\mathrm{Y}$ & $\mathrm{Z}$ & $\mathrm{W}$ & $\mathrm{W}$ \\
\hline Rank: & 1. & 2. & 3. & 4. & 5. & 6. & - & - \\
\hline $\begin{array}{r}\text { Wage } \\
\text { requests: }\end{array}$ & 60 & 77 & 100 & 145 & 160 & 170 & \multicolumn{2}{c|}{$\begin{array}{c}\text { Does not } \\
\text { participate }\end{array}$} \\
\hline $\begin{array}{r}\text { Firms' wage } \\
\text { offers: }\end{array}$ & 120 & 115 & $105^{*}$ & 95 & 60 & 50 & 40 & - \\
\hline
\end{tabular}

First, let us check which jobs are done:

- The $1^{\text {st }}$ wage request is 60 , which is lower than the $1^{\text {st }}$ wage offer of 120 . Therefore, worker $\mathbf{X}$ is hired to do his first job.

- The $2^{\text {nd }}$ wage request is 77 , which is lower than the $2^{\text {nd }}$ wage offer of 115 . Therefore, worker $\mathbf{Y}$ is hired to do his first job.

- The $3^{\text {rd }}$ wage request is 100 , which is lower than the $3^{\text {rd }}$ wage offer of 105 . Therefore, worker $\mathbf{X}$ is hired to do a second job.

- The $4^{\text {th }}$ wage request is 145 , which is higher than the $4^{\text {th }}$ wage offer of 95 . Therefore, worker $\mathbf{Z}$ is NOT hired for this job. This is also true for the $5^{\text {th }}$ and $6^{\text {th }}$ wage requests.

- As worker $\mathbf{W}$ does not participate in the market, he is not hired for a job.

Let us now explain how the market wage is determined in this example. We have two candidate wages, which are shaded in Table 1:

- Market wage candidate 1 is the last firm wage offer that is higher than the wage request with the same rank. That is the $3^{\text {rd }}$ wage offer, 105 .

- Market wage candidate 2 is the first wage request that is higher than the wage offer with the same rank. That is the $4^{\text {th }}$ wage request, 145 .

The market wage is the lowest of the two, that is 105 (Market wage candidate 1), indicated by a "* * in Table 1. Therefore, $\mathrm{X}$ is hired to do two jobs and receives 105 for each of them, $\mathrm{Y}$ is hired to do one job and receives 105 , and $\mathrm{Z}$ and $\mathrm{W}$ do no jobs and receive no wage.

\section{How your earnings are computed:}

At the beginning of Part II, you will receive an initial payment of 200 points for this part. You can earn additional money in every market round if you are hired to do a job.

Each job for which you are hired means you incur a cost. Let's call the cost of the first job for which you are hired Cost Job1. If you are hired for a second job, this job costs you another (higher) cost, called Cost Job2. If you do no job (because you are not hired or you choose not to participate in the market), you do not incur any cost.

In this experiment, Cost Job1 is $\mathbf{5 0}$ points, and Cost $\mathbf{J o b 2}$ is $\mathbf{1 1 0}$ points. Costs are the same for all workers.

Your additional earnings in a round are calculated as follows: 
1. If you are hired for 0 jobs:

$$
\text { Earnings }=0
$$

2. If you are hired for 1 job:

$$
\text { Earnings }=\text { market wage }- \text { Cost Job1 }=\text { market wage }-50
$$

3. If you are hired for 2 jobs:

$$
\text { Earnings }=2 \times \text { market wage }- \text { Cost Job1 }- \text { Cost Job2 }=2 \times \text { market wage }-160
$$

Let us compute the earnings of workers $\mathrm{W}, \mathrm{X}, \mathrm{Y}$ and $\mathrm{Z}$ in the round described in our example above:

- Suppose that Cost Job1 is 60 and Cost Job2 is 100 . These are not the values that apply to you, but we use these hypothetical values for the example.

- As discussed above, the market wage in this example is 105.

- Worker $\mathrm{X}$ is hired to do 2 jobs. Therefore his earnings for this round are $2 \times 105-60-100=$ 50 .

- Worker $\mathrm{Y}$ is hired to do 1 job, therefore his earnings for this round are $105-60=45$.

- Workers $\mathrm{Z}$ and $\mathrm{W}$ : Worker $\mathrm{Z}$ is not hired for any job and worker $\mathrm{W}$ does not participate in the market. Therefore both $\mathrm{Z}$ and $\mathrm{W}$ earn 0 in this round.

An important rule in the market is that you may not submit wage requests below your costs. Otherwise, you may lose money in a round if your wage requests are accepted. Therefore, the computer will not allow you to submit a wage request below 50 for the first job and below 110 for the second job.

\section{The market rounds:}

You will play 15 market rounds. At the end of each market round, you will be informed about:

- the total quantity of jobs that were provided in your market,

- the market wage,

- the history of market wages and quantities of all previous rounds,

- the number of jobs for which you are hired,

- the history of the number of jobs provided by every worker in every previous round.

- your individual earnings in this round,

- the history of the accumulated earnings of all workers up to the current round,

- you will also see the portrait of every worker in your market.

The outcome screen appears at the end of each trading period. On the next page you can find an example of an outcome screen. Please take a moment to review the outcome screen, to familiarize yourself with what feedback you receive at the end of a market round. Note that the reporting screen shows the portraits in a manner that allows all six workers in a market to connect the portraits to both the number of jobs provided and the accumulated earnings of every worker.

If you have any questions, please raise your hand and wait for a staff member to come and help you. 


\section{Example of an outcome screen:}

\section{Color Scheme:}

- Information about you is in blue.

- We assigned another color to all other workers in your market (green, red, purple, orange and turquoise).

- The assigned color will not change during the 15 rounds and allows you to observe outcomes for each worker across rounds.
History of market wage and quantity.

Black crosses $(\mathrm{x})$, connected by a line, represent market wages across rounds.

- $\quad$ Black squares ( $)$ represent the total number jobs done in the market.

- The number of jobs done is subdivided by the quantity done by different workers, illustrated by bars in the workers' assigned colors.

Example: Look at period 1. The turquoise, and the red workers did two jobs. You (blue), the green, the purple, and the orange workers each did no job. In total, this results in 4 jobs (as indicated by the black square).

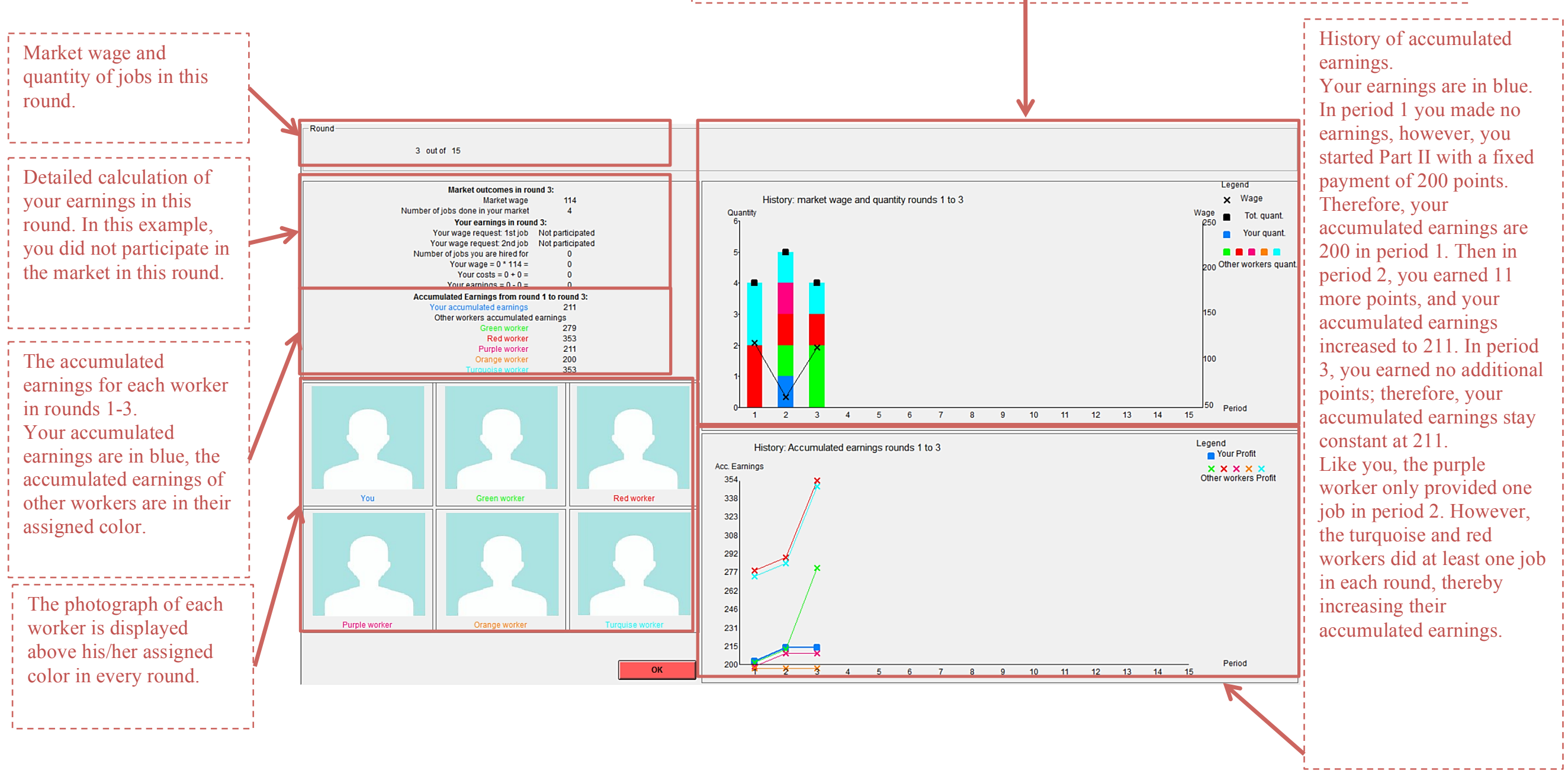




\section{F.2.4 Understanding questions market}

Here is an example of a trading period. Again, this example is hypothetical; the numbers used are not representative of the experiment. There are 6 workers $(\mathrm{U}, \mathrm{V}, \mathrm{W}$, $\mathrm{X}, \mathrm{Y}$ and $\mathrm{Z}$ ). In the table below, you find the workers' wage requests and the firms' wage offers. They are already ordered accordingly. Costs are:

Cost Job1 $=40$

Cost Job2 $=60$

\begin{tabular}{cccccccccccccc|}
\hline Worker: & $\mathrm{U}$ & $\mathrm{V}$ & $\mathrm{W}$ & $\mathrm{X}$ & $\mathrm{U}$ & $\mathrm{W}$ & $\mathrm{Y}$ & $\mathrm{V}$ & $\mathrm{X}$ & $\mathrm{Y}$ & $\mathrm{Z}$ & $\mathrm{Z}$ \\
Rank: & 1. & 2. & 3. & 4. & 5. & 6. & 7. & 8. & 9. & 10. & - & - \\
Wage requests: & 70 & 80 & 80 & 92 & 110 & 115 & 120 & 135 & 160 & 161 & $\left(^{*}\right)$ & $\left(^{*}\right)$ \\
Firms' wage offers: & 134 & 131 & 125 & 122 & 120 & 110 & & & & & & \\
\hline
\end{tabular}

(*) means the worker decided not to participate in the market.

1. What is the market wage? (Solution=115)

2. How many jobs are performed in this market round? (Solution=5)

3 . What are the earnings of worker U? (Solution=130) 


\section{Part II: Job description}

Please do not click the OK button on the screen until the experimenter asks you to do so.

As part of this experiment, UNICEF can receive money to buy and distribute antimalarial drugs to infected children in countries affected by malaria. Please read the box "Malaria, UNICEF and Antimalarial Drugs" on the next page to obtain more information about malaria, UNICEF and how antimalarial drugs can save infected children. 


\section{Malaria, UNICEF and Antimalarial Drugs}

\section{What is Malaria?}

Malaria is a disease transmitted by infected mosquitos. Their bite introduces parasites from the mosquito's saliva into a person's blood, where they mature and reproduce. The classic symptoms of malaria consist of bouts of fever and convulsions, chills and sweats, headaches, severe anemia, nausea and vomiting, leading to coma and death if left untreated. ${ }^{1}$ Worldwide, malaria is one of the top killers of children under 5 years of age, causing the death of 1900 children each day, mostly in developing countries. ${ }^{2}$ This is equivalent to 7 jumbo jets full of children disappearing, every day.

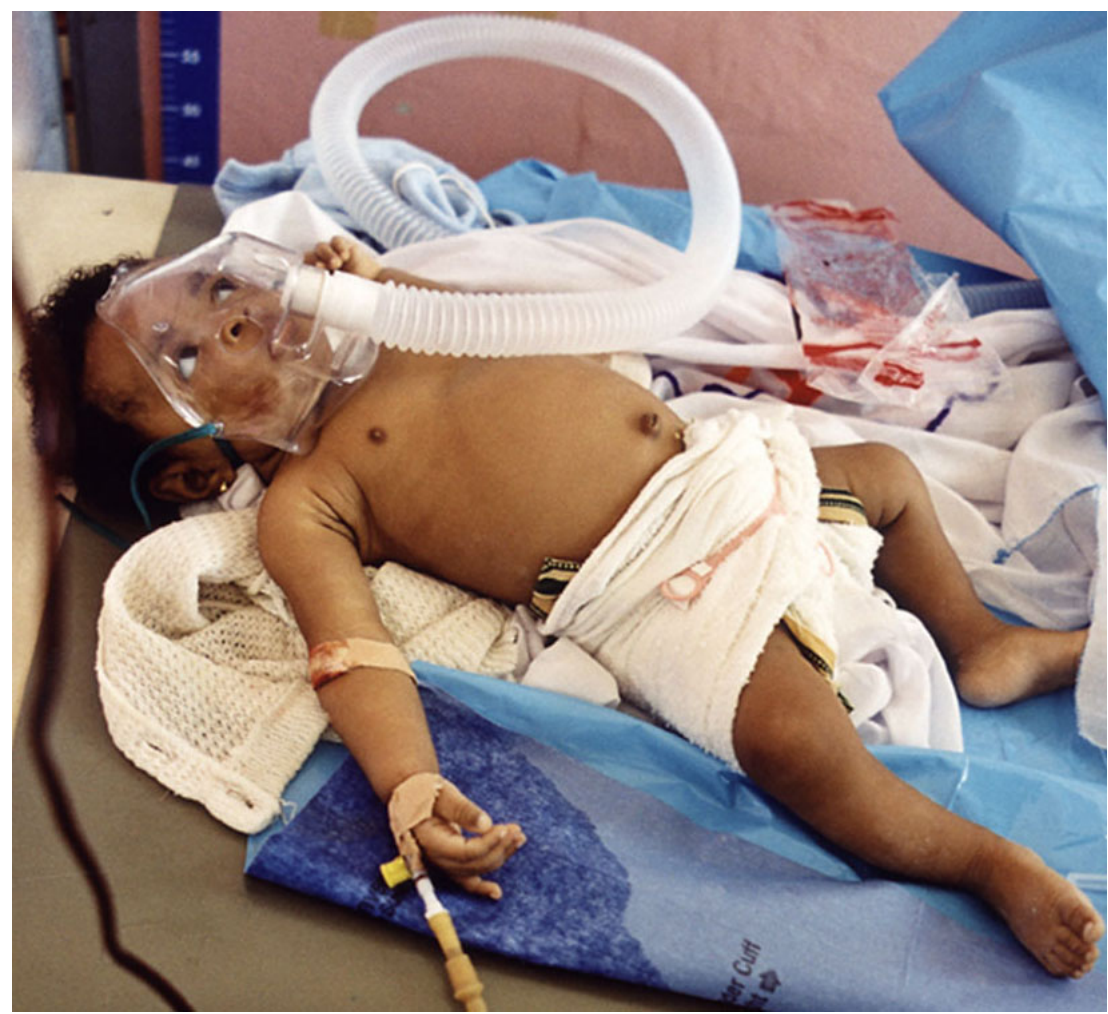

Child suffering from Malaria in a local hospital (Source: Nationales Genomforschungsnetz).

\section{UNICEF and antimalarial drugs}

Children infected with malaria do not have to die. If they receive antimalarial drugs, their chances for survival are good. Donating antimalarial drugs greatly increases the likelihood that an infected child can be saved from death. The United Nations Children's Fund (UNICEF) is a United Nations program that provides humanitarian and developmental assistance to children and mothers in developing countries. UNICEF helps fight malaria by distributing antimalarial drugs in developing countries.

\footnotetext{
${ }^{1}$ Source: Malaria Consortium, a world leading non-profit organization in the prevention, control and treatment of malaria.

${ }^{2}$ Source: Dutch Malaria Foundation, a charity organization that fights malaria.
} 
Prior to today's session, we worked with a local organization that collects blood donations, the Swiss Red Cross. Individuals who donated blood as part of a donation campaign were given the opportunity to also generate money for UNICEF to save children infected by malaria. Every market in this session is matched with a group of 24 donors who each donated blood and thereby generated a donation to save 1 infected child. Therefore, in combination, these donations contributed to saving a total of 24 infected children (that is, the number of children who receive the antimalarial drug).

However, you and the other workers in your market now have the possibility to influence how many children are actually saved. The final number of children saved may be higher or lower than 24 and depends partly on the decisions made by participants in Part II of this experiment. The impact of these decisions on the total donation is independent from the choice situation in Part I.

We will now describe in detail what, exactly, the job involves. If you are hired for one job, you will have to advise a student who is not participating in this experiment to choose from several options. You may think of this student as a Client for the firm that hires you. The Client will be a student recruited at the University of Zurich or the ETH.

Clients make decisions that influence their own financial reward for completing a short survey, as well as the size of the donation to UNICEF. Each Client must choose between $\mathbf{1 0}$ options, described as " $A$ " through " $J$ " in Table 1. The Client's decision will increase or decrease the final number of children saved as well as the Client's own financial reward. However, the Client will not know the consequences associated with each option. That is, the Client does not observe Table 1, but only knows that he has to make a choice, from A to J, that can affect his financial reward and how many children receive the antimalarial drug.

\begin{tabular}{|c|c|c|c|c|c|c|c|c|c|c|}
\hline \multicolumn{10}{|c|}{ Table 1: Options available to the Client } \\
\hline Option & A & B & C & D & E & F & G & H & I & J \\
\hline $\begin{array}{c}\text { Additional } \\
\text { number of } \\
\text { children } \\
\text { saved }\end{array}$ & 1 & 1 & 1 & 1 & -1 & 1 & 1 & 1 & 1 & 1 \\
\hline $\begin{array}{c}\text { Financial } \\
\text { reward for } \\
\text { Client }\end{array}$ & $1 \mathrm{CHF}$ & $1 \mathrm{CHF}$ & $1 \mathrm{CHF}$ & $1 \mathrm{CHF}$ & $0 \mathrm{CHF}$ & $1 \mathrm{CHF}$ & $1 \mathrm{CHF}$ & $1 \mathrm{CHF}$ & $1 \mathrm{CHF}$ & $1 \mathrm{CHF}$ \\
\hline
\end{tabular}

Note that:

- If the Client picks option $\mathrm{E}$, the total number of children saved decreases by 1 . The Client's financial reward is $0 \mathrm{CHF}$.

- If the Client picks option G (or any other option than E), 1 more child will be saved. The Client's financial reward is 1 CHF. 
If you are hired to do the job in a round, then you are required to write the Client a recommendation to pick option E. Specifically, you will complete a statement, by writing your initials and the name of the recommended option (that is, option "E"), on a piece of paper that will be given to the Client. The statement will read,

I, [your initials], have reviewed your possible choices and I recommend that you select the option [E]. Following my advice will save the highest number of children and will give you the highest financial reward.

Your advisor: [your initials]

Every other worker is hired to do exactly the same job; that is, every worker who is hired to do a job also has to recommend option E.

\section{The Client}

In every round, firms are randomly selected to be possibly matched with a Client. The probability that a firm is matched with a Client in a round is 25 percent. This probability is independent of whether or not the firm was able to hire a worker.

To play the role of Clients, we will recruit students on the campus of the University of Zurich or the ETH. We will invite students to complete a survey and to participate in a brief choice experiment in which they may generate money for UNICEF to save children infected by malaria. The Client's own financial reward for completing the survey also depends on his decision (see Table 1). For every round, if a firm is matched with a Client, that Client has to pick one of the ten options. Clients have no information about the options. If a Client is matched with a firm that hired a worker in this round, the Client will receive a recommendation to pick the specified option. If the firm was not able to hire a worker, the Client will receive no recommendation. This means that the Client will choose among the 10 options, without knowing anything more.

As shown in Table 1, the Client's chosen option will determine the impact on the total number of children who receive the antimalarial treatment and the Client's financial reward.

The next two pages present the exact forms that will be shown to students recruited to participate as Clients. The first example corresponds to the case in which a firm hired a worker to provide a recommendation. The second example corresponds to the case in which a firm was not able to hire any worker for that specific job. 
If a Client receives a recommendation, his instructions will look as follows:

Thank you for volunteering!

Worldwide, malaria is one of the top killers of children under 5 years of age, causing the death of 1900 children each day, mostly in developing countries. ${ }^{1}$ This is equivalent to 7 jumbo jets full of children disappearing, every day. However, children infected with malaria do not have to die. If they receive antimalarial drugs, their chances for survival are good. Donating antimalarial drugs greatly increases the likelihood that infected children can be saved from death.

You can now influence the number of infected children that will receive antimalarial drugs by choosing one of ten options: A, B, C, D, E, F, G, H, I or J.

Each option influences the number of antimalarial drugs that are donated. Your choice will also determine your payment for participating. Your payment is always higher if you select an option that saves more children.

You have no additional information about these options, except for a recommendation that is attached to this page. This recommendation was written by your advisor-a participant in another study who has been paired with you and who had full information about the consequences of each option.

Please put a cross in the following table, under the option you would like to choose. The option you choose will be implemented.

\begin{tabular}{|c|c|c|c|c|c|c|c|c|c|}
\hline \multicolumn{10}{|c|}{ Options } \\
\hline A & B & $\mathrm{C}$ & D & $\mathrm{E}$ & $\mathrm{F}$ & G & $\mathrm{H}$ & 1 & $\mathrm{~J}$ \\
\hline ............... & ............... & ............... & ............... & .................... & ............... & ................. & ................. & ................... & ................. \\
\hline
\end{tabular}

The recommendation from your advisor is:

The following statement was generated in an
experiment that raises donations for UNICEF.
Your advisor recommends you the following:
I, M.W. have reviewed your possible
choices and I recommend that you select
the option ... E.m. . Following my advice will
save the highest number of children and
will give you the highest financial reward.
your advisor: .............

Note that:

- The Client has no information about the options, except for the recommendation that you complete by hand.

- The Client knows that you are informed about the outcomes of the options.

- The Client does not know that you have to recommend a specific option.

- The Client will see your initials but will not see your portrait. 
If a Client does not receive a recommendation, his instructions will look as follows:

Thank you for volunteering!

Worldwide, malaria is one of the top killers of children under 5 years of age, causing the death of 1900 children each day, mostly in developing countries. ${ }^{1}$ This is equivalent to 7 jumbo jets full of children disappearing, every day. However, children infected with malaria do not have to die. If they receive antimalarial drugs, their chances for survival are good. Donating antimalarial drugs greatly increases the likelihood that infected children can be saved from death.

You can now influence the number of infected children that will receive antimalarial drugs by choosing one of ten options: A, B, C, D, E, F, G, H, I or J.

Each option influences the number of antimalarial drugs that are donated. Your choice will also determine your payment for participating. Your payment is always higher if you select an option that saves more children.

You have no additional information about these options.

Please put a cross in the following table, under the option you would like to choose. The option you choose will be implemented.

\begin{tabular}{|c|c|c|c|c|c|c|c|c|c|}
\hline \multicolumn{10}{|c|}{ Options } \\
\hline$A$ & B & C & D & $E$ & $\mathrm{~F}$ & G & $\mathrm{H}$ & I & J \\
\hline .............. & ……........ & ……........ & ............... & .............. & .............. & .............. & .............. & . ……..... & ............... \\
\hline
\end{tabular}

Note that you will receive your earnings from the market in a round independently of whether or not any of your recommendations are distributed to Clients. That is, even if the firm for which you are hired is not matched with a Client, you will still receive your earnings from doing that job.

\section{Completing the recommendation:}

At the end of any round in which you are hired by a firm, you have to complete any recommendations for which you have been hired.

You are not allowed to recommend a different option than the one specified above. You are also not allowed to give additional information to the Client. Also, note that you do not know and will not know the identity of the Client and this student will not see your portrait, he will only know your initials.

Remember that you have to complete all the recommendations for which you are hired, at the end of every market round. For this purpose, there is a booklet, labeled Recommendation Booklet on your desk. At the end of each market round, if you have been hired in that round, you should take the booklet and complete the one or two recommendations in the section with the corresponding job identification number (Job ID). This number will be indicated on your screen at the end of every round. 
If you have not been hired for any jobs, or if you decided not to participate in the market, please cross "I was not hired/did not participate" next to the corresponding job identification number.

Suppose for example that the Job ID is $2 \mathrm{~A}$ :

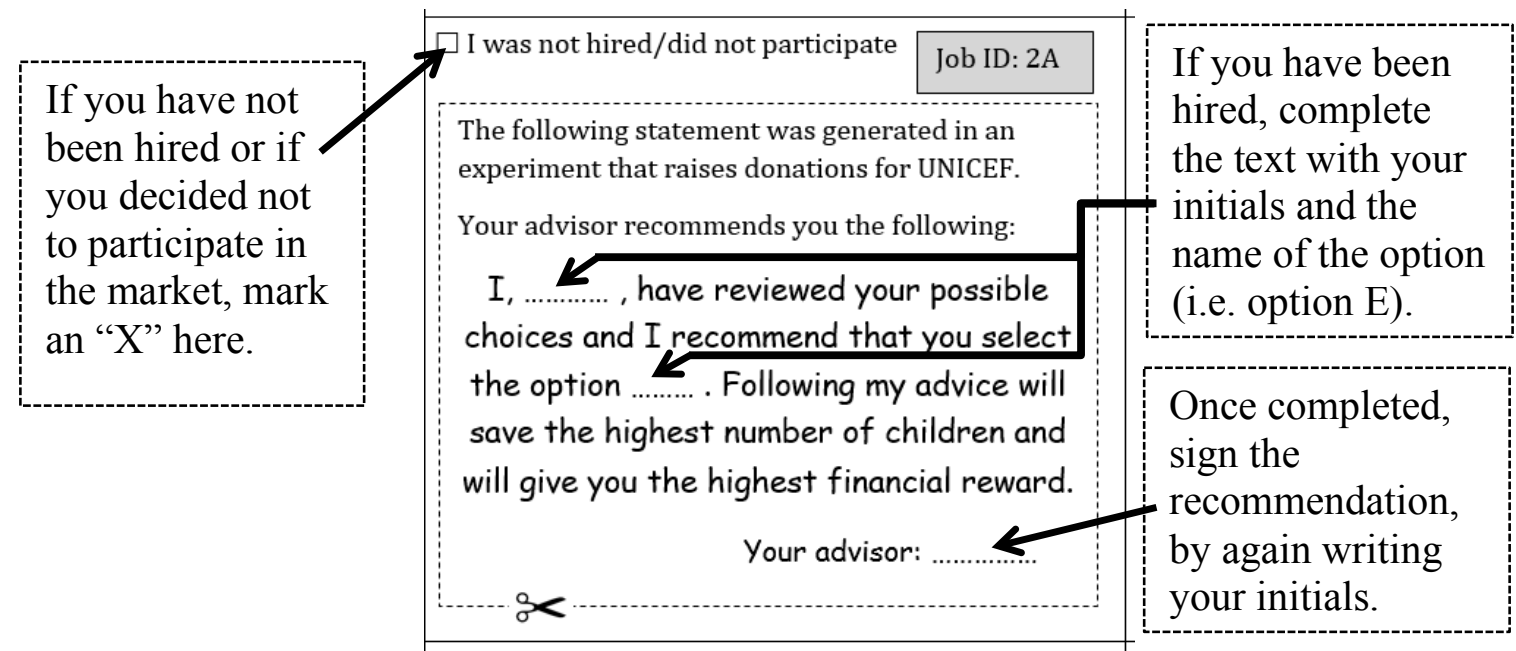

At the end of the experiment, we will check that you have carefully completed all the recommendations for the rounds in which you were hired. If a recommendation is illegible, is wrong (e.g., you recommend a different option), is incomplete or gives additional information to the Client, we will ask you to write it again. If you refuse to complete all recommendation(s) for which you were hired, you will not receive any payment for this experiment (you will not even receive your participation fee). Note that you will always have the option not to accept any jobs in a round and thereby not have to write any recommendations.

If a firm is not matched with a Client in a round, then any recommendation you produced for this firm will be returned to you at the end of today's session and will therefore not be used.

To summarize, Table 2 presents four cases that may arise, based on whether a firm is randomly drawn to have a Client in a round and whether the firm was able to hire a worker. 


\begin{tabular}{|c|l|l|}
\hline \multicolumn{3}{|c|}{ Table 2 } \\
\hline & \multicolumn{1}{|c|}{$\begin{array}{c}\text { Firm F was able to hire } \\
\text { worker X }\end{array}$} & $\begin{array}{c}\text { Firm F was not able to hire } \\
\text { any worker }\end{array}$ \\
\hline $\begin{array}{c}\text { Firm F is drawn to be } \\
\text { matched with a Client }\end{array}$ & $\begin{array}{l}\text { The matched Client receives } \\
\text { a recommendation to choose } \\
\text { E, completed by worker X. }\end{array}$ & $\begin{array}{l}\text { The matched Client receives } \\
\text { no recommendation. }\end{array}$ \\
\hline $\begin{array}{c}\text { Firm F is not drawn to be } \\
\text { matched with a Client }\end{array}$ & $\begin{array}{l}\text { Firm F is not matched with } \\
\text { any Client. } \\
\text { Worker X's recommendation } \\
\text { is not used and is returned to } \\
\text { Worker X. }\end{array}$ & $\begin{array}{l}\text { Firm F is not matched with } \\
\text { any Client. }\end{array}$ \\
\hline
\end{tabular}

At the end of the experiment, we will tell you which of your recommendations will be given to a Client and which will not be used and will be returned to you. Again, note that you will receive your earnings independently of whether or not any of your recommendations are distributed to Clients.

Remember that according to the scientific standards at the Decision Science Laboratory, we are not allowed to lie to you at any point in time. We will actually hire Clients and give them the recommendations completed in this experiment, and they will make the choices described above. These choices will then determine the number of infected children who receive the anti-malaria drugs through donations to UNICEF. Remember: children who do not receive anti-malarial drugs are very likely to die. At the end of the study, we can provide you with a receipt documenting the final amount donated to UNICEF. If you would like to obtain a copy, please write an email to decision-study@econ.uzh.ch with "Receipt - UNICEF" as the header.

If you have any questions, please raise your hand. 


\section{Recommendation Booklet}

Note: Please only complete a recommendation if you are instructed to do so by the computer.

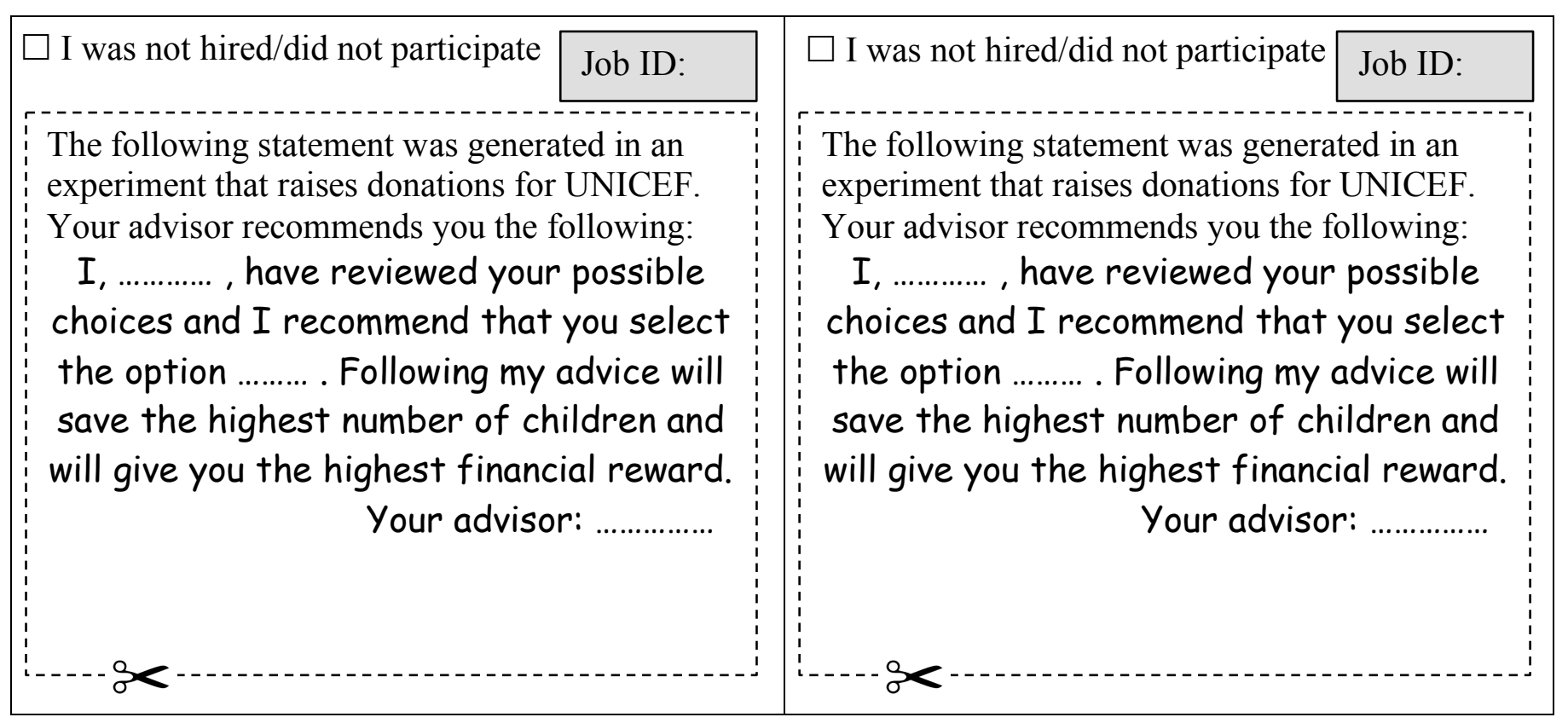




\section{F.2.7 Understanding questions market}

1. Which option do you have to recommend if you are hired to do a job?

o A

o B

$\cdots$

o J

2. Suppose you write a recommendation for a firm that is not matched to a Client in the round.

i) What will happen with your recommendation?

o You can keep it

o We will keep it

o We will give it to another Client

(Solution=You can keep it)

ii) What are your earnings from this job?

o You receive no earnings as your recommendation is unused

o You receive the market wage in this round

(Solution=You receive the market wage in this round)

3. Suppose that in a round, a firm is matched with a Client but the firm was not able to hire a worker in that round. What happens to the matched Client?

o He receives a recommendation from another firm

o He receives no recommendation at all

(Solution $=\mathrm{He}$ receives no recommendation at all)

4. Suppose that a Client received a recommendation from you. Check every piece of information he has when he chooses between the options. The Client knows:

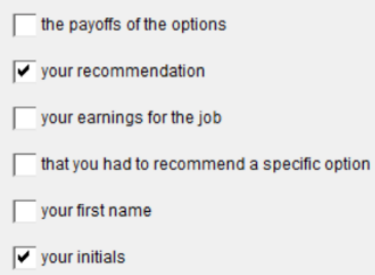

(Solution=your recommendation and your initials) 


\section{F.2.8 Survey end of experiment}

After subjects participated in the market, but before they learn about their final earnings, they answer the following questions:

1. How are you feeling at the moment?

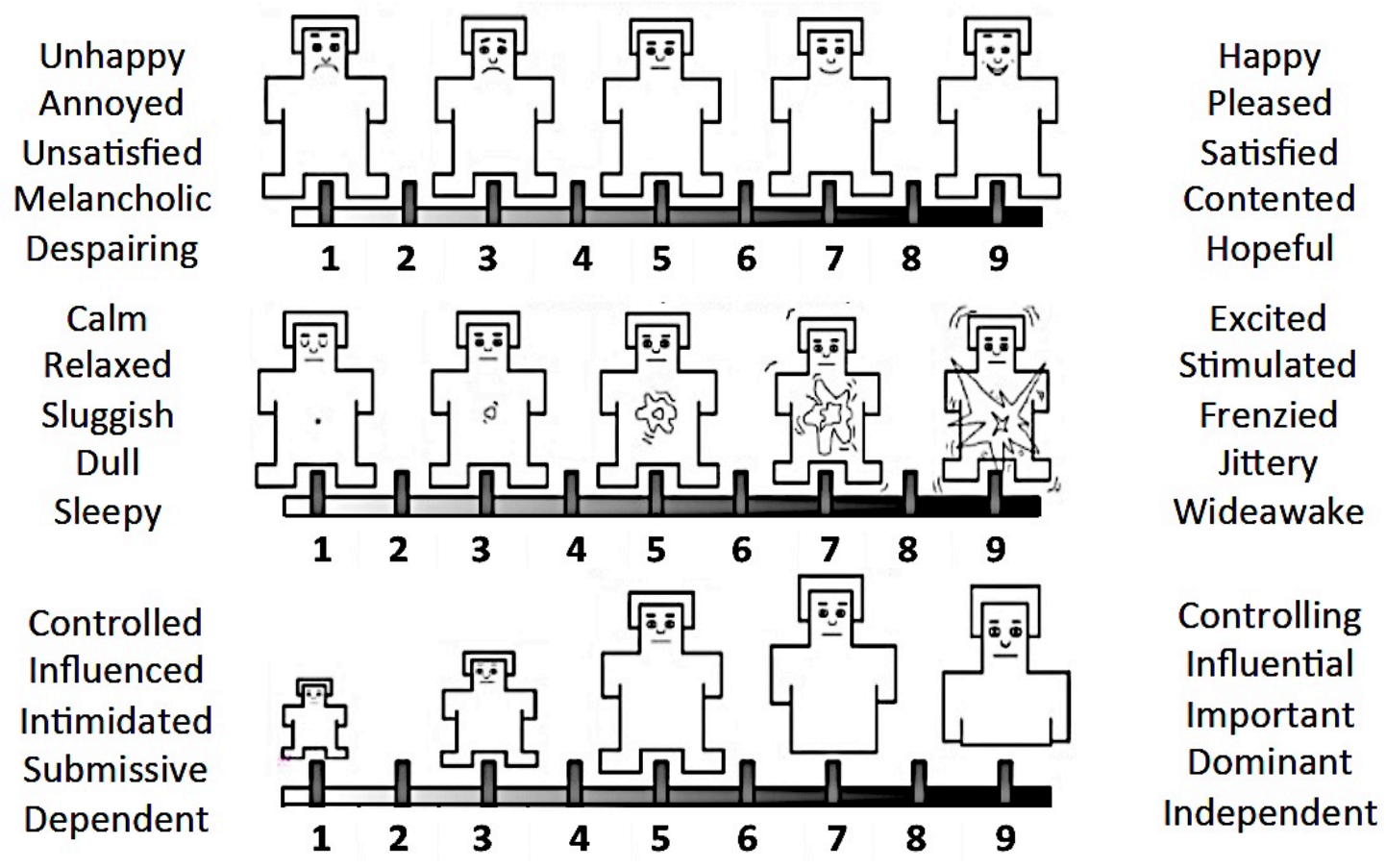

2. What do you think is the share of Clients who will follow the recommendation they receive?
о $0-10 \%$
o $11-20 \%$
o $21-30 \%$
o $31-40 \%$
o $41-50 \%$
о $51-60 \%$
o $61-70 \%$
o $71-80 \%$
o $81-90 \%$
о $91-100 \%$

3. If you stayed out of the market for at least one market round, what was your specific reason for doing so?

4. If you participated in the market for at least one market round, what was your specific reason for doing so? 
5. If you participated in the market, indicate how much the following reasons influenced your behavior?

a) I did not like accepting the job, but wanted to earn money.

did not at all affect my behavior o o o o o greatly affected my behavior

b) I don't mind lying to Clients.

did not at all affect my behavior o o o o o greatly affected my behavior

c) It is efficient to lie, as the Clients lose less than I gain.

did not at all affect my behavior o o o o o greatly affected my behavior

d) The probability that a Client receives my recommendation was low. did not at all affect my behavior o o o o o greatly affected my behavior

e) I did not like that dishonest people received high wages by accepting jobs, and therefore wanted to catch up.

did not at all affect my behavior o o o o o greatly affected my behavior

f) I did not like that dishonest people received high wages by accepting jobs. I accepted the job to lower the wage received by these dishonest people. did not at all affect my behavior o o o o o greatly affected my behavior

g) If I don't do the job, somebody else will do it.

did not at all affect my behavior o o o o o greatly affected my behavior

h) As many participants accepted the job, it is ok to do it as well.

did not at all affect my behavior o o o o o greatly affected my behavior

i) In a market, there is no reason to behave nicely.

did not at all affect my behavior o o o o o greatly affected my behavior

j) I do not care for UNICEF or for the infected children.

did not at all affect my behavior o o o o o greatly affected my behavior

k) I just give advice, it is the Client's responsibility to implement the best option. did not at all affect my behavior o o o o o greatly affected my behavior

1) The Client will not follow my recommendation anyway.

did not at all affect my behavior o o o o o greatly affected my behavior

m) I'm not concerned about what other people think of me.

did not at all affect my behavior o o o o o greatly affected my behavior 
6. For each of the statements, indicate how much each statement is like you by using the following scale: a lot like me, somewhat like me, a little like me and not like me at all.

Please be as honest as you can throughout, and try not to let your responses to one question influence your response to other questions. There are no right or wrong answers.

a) I'm concerned about my style of doing things.

o a lot like me

o somewhat like me

o a little like me

o not like me at all

b) I care a lot about how I present myself to others.

o a lot like me

o somewhat like me

o a little like me

o not like me at all

c) I'm self-conscious about the way I look.

o a lot like me

o somewhat like me

o a little like me

o not like me at all

d) I usually worry about making a good impression.

o a lot like me

o somewhat like me

o a little like me

o not like me at all

e) Before I leave my house, I check how I look.

o a lot like me

o somewhat like me

o a little like me

o not like me at all

f) I'm concerned about what other people think of me.

o a lot like me

o somewhat like me

o a little like me

o not like me at all

g) I'm usually aware of my appearance

o a lot like me

o somewhat like me

o a little like me

o not like me at all 


\section{F.3 Online survey}

\section{F.3.1 Welcome-Screen}

Thank you for your participation in our experiment.

Our experiment consists of two parts: an online survey that you are about to complete, and a subsequent session in the laboratory. For participating in the online survey, you will receive CHF 10. You will receive this payment in cash at the end of the laboratory study.

The online survey will last about $25 \mathrm{~min}$. There are no right or wrong answers, and we ask you to answer truthfully and with care. All the information gathered in this experiment is kept strictly anonymous.

In order to participate in this experiment you are required to complete the online survey at least 4 days before the lab session starts. If you do not complete it in time you will not be allowed to participate in the lab session and will receive no payment.

Please choose a silent environment in order to remain focused and to avoid being interrupted while answering. Your answers will be saved by mean of a cookie that is placed on your computer. Make sure that your computer does not block it, or complete the survey in one sitting. Also, it is important that you complete the entire survey using the same computer and the same web browser.

Once you are ready, please click Next on the bottom right of this page to access the next screen.

\section{F.3.2 Demographics}

How old are you?

Please, indicate your gender:

o Female

o Male

What is your highest educational attainment?

o High school

o Bachelor degree

o Master degree

o $\mathrm{PhD}$ degree

o Other

At which of the following institutions have you completed most of your studies until now?

o University

o ETHZ or EPFL

o University for Applied Sciences

o Other 
What is(are) your field(s) of study?

Major:

Minor (if any)

Please, indicate all your nationalities

What do you think will be your first full-time job after your studies? Please indicate only one job.

How much do you think you will earn when you are 40 years old? Indicate your predictions for your monthly gross wage in CHF (do not take into account the 13th income)

$\mathrm{CHF}$

\section{F.3.3 Willingness to work in industries}

How willing would you be to work in each of the following industry in Switzerland?

\begin{tabular}{|c|c|c|c|c|c|}
\hline & $\begin{array}{l}\text { Not willing } \\
\text { at all }\end{array}$ & $\begin{array}{l}\text { Not really } \\
\text { willing }\end{array}$ & Indifferent & $\begin{array}{l}\text { Quite } \\
\text { willing }\end{array}$ & $\begin{array}{l}\text { Really } \\
\text { much } \\
\text { willing }\end{array}$ \\
\hline $\begin{array}{l}\text { Monetary intermediation } \\
\text { (cantonal banks, commercial } \\
\text { banks, stock exchange } \\
\text { banks, private bankers...) }\end{array}$ & o & o & o & o & 0 \\
\hline $\begin{array}{l}\text { Gambling and betting } \\
\text { activities }\end{array}$ & o & o & o & o & o \\
\hline $\begin{array}{l}\text { Non-life insurance (accident } \\
\text { insurance, health } \\
\text { insurance...) }\end{array}$ & o & o & o & o & o \\
\hline $\begin{array}{l}\text { Manufacture of tobacco } \\
\text { products }\end{array}$ & o & $\mathrm{o}$ & $\mathrm{o}$ & o & o \\
\hline $\begin{array}{l}\text { Wholesale of perfume and } \\
\text { cosmetics }\end{array}$ & o & o & o & o & o \\
\hline $\begin{array}{l}\text { Manufacture of paper and } \\
\text { paperboard }\end{array}$ & o & o & o & o & o \\
\hline $\begin{array}{l}\text { Wholesale of tobacco } \\
\text { products }\end{array}$ & o & o & o & o & $\mathrm{o}$ \\
\hline $\begin{array}{l}\text { Manufacture of electronic } \\
\text { components }\end{array}$ & o & o & o & o & $\mathrm{o}$ \\
\hline $\begin{array}{l}\text { Manufacture of weapons } \\
\text { and ammunition }\end{array}$ & o & o & o & o & o \\
\hline $\begin{array}{l}\text { Maintenance and repair of } \\
\text { motor vehicles }\end{array}$ & o & o & o & o & o \\
\hline $\begin{array}{l}\text { Hotels and similar } \\
\text { accommodation }\end{array}$ & o & o & o & o & o \\
\hline Construction of buildings & 0 & 0 & 0 & o & o \\
\hline
\end{tabular}




\begin{tabular}{|c|c|c|c|c|c|}
\hline $\begin{array}{l}\text { General public } \\
\text { administration activities }\end{array}$ & $\mathrm{o}$ & $\mathrm{o}$ & $\mathrm{o}$ & $\mathrm{o}$ & $\mathrm{o}$ \\
\hline $\begin{array}{l}\text { Restaurants and mobile food } \\
\text { service activities }\end{array}$ & $\mathrm{o}$ & $\mathrm{o}$ & $\mathrm{o}$ & $\mathrm{o}$ & $\mathrm{o}$ \\
\hline $\begin{array}{l}\text { Organization and operation } \\
\text { of sport facilities for indoor } \\
\text { or outdoor sports events }\end{array}$ & $\mathrm{o}$ & $\mathrm{o}$ & o & o & $\mathrm{o}$ \\
\hline Credit granting & $\mathrm{o}$ & $\mathrm{o}$ & $\mathrm{O}$ & $\mathrm{O}$ & $\mathrm{O}$ \\
\hline Processing of tea and coffee & $\mathrm{O}$ & $\mathrm{O}$ & 0 & o & $\mathrm{O}$ \\
\hline $\begin{array}{l}\text { Wholesale of clothing and } \\
\text { footwear }\end{array}$ & o & o & o & o & o \\
\hline $\begin{array}{l}\text { Wholesale of watches and } \\
\text { jewelery }\end{array}$ & $\mathrm{o}$ & $\mathrm{o}$ & $\mathrm{o}$ & $\mathrm{o}$ & $\mathrm{o}$ \\
\hline Fitness facilities & o & o & o & o & o \\
\hline
\end{tabular}

\section{F.3.4 Willingness to work in firms}

How willing would you be to work for one of the following organization?

\begin{tabular}{|c|c|c|c|c|c|c|}
\hline & $\begin{array}{l}\text { Not willing } \\
\text { at all }\end{array}$ & $\begin{array}{l}\text { Not really } \\
\text { willing }\end{array}$ & Indifferent & $\begin{array}{l}\text { Quite } \\
\text { willing }\end{array}$ & $\begin{array}{l}\text { Really much } \\
\text { willing }\end{array}$ & $\begin{array}{l}\text { I don't know } \\
\text { this } \\
\text { organization }\end{array}$ \\
\hline Glencore & 0 & 0 & 0 & 0 & 0 & 0 \\
\hline Novartis & $\mathrm{o}$ & $\mathrm{o}$ & $\mathrm{o}$ & $\mathrm{o}$ & $\mathrm{o}$ & $\mathrm{o}$ \\
\hline Roche & 0 & o & o & 0 & o & $\mathrm{o}$ \\
\hline $\mathrm{ABB}$ & $\mathrm{o}$ & $\mathrm{O}$ & $\mathrm{O}$ & $\mathrm{O}$ & $\mathrm{O}$ & $\mathrm{o}$ \\
\hline UNICEF & 0 & $\mathrm{o}$ & $\mathrm{o}$ & 0 & o & $\mathrm{o}$ \\
\hline Adecco & $\mathrm{o}$ & 0 & 0 & $\mathrm{o}$ & 0 & $\mathrm{o}$ \\
\hline Migros & 0 & 0 & 0 & 0 & o & 0 \\
\hline Holcim & 0 & 0 & 0 & 0 & 0 & 0 \\
\hline Pro Juventute & $\mathrm{O}$ & $\mathrm{o}$ & $\mathrm{o}$ & $\mathrm{O}$ & $\mathrm{O}$ & $\mathrm{o}$ \\
\hline Credit Suisse & $\mathrm{o}$ & o & o & o & $\mathrm{o}$ & $\mathrm{o}$ \\
\hline Swisscom & $\mathrm{O}$ & $\mathrm{O}$ & $\mathrm{O}$ & $\mathrm{o}$ & $\mathrm{O}$ & $\mathrm{o}$ \\
\hline Swatch & $\mathrm{o}$ & o & o & $\mathrm{o}$ & o & $\mathrm{o}$ \\
\hline UBS & $\mathrm{o}$ & $\mathrm{o}$ & $\mathrm{O}$ & $\mathrm{o}$ & 0 & $\mathrm{o}$ \\
\hline Red Cross & 0 & o & 0 & 0 & o & $\mathrm{o}$ \\
\hline Marlboro & $\mathrm{o}$ & $\mathrm{o}$ & $\mathrm{o}$ & $\mathrm{O}$ & $\mathrm{O}$ & $\mathrm{o}$ \\
\hline Monsanto Co. & $\mathrm{o}$ & o & $\mathrm{o}$ & $\mathrm{O}$ & $\mathrm{o}$ & o \\
\hline Nestlé & $\mathrm{o}$ & o & o & $\mathrm{o}$ & o & $\mathrm{o}$ \\
\hline WWF & $\mathrm{O}$ & $\mathrm{O}$ & $\mathrm{O}$ & $\mathrm{O}$ & $\mathrm{O}$ & $\mathrm{O}$ \\
\hline Tamoil & 0 & 0 & 0 & 0 & 0 & $\mathrm{o}$ \\
\hline Ernst \& Young & $\mathrm{O}$ & $\mathrm{O}$ & $\mathrm{O}$ & $\mathrm{O}$ & $\mathrm{O}$ & $\mathrm{O}$ \\
\hline Pro natura & $\mathrm{O}$ & o & $\mathrm{O}$ & $\mathrm{O}$ & $\mathrm{O}$ & o \\
\hline $\begin{array}{l}\text { Winterthur } \\
\text { assurance }\end{array}$ & $\mathrm{o}$ & o & o & o & o & $\mathrm{o}$ \\
\hline Syngenta & 0 & 0 & 0 & 0 & 0 & 0 \\
\hline Firmenich & $\mathrm{o}$ & $\mathrm{o}$ & 0 & 0 & 0 & $\mathrm{o}$ \\
\hline $\begin{array}{l}\text { Phillip Morris } \\
\text { International inc. }\end{array}$ & $\mathrm{o}$ & o & o & $\mathrm{o}$ & o & o \\
\hline Swiss Life & o & o & o & 0 & o & $\mathrm{o}$ \\
\hline
\end{tabular}




\section{F.3.5 Charity attitude index}

Please indicate whether you agree with the following statements about charities.

\begin{tabular}{|l|c|c|c|c|c|}
\hline & $\begin{array}{l}\text { Strongly } \\
\text { disagree }\end{array}$ & Disagree & $\begin{array}{l}\text { Neither } \\
\text { agree nor } \\
\text { disagree }\end{array}$ & Agree & $\begin{array}{l}\text { Strongly } \\
\text { agree }\end{array}$ \\
\hline $\begin{array}{l}\text { People should be willing to } \\
\text { help others who are less } \\
\text { fortunate. }\end{array}$ & 0 & 0 & 0 & 0 & 0 \\
\hline $\begin{array}{l}\text { Helping troubled people } \\
\text { with their problems is very } \\
\text { important to me. }\end{array}$ & 0 & 0 & 0 & 0 & 0 \\
\hline $\begin{array}{l}\text { People should be more } \\
\text { charitable toward others in } \\
\text { society. }\end{array}$ & 0 & 0 & 0 & 0 & 0 \\
\hline $\begin{array}{l}\text { People in need should } \\
\text { receive support from others. }\end{array}$ & 0 & 0 & 0 & 0 & 0 \\
\hline $\begin{array}{l}\text { The money given to } \\
\text { charities goes for good } \\
\text { causes. }\end{array}$ & 0 & 0 & 0 & 0 & 0 \\
\hline $\begin{array}{l}\text { Much of the money donated } \\
\text { to charity is wasted. }\end{array}$ & 0 & 0 & 0 & 0 & 0 \\
\hline $\begin{array}{l}\text { My image of charitable } \\
\text { organizations is positive. }\end{array}$ & 0 & 0 & 0 & 0 & 0 \\
\hline $\begin{array}{l}\text { Charitable organizations } \\
\text { have been quite successful } \\
\text { in helping the needy. }\end{array}$ & 0 & 0 & 0 & 0 & 0 \\
\hline $\begin{array}{l}\text { Charity organizations } \\
\text { perform a useful function } \\
\text { for society. }\end{array}$ & 0 & 0 & 0 & 0 & 0 \\
\hline
\end{tabular}




\section{F.3.6 HEXACO-PI}

Here is a series of 10 statements that might apply to you. Please read each statement and decide how much you agree or disagree with that statement. Then pick the element of the following scale that best represents your position:

Please answer every statement, even if you are not completely sure of your response.

\begin{tabular}{|l|c|c|c|c|c|}
\hline & $\begin{array}{l}\text { Strongly } \\
\text { disagree }\end{array}$ & Disagree & $\begin{array}{l}\text { Neither } \\
\text { agree nor } \\
\text { disagree }\end{array}$ & Agree & $\begin{array}{l}\text { Strongly } \\
\text { agree }\end{array}$ \\
\hline $\begin{array}{l}\text { I wouldn't use flattery to get } \\
\text { a raise or promotion at } \\
\text { work, even if I thought it } \\
\text { would succeed. }\end{array}$ & o & o & o & 0 & 0 \\
\hline $\begin{array}{l}\text { If I want something from } \\
\text { someone, I will laugh at that } \\
\text { person's worst jokes. }\end{array}$ & o & o & 0 & 0 & 0 \\
\hline $\begin{array}{l}\text { I wouldn't pretend to like } \\
\text { someone just to get that } \\
\text { person to do favors for me. }\end{array}$ & 0 & 0 & 0 & 0 & 0 \\
\hline $\begin{array}{l}\text { If I knew that Icould never } \\
\text { get caught, I would be } \\
\text { willing to steal a million } \\
\text { dollars. }\end{array}$ & 0 & 0 & 0 & 0 & 0 \\
\hline $\begin{array}{l}\text { I would never accept a } \\
\text { bribe, even if it were very } \\
\text { large. }\end{array}$ & 0 & 0 & 0 & 0 & 0 \\
\hline $\begin{array}{l}\text { I'd be tempted to use } \\
\text { counterfeit money, if I were } \\
\text { sure I could get away with } \\
\text { it. }\end{array}$ & 0 & 0 & 0 & 0 & 0 \\
\hline $\begin{array}{l}\text { Having a lot of money is not } \\
\text { especially important to me. }\end{array}$ & 0 & 0 & 0 & 0 & 0 \\
\hline $\begin{array}{l}\text { I would get a lot of pleasure } \\
\text { from owning expensive } \\
\text { luxury goods. }\end{array}$ & 0 & 0 & 0 & 0 & 0 \\
\hline $\begin{array}{l}\text { I think that I am entitled to } \\
\text { more respect than the } \\
\text { average person is. }\end{array}$ & 0 & 0 & 0 & 0 & 0 \\
\hline $\begin{array}{l}\text { I want people to know that I } \\
\text { am an important person of } \\
\text { high status. }\end{array}$ & 0 & 0 & 0 & & \\
\hline
\end{tabular}




\section{F.3.7 Protected Value 1}

The next two questions are about financial advisers. Because financial advisers may have larger margins on bad assets, they have an incentive to recommend sub-optimal assets to their clients. What is your opinion on advisers who recommend these bad assets in order to make more profits?

Please select a number for each category.

\begin{tabular}{|l|c|c|c|c|c|c|c|l|}
\hline & 1 & 2 & 3 & 4 & 5 & 6 & 7 & \\
\hline $\begin{array}{l}\text { Very } \\
\text { immoral }\end{array}$ & 0 & 0 & 0 & 0 & 0 & 0 & 0 & Very moral \\
\hline $\begin{array}{l}\text { Not at all } \\
\text { praiseworthy }\end{array}$ & 0 & 0 & 0 & 0 & 0 & 0 & 0 & $\begin{array}{l}\text { Very } \\
\text { praiseworthy }\end{array}$ \\
\hline $\begin{array}{l}\text { Not at all } \\
\text { blameworthy }\end{array}$ & 0 & 0 & 0 & 0 & 0 & 0 & 0 & $\begin{array}{l}\text { Very } \\
\text { blameworthy }\end{array}$ \\
\hline $\begin{array}{l}\text { Not at all } \\
\text { outrageous }\end{array}$ & 0 & 0 & 0 & 0 & 0 & 0 & 0 & $\begin{array}{l}\text { Very } \\
\text { outrageous }\end{array}$ \\
\hline $\begin{array}{l}\text { Not at all } \\
\text { acceptable }\end{array}$ & 0 & 0 & 0 & 0 & 0 & 0 & 0 & $\begin{array}{l}\text { Very } \\
\text { acceptable }\end{array}$ \\
\hline
\end{tabular}

\section{F.3.8 Protected Value 2}

Financial advisers have the opportunity to recommend suboptimal assets to their clients. Some view such a behavior as a violation of truthfulness, others regard it as acceptable protection of personal interests. What do you think about the value of truthfulness in such a situation? Truthfulness is something...

Please select the appropriate category

\begin{tabular}{|l|c|c|c|c|c|}
\hline & $\begin{array}{l}\text { Strongly } \\
\text { disagree }\end{array}$ & Disagree & $\begin{array}{l}\text { Neither } \\
\text { agree nor } \\
\text { disagree }\end{array}$ & Agree & $\begin{array}{l}\text { Strongly } \\
\text { agree }\end{array}$ \\
\hline $\begin{array}{l}\text {.. that one should not } \\
\text { sacrifice, no matter what the } \\
\text { (material or other) benefits. }\end{array}$ & 0 & 0 & 0 & 0 & 0 \\
\hline $\begin{array}{l}\ldots \text { for which I think it is } \\
\text { right to make a cost-benefit } \\
\text { analysis. }\end{array}$ & 0 & 0 & 0 & 0 & 0 \\
\hline $\begin{array}{l}\text {..that cannot be measured } \\
\text { in monetary terms. }\end{array}$ & 0 & 0 & 0 & 0 & 0 \\
\hline $\begin{array}{l}\ldots \text { about which I can be } \\
\text { flexible if the situation } \\
\text { demands it. }\end{array}$ & 0 & 0 & 0 & 0 & 0 \\
\hline
\end{tabular}




\section{F.3.9 Integrity and Work Ethics Test 1}

Read the description of the following situations and select the answer that fits best your opinion.

Situation 1:

Tom and Tina are discussing whether or not they think that most people are fundamentally honest.

Tom: The majority of people out there in this world are basically honest. They know the difference between right and wrong, and they act accordingly.

Tina: I think that when faced with an enticing situation where they are not likely to be caught doing something wrong, most people will succumb the temptation.

Tom: I think your view of the world is too cynical - you don't have enough faith in the people!

Tina: Well, I think you are naive!

o I agree almost entirely with Tom.

o I agree with Tom, but I think Tina makes some good points.

o I agree equally with Tina and Tom.

o I agree with Tina, but I think Tom makes some good points.

o I agree almost entirely with Tina.

\section{F.3.10 Integrity and Work Ethics Test 2}

Situation 2:

Bob and Betsy are debating whether using a sick day for reasons other than illness is wrong.

Bob: The other day the weather was so nice, I couldn't stand the thought of going to work. I didn't think I could handle another minute of the daily grind without some kind of break. So I called in sick.

Betsy: Really? Personally, I think that was dishonest of you. Your boss should be able to count on you - you should be at work unless you are too sick to come in.

Bob: I get five sick days a year, and I rarely use them. It makes no difference for my employer whether I'm really sick or just need to slow down!

o I agree almost entirely with Bob.

o I agree with Bob, but I think Betsy makes some good points.

o I agree equally with Bob and Betsy.

o I agree with Betsy, but I think Bob makes some good points.

o I agree almost entirely with Betsy.

\section{F.3.11 Support non-profit organizations}

Do you agree with the statement that the following non-profit organizations are worth supporting?

\begin{tabular}{|l|c|c|l|l|l|l|}
\hline & $\begin{array}{l}\text { Strongly } \\
\text { disagree }\end{array}$ & Disagree & $\begin{array}{l}\text { Neither } \\
\text { agree nor } \\
\text { disagree }\end{array}$ & Agree & $\begin{array}{l}\text { Strongly } \\
\text { agree }\end{array}$ & $\begin{array}{l}\text { I don't know } \\
\text { this } \\
\text { organization }\end{array}$ \\
\hline Red cross & 0 & 0 & 0 & 0 & 0 & 0 \\
\hline
\end{tabular}




\begin{tabular}{|l|c|c|c|c|c|c|}
\hline Pro juventute & o & o & o & 0 & 0 & 0 \\
\hline $\begin{array}{l}\text { World Wildlife } \\
\text { Fund (WWF) }\end{array}$ & 0 & 0 & 0 & 0 & 0 & 0 \\
\hline Pro natura & 0 & 0 & 0 & 0 & 0 & 0 \\
\hline UNICEF & 0 & 0 & 0 & 0 & 0 & 0 \\
\hline
\end{tabular}

\section{F.3.12 Big Five}

Here is a series of 10 statements that might apply to you. Please read each statement and decide how much you agree or disagree with that statement. Then pick the element of the following scale that best represents your position:

Please answer every statement, even if you are not completely sure of your response.

\begin{tabular}{|l|c|c|c|c|c|c|c|}
\hline & $\begin{array}{c}\text { Strongly } \\
\text { disagree }\end{array}$ & $\begin{array}{c}\text { Moderat } \\
\text { ely } \\
\text { disagree }\end{array}$ & $\begin{array}{c}\text { Disagree } \\
\text { a little }\end{array}$ & $\begin{array}{c}\text { Neither } \\
\text { agree nor } \\
\text { disagree }\end{array}$ & $\begin{array}{c}\text { Agree a } \\
\text { little }\end{array}$ & $\begin{array}{c}\text { Moderat } \\
\text { ely agree }\end{array}$ & $\begin{array}{c}\text { Strongly } \\
\text { agree }\end{array}$ \\
\hline $\begin{array}{l}\text { Extraverted, } \\
\text { enthusiastic. }\end{array}$ & 0 & 0 & 0 & 0 & 0 & 0 & 0 \\
\hline $\begin{array}{l}\text { Critical, } \\
\text { quarrelsome. }\end{array}$ & 0 & 0 & 0 & 0 & 0 & 0 & 0 \\
\hline $\begin{array}{l}\text { Dependable, } \\
\text { self- } \\
\text { disciplined. }\end{array}$ & 0 & 0 & 0 & 0 & 0 & 0 & 0 \\
\hline $\begin{array}{l}\text { Anxious, } \\
\text { easily upset. }\end{array}$ & 0 & 0 & 0 & 0 & 0 & 0 & 0 \\
\hline $\begin{array}{l}\text { Open to new } \\
\text { experiences, } \\
\text { complex. }\end{array}$ & 0 & 0 & 0 & 0 & 0 & 0 & 0 \\
\hline $\begin{array}{l}\text { Reserved, } \\
\text { quiet. }\end{array}$ & 0 & 0 & 0 & 0 & 0 & 0 & 0 \\
\hline $\begin{array}{l}\text { Sympathetic, } \\
\text { warm. }\end{array}$ & 0 & 0 & 0 & 0 & 0 & 0 & 0 \\
\hline $\begin{array}{l}\text { Disorganized, } \\
\text { careless. }\end{array}$ & 0 & 0 & 0 & 0 & 0 & 0 & 0 \\
\hline $\begin{array}{l}\text { Calm, } \\
\text { emotionally } \\
\text { stable. }\end{array}$ & 0 & 0 & 0 & 0 & 0 & 0 & 0 \\
\hline $\begin{array}{l}\text { Conventional, } \\
\text { uncreative. }\end{array}$ & 0 & 0 & 0 & 0 & 0 & 0 & 0 \\
\hline
\end{tabular}

\section{F.3.13 Identification code}

In order to anonymously link your answers from this survey to your answers in the lab experiment that you will attend in the near future, we need you to generate a personal identification code. To do so, please, follow the instructions below.

To generate your identification code, you will have to enter the corresponding character for each of the following categories in each field below. Please, use only lower case letters. 
1) The first letter of your father's first name*

2) The last letter of your father's first name*

3) The first letter of your mother's first name*

4) The last letter of your mother's first name*

5) The first digit of your current home address's street number

* First name means Prénom in French, Vorname in German and Nombre in Spanish.

During the lab experiment, you will be asked those 5 questions again, as a way of anonymously matching your responses across the two sessions. Since you will see the questions again, you do not need to remember your identification code as long as you recall the answers. If you would like, you may take a picture of this screen with your mobile phone once you have entered the 5 characters. It is important that you are able to reproduce your identification code in the lab.

If you cannot reproduce your identification code in the lab, you will not be paid the $10 \mathrm{CHF}$ for completing this survey.

Example: if your father is called Simon Müller, and your mother is called Lisa Müller, and if you live at Blümlisalpstrasse 29, then, you will write:

$\mathrm{s}$ in the first field

$\mathrm{n}$ in the second field

1 in the third field

a in the fourth field

2 in the fifth field

The first letter of your father's first name*:

The last letter of your father's first name*:

The first letter of your mother's first name*:

The last letter of your mother's first name*: ...

The first digit of your current home address's number: 